\title{
Kapitel 5. \\ Nonnos und die literarische Tradition
}

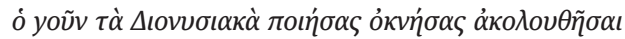

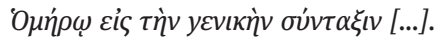

Eustathios, Comm. ad Hom. Il. 3,235.

\subsection{Quellen und Vorbilder der Dionysiaka}

Die Dionysiaka umspannen nicht nur den gesamten mythologischen Kosmos der Antike, sondern blicken auch auf wegweisende Vertreter griechischen Dichtens zurück. Nonnos bedient sich des Wortschatzes und der Formensprache Homers und Pindars und greift literarische Motive und Themen aus den hellenistischen Dichtungen des Kallimachos, Apollonios Rhodios und Theokrit sowie der Bukoliker Bion und Moschos auf, indem er poetische Traditionen in einem opus magnum der griechischen Literatur der ausgehenden Antike vereinigt. ${ }^{1}$

An dieser Stelle gilt es, am Beispiel der Ampelos-Episode Nonnos’ Verarbeitung von Referenztexten auf den Grund zu gehen, nicht mit dem Ziel, eine vollständige Auflistung sämtlicher sprachlicher und inhaltlicher Parallelstellen zu liefern, sondern vielmehr, um den kreativ-innovativen Umgang des Dichters mit seinen Vorbildern aufzuzeigen. Die Aufnahme einer traditionellen poetischen Formensprache in den neuen dionysischen Kontext wird ebenso beleuchtet wie die Verzahnung unterschiedlicher literarischer Genera im spätantiken Epos. ${ }^{2}$ Erörtert wird das Verhältnis der Ampelos-Episode zur homerischen Epik, im Besonderen Nonnos' Orientierung an den narrativen Techniken und dem epischen Sprachfundus Homers sowie die Übernahme epischer Erzählformen und Stilprinzipien, die Modulationen und Adaptationen, die der spätantike Dichter unternimmt, um das traditionelle Epos in den dionysischen Kontext einzufügen. Anhand ausgewählter Passagen der Bücher 10 -12 der Dionysiaka wird auf den künstlerischen Agon des Nonnos mit Homer, ${ }^{3}$ die Wiederaufnahme von Debatten der Homer-Philologie und die beinahe parodistische Umdeutung des epischen Ausgangstexts eingegangen. Illustriert werden ferner Nonnos’ Beziehungen zu anderen Genera der antiken Literatur. ${ }^{4}$ An signifikanten Stellen der Ampelos-Episode hält er sich an die hellenistische Dichtung, vorzugsweise die Bukolik, desgleichen an

1 Für einen Überblick über die Quellen der Dionysiaka siehe D’Ippolito (1964) 69-85; Manterola u. Pinkler (1995) 38-41; Liebeschuetz (2001) $232 \mathrm{f}$.

2 Vgl. Schmitz (2005) 202; Hernández de la Fuente (2008) 47 -52; für die Genusmischung in der lateinischen Dichtung der Spätantike vgl. Weber (1995) 238-244; Wasyl (2011) 7, $20,67$.

3 Bereits Ouwaroff (1817) 22 konstatiert, dass Nonnos Homer nicht bloß imitiert, sondern diesen im Sinne der künsterlischen aemulatio zu übertreffen sucht.

4 Vgl. Agosti (2012) 371: „[...] all literary genres are represented in this great literary container.“ 
den Roman, und auch das antike Theater als Kultinstitution für Dionysos wird einbezogen. Dabei gilt es, nicht bei der bloßen Quellenfrage stehen zu bleiben, sondern die Funktion dieser Übernahmen innerhalb der Ampelos-Episode zu bestimmen. Die genaue Analyse der Zitate, der motivisch-typologischen Vor- und Musterbilder in der Ampelos-Episode soll zum einen Licht auf die Kompositionsprinzipien der Dionysiaka insgesamt werfen, zum anderen das nonnianische Epos als Exponenten einer kollektiven „immaginazione culturale ${ }^{\text {“5 }}$ in den Kontext spätantiken Kunstschaffens einordnen.

\subsection{Nonnos und Homer}

\section{Homer in den Dionysiaka}

Die Anknüpfung an Homer bei gleichzeitiger Lösung von diesem literarischen Vorbild wurde dem Dichter aus Panopolis in der Vergangenheit als künstlerischer Mangel und Defekt angelastet. In der Geschichte der griechischen Literatur fällen Wilhelm Schmidt und Otto Stählin ein ähnlich negatives Urteil wie Rudolf Keydell, der Nonnos' HomerVerarbeitung als dichterisches Scheitern einstuft. ${ }^{6}$ Noch zu Beginn der 80er Jahre des 20. Jh. ist in einer griechischen Literaturgeschichte zu lesen: In der Schilderung des Indien-Feldzuges „,...] wollte er [sc. Nonnos] offensichtlich mit Homer wetteifern, was ihm zumindest in kompositorischer Hinsicht nicht gelungen ist. Die Fülle des Materials und die vielen Episoden (zum Beispiel die Liebesgeschichten und Idylle) bringen es mit sich, daß der Leser leicht den Faden verliert. Nichtsdestoweniger bleibt dieses Dionysos-Epos eine bewundernswerte literarische Leistung der Spätantike. “7 Selbst Dietrich Ebener charakterisiert in der Einleitung seiner Übersetzung Nonnos’ Umgang mit Homer als „mangelhafte Abstimmung, Verknüpfung, Begründung und Durchführung ganzer Handlungskomplexe“ und ist der Meinung, dass der Dichter „keine glückliche Hand bei der Übernahme homerischer Motive“ hatte. ${ }^{8}$ Zur selben Zeit finden sich jedoch auch positivere Bewertungen: „Dennoch ist Nonnos kein Homer-Epigone. Daran hindert ihn nicht nur sein Mangel an Sinn für Ökonomie und Gleichmaß positiv ausgedrückt: seine immense, exaltierte, grandiose, unerschöpfliche Phantasie -, sondern vor allem sein ganz und gar hellenistisches Bildungsbewußtsein. Er will

5 Agosti (2013a) 89.

6 Vgl. Schmid u. Stählin (1980/61924) 965: „Ein Christ, der den Hochgesang bakchischer Ekstase ertönen läßt, ein Homeride, der in die homerische Form einen ihrem Geist widerstrebenden Inhalt zwängt - das sind Widersprüche, die zeigen, mit welchen unnatürlichen Verrenkungen diese neue und letzte Epik erkauft war“; vgl. Keydell (1932) 186f. (498f.).

7 Bergson (1981) 508.

8 Ebener (1985) Bd. 1, XI. 
nicht nur Homer übertreffen, sondern zugleich den Kosmos einer tausendjährigen Tradition griechischer Dichtung in sein Werk eingehen lassen. “9

Nonnos nimmt auf ganz unterschiedliche Weise auf Homer Bezug: ${ }^{10}$ Er imitiert und rühmt ihn, Homer dient ihm zugleich aber auch als Gegenpol für sein eigenes, dichterisches Schaffen. In der aktuellen Forschung wird Nonnos' Umgang mit Homer

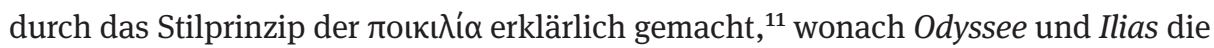
Ausgangspunkte für die großen Erzähllinien der Dionysiaka bilden: Der Beginn des Epos mit den Abenteuern des Kadmos (Nonn. D.1-5) sowie Dionysos' Zug nach Indien (Nonn. D. 13-24) sind hinsichtlich ihrer narrativen Konzeption durch die Odyssee inspiriert, die Indien-Bücher vom Kampfgeschehen in der Ilias (Nonn. D. 25-40). ${ }^{12}$ Nonnos übernimmt sodann eine breite Palette an typischen Szenen, wobei die IndienBücher vor allem aus der Ilias schöpfen: Heereskataloge und Heeresversammlung, der

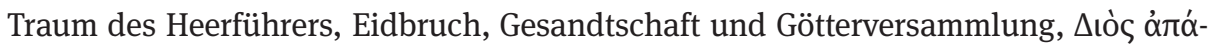

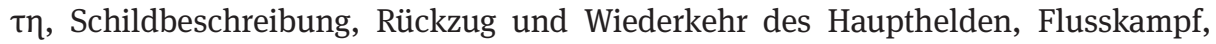
Leichenspiele, all dies gehört seit Homer zum Standardrepertoire epischer Dichtung; mit der Schilderung von Dionysos' Ankunft in Athen wird an die Nostoi der TroiaHeimkehrer angeknüpft, mit dem Wettkampf zwischen Dionysos und Poseidon um Beroe an Odysseus' Bogenkampf und mit Ikarios an Odysseus' Vater Laertes. ${ }^{13}$ Homerische Themen werden auch in Zusammenhang mit Kadmos in die Dionysiaka eingeführt; so setzen etwa Kadmos' Seereise, sein Schiffbruch, seine Landung auf Samothrake, seine Aufnahme im Palast Emathions und seine Reise durch Griechenland sowohl die Argonautenfahrt als auch Odysseus' Irrfahrten voraus. ${ }^{14}$ Nonnos' unbestrittene Abhängigkeit vom griechischen Dichter par excellence gilt nicht nur für die Bereiche Motivik und Komposition, sondern auch für die Sprache und Stilistik. Die herausragende Autorität Homers wird zudem daran sichtbar, dass er neben Pindar als einziger antiker Autor in den Dionysiaka namentlich genannt wird (Nonn. D. 1,37; 13,50; 25,8, 265 und 269; 32,184; 42,181). ${ }^{15}$

Homer ist der künstlerische Pol, auf den Nonnos seine Dionysiaka ausrichtet, er dient ihm vielfach als Ausgangspunkt für eine neue Art von Dichtung, ${ }^{16}$ welche sich

9 Schmalzriedt (1976) 478.

10 Zum Einfluss Homers auf Nonnos vgl. Wild (1885-1886); Haidacher (1949) 7-16; D’Ippolito (1964) 37 - 41; Vian (1991); Hopkinson (1994a); Hopkinson (1994b) 122 f.; Frangoulis (1995); Boned Cólera (1998); Kuhlmann (1999); Shorrock (2001) 59-95; Auger (2003); Hernández de la Fuente (2008) 41f.; Chuvin (2009) 160f.; Chuvin (2009a); Bannert (2008); Frangoulis (2011); Frangoulis (2012); Mazza (2012) 228-240; Verhelst (2013); Bannert u. Kröll (2016); Agosti u. Magnelli (2017). 11 Vgl. String (1966) 33-70; Vian (1991) 14f. (478f.) und 18 (482); Lasek (2012).

12 Vgl. Chuvin (2009a) 473.

13 Vgl. Vian (1991) 7 f. (471f.); Shorrock (2001) 95-111.

14 Vgl. Shorrock (2001) 39-50.

15 Vgl. Vian (1991) 5f. (469f.); Hopkinson (1994a) 9-14; Chuvin (2009a) 472f.; zur Nennung Pindars in den Dionysiaka siehe Nonn. D. 25,21.

16 Vgl. Hopkinson (1994a) 14-17 und 20: „[...] his [sc. Nonnos’] aim is often to point similarity by ostentatiously adapting Homeric passages to his own Dionysiac purposes.“ 
hinsichtlich der Komposition zwar an ihrem Vorbild orientiert, dieses jedoch in einem weiteren Schritt zu überbieten sucht. Dies zeigt sich etwa in der bewussten Entscheidung, nicht eine einzelne Episode aus dem Troia-Mythos aufzugreifen, wie dies Homer mit dem Zorn Achills tut, sondern in den Indien-Büchern eine Gesamtschau der Ereignisse um den Weingott und sein bakchisches Heer zu bieten, die den gesamten Troia-Mythos spiegeln. ${ }^{17}$ Das Thema der dionysischen Wirkkraft zieht sich durch die komplexen und beziehungsreichen Einzelerzählungen der Dionysiaka und ist den übernommenen homerischen Motiven stets übergeordnet. Durch die Inszenierung von Dionysos als neuem epischen Helden, dessen göttliche Macht auf vielfältige Weise und in unterschiedlichen Schattierungen sichtbar wird, formuliert der Dichter sein persönliches literarisches Programm und knüpft daran seinen dichtungstheoretischen Ansatz: Zeus und Dionysos, die Repräsentanten einer alten und einer neuen Göttergeneration, dürfen als stellvertretend für Homer und Nonnos gelten. ${ }^{18}$ Genauso wie Dionysos an seinen Aufgaben zu einer allseits anerkannten Gottheit wächst und sich Schritt für Schritt seinem Vater Zeus annähert, um diesen letztlich gleichsam zu entthronen, gelingt es Nonnos, Homer zu übertreffen und diesem seine neue Art des Epos entgegenzuhalten.

Was für die Gesamtheit der Dionysiaka gilt, wird auch in den Büchern 10, 11 und 12 deutlich: Wie in den großen Kompositionslinien greift Nonnos auch in der AmpelosEpisode auf die homerischen Epen, insbesondere die Ilias zurück. In der folgenden Analyse des sportlichen Agons zwischen Dionysos und Ampelos am Ende des 10. und Beginn des 12. Buches wird Nonnos' Umgang mit seinem Vorbild Homer in der geschlossenen narrativen Einheit einer ausgewählten Szene diskutiert. Obwohl die Leichenspiele zu Ehren des Patroklos im 23. Gesang der Ilias die Basis für die Spiele in den Dionysiaka darstellen, bietet Nonnos dennoch mehr als eine bloße Repetition von Bekanntem und verwandelt die dionysischen Wettkämpfe in eine durchaus kontroversielle künstlerische und philologische Debatte in poetischem Gewand. In einem gelehrten Spiel bezieht der Dichter den zeitgenössischen Rezipienten mit ein, der, wie auch Nonnos selbst, als Angehöriger der hellenischen Oberschicht im spätantiken Ägypten aus einer gemeinsamen Bildungsgrundlage schöpft, als deren maßgeblicher Bezugspunkt Homer anzusehen ist. ${ }^{19}$

17 Vian (1991) 7 f. (471f.) exemplifiziert dies am Beispiel der Bücher 13 - 24, die dem epischen Kyklos entsprechen, wie er in der Bibliotheke Apollodors präsentiert wird; zur Umsetzung des Troia-Mythos in den Dionysiaka siehe auch Shorrock (2007).

18 Vgl. Shorrock (2001) 116-119.

19 Zu Nonnos' Publikum vgl. Kap. 8.2; Abel-Wilmanns (1977) 203 - 219; Chuvin (1986); Agosti (2001) $97 \mathrm{f}$. 


\section{Die Wettspiele}

Insgesamt finden sich in den Dionysiaka vier Wettkampfszenen: die Leichenspiele zu Ehren des assyrischen Königs Staphylos (Nonn. D. 19,59-348) und des Inders Opheltes (37,103-778), der Ringkampf zwischen Dionysos und Pallene (48,106-182) sowie die sportlichen Wettspiele zwischen Dionysos und Ampelos (10,339-430; 11,1-55). ${ }^{20}$ Nonnos übertrifft die Anzahl der Spiele in Ilias und Odyssee, indem er den dreien bei Homer - den Leichenspielen für Patroklos (Hom. Il. 23), den Wettkämpfen am Hofe der Phaiaken (Hom. Od. 8,105-255) und Odysseus' Bogenkampf (Hom. Od. 21) - ein weiteres hinzufügt. Er folgt seinem Vorbild besonders eng in der Schilderung der Leichenspiele für Opheltes (Nonn. D. 37), in welcher die Abfolge der Spiele - Wagenrennen, Faust-, Ringkampf, Wettlauf, Diskuswurf, Bogenschießen und Speerwurf im Wesentlichen den Leichenspielen für Patroklos entspricht ${ }^{21}$ und Wagenrennen und Wettlauf ausführlich geschildert werden. Auch in sprachlichen und inhaltlichen Details finden sich Entsprechungen zwischen den Passagen in den Dionysiaka und in der Ilias: So stürzt etwa im Laufwettbewerb in den Dionysiaka Okythoos ebenso wie der kleine Aias in der Ilias, was die Zuschauer hier wie dort amüsiert.

Im Unterschied zu den Leichenspielen für Opheltes setzt sich Nonnos in denen für Staphylos inhaltlich deutlich von Homer ab, und zwar insofern, als es sich dabei nicht um athletische, sondern musische Wettkämpfe handelt: ${ }^{22}$ Auf den Wettkampf im Lyraspiel zwischen Erechtheus und Oiagros folgt ein ausführlich geschilderter tänzerischer und mimischer Wettbewerb zwischen Maron und Silenos. Vergleichbar sind diese musischen Spiele in den homerischen Epen nur mit den Spielen am Hof der Phaiaken im 8. Gesang der Odyssee, wo auf den Diskuswettbewerb eine tänzerische und mimetische Darbietung mit musikalischer Begleitung durch den Sänger Demodokos folgt (Hom. Od. 8,256-380). Mit den Spielen für Staphylos legt Nonnos den Schwerpunkt auf den musischen Agon und rückt so die spezifisch dionysische Art des Dichtens ins Blickfeld. Explizit wird dies bereits im musischen Wettstreit zwischen Erechtheus und Oiagros, wenn nämlich Erechtheus mit seiner Darbietung eines traditionellen Enkomions gegenüber Oiagros und seinem dionysischen Lied auf den toten Staphylos schon vorweg zum Scheitern verurteilt ist (Nonn. D. 19,102-105). Auch im pantomimischen Wettbewerb zwischen Maron und Silenos erfolgt die Präsentation dionysischer Wirkkraft, indem der Weinkonsum der olympischen Götter sowie der

20 Vgl. Böhm (1960); zur Tradition von sportlichen Wettkämpfen im Epos siehe Willis (1941).

21 Lediglich der in der Ilias geschilderte Speerkampf (Hom. Il. 23,798-825) wird von Nonnos nicht übernommen, stattdessen führt er den bei Homer nur angekündigten, aber nicht ausgeführten Speerweitwurf weiter aus (Hom. Il. 23,884-897), vgl. Hopkinson (1994a) 31; zur Komposition der Leichenspiele in Hom. Il. 23 vgl. Bannert (1988) 129-151.

22 Vgl. Hopkinson (1994a) 30 f. bes. 31: „The contests described in Books 10 and 19 differ widely in tone and context from the Homeric passages by which they are inspired. Book 37, on the other hand, treats the funeral games for Opheltes in a manner surprisingly similar in both scale and details to the equivalent Homeric episode.“ 
Wettstreit zwischen Aristaios (Honig) und Dionysos (Wein) dargestellt werden. Der Sieg der dionysischen Themen in den Wettspielen geht mit der Aufwertung des neuen Gottes Dionysos gegenüber den traditionellen homerischen Göttern einher. Nonnos nimmt hierbei Homer stets nur als Ausgangspunkt für seine eigene Art zu dichten und gewährt - ähnlich wie im Proömion seines Epos - einen Einblick in seine Poetik des Dionysischen. ${ }^{23}$ Durch die Präsenz des Weingottes und seiner Begleiter verleiht er den Szenen eine spezifisch dionysische Note und erweist sich durch seinen souveränen Umgang mit dem epischen Musterbild als Repräsentant einer neuen Kunstauffassung. Die Verarbeitung von Quellen und Vorbildern durch Nonnos ist, wie im Folgenden am Beispiel von Ringkampf, Wettlauf und Wettschwimmen veranschaulicht werden soll, von größter Vielschichtigkeit und Komplexität.

\section{Der Ringkampf}

Nonnos schließt in der Ampelos-Episode an Homer an und lässt sich von den Leichenspielen zu Ehren des Patroklos (Hom. Il. 23) inspirieren. Im homerischen Ringkampf folgt auf die Ankündigung des Wettbewerbs sowie auf die Vorstellung des Schiedsrichters Achill und der in Aussicht gestellten Kampfpreise (Hom. Il. 23,700 707) die Präsentation der beiden Kontrahenten, des großen Aias und des Odysseus (Hom. Il. 23,708f.), sowie die eigentliche Kampfschilderung (Hom. Il. 23,710 - 732); da am Ende kein eindeutiger Sieger feststeht, wird der Kampf vorzeitig abgebrochen und durch Achill beiden Ringern der Sieg zuerkannt (Hom. Il. 23,733-739). Nonnos hält sich mit geringen Abweichungen an dieses von Homer vorgegebene Gerüst: ${ }^{24}$ In umgekehrter Reihenfolge werden zunächst die beiden Ringer Dionysos und Ampelos vorgestellt (Nonn. D. 10,330-332), sodann die Kampfpreise und der Schiedsrichter (333-338), ausführlich geschildert wird der Wettkampf (339-372). Das frühzeitige Ende des Ringens bei Homer modifiziert Nonnos insofern, als er das Kräftemessen nicht durch ein Unentschieden und das Eingreifen eines Schiedsrichters beendet, sondern Dionysos freiwillig Ampelos zum Sieger und Preisträger küren lässt (Nonn. $D$. 10,373 - 382). Ein detaillierter Blick auf die Textpassage zeigt, dass diese strukturellen

23 Vgl. Miguélez Cavero (2008) 168: „[...] the Homeric variation is simply not enough for Nonnus and has to be taken to its limits.“

24 Die typische Szene Ringkampf wird auch von Vergil (Verg. Aen. 5,104-544) und Quintus Smyrnaeus (Q. S. 4,180 - 595) wiederaufgenommen, vgl. Gigli Piccardi (2003) 632. - Einen wesentlichen Unterschied zur homerischen Textpassage bildet die Erzähltechnik des Nonnos, der im Gegensatz zu seinem Vorbild keine direkten Reden einsetzt. - Frei mit dem Thema Ringkampf geht auch Heliodor im 10. Buch seiner Aithiopika um (Hld. 10,31,1 - 10,32,2): Gegen Ende des Romans schenkt Meroebos, der Neffe des Hydaspes, diesem einen Ringer, der alle Anwesenden an Größe und Kraft übertrifft. Allein Theagenes stellt sich einem Ringkampf mit dem Riesen und siegt zum Staunen der Zuschauer. Theagenes ist im Unterschied zum plumpen und schwerfälligen Riesen wendig und flink und tritt seinem Kontrahenten ebenfalls in die Kniekehle. (Für diesen Hinweis danke ich Bettina Feuchtenhofer.) 
Gemeinsamkeiten mit Homer auch in der sprachlichen Umsetzung durch Nonnos wiederzufinden sind (Nonn. D. 10,339-372):

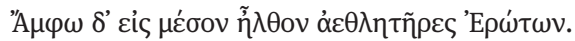

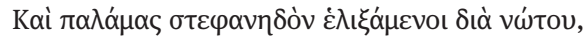
340

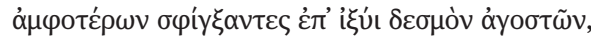

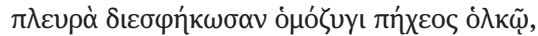

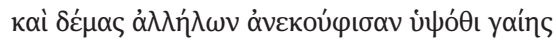

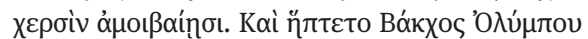

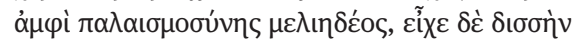

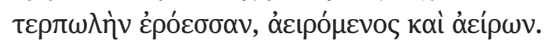

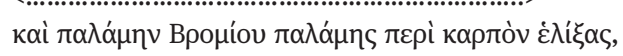

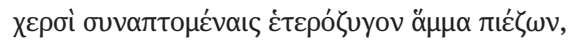

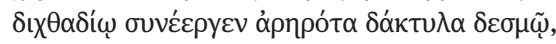

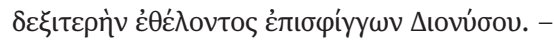

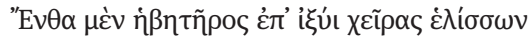

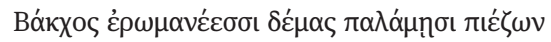

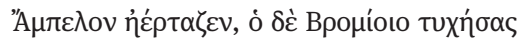

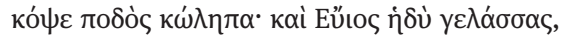

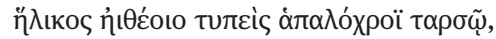

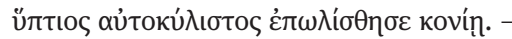

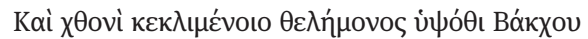

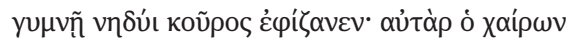

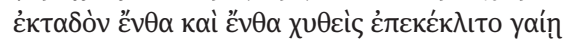

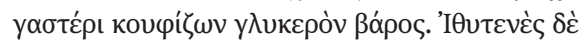

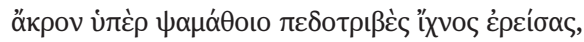

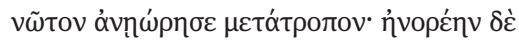

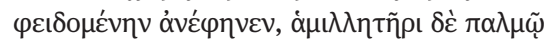

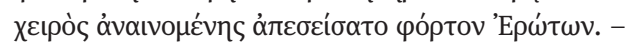

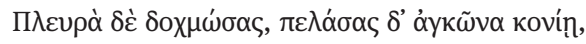

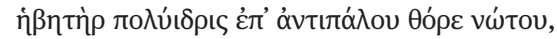

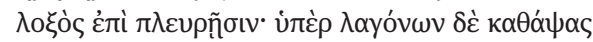

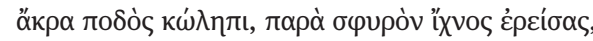

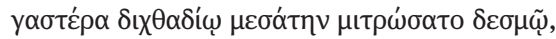

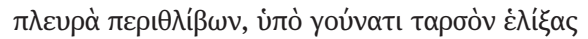

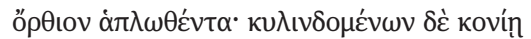

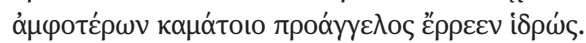

Und beide Eroten-Wettstreiter traten in die Mitte (340) und wanden die Hände kranzartig auf dem Rücken [des anderen] zusammen, fixierten die Fessel beider Arme auf dem Leib [des anderen], zogen die Arme mit angespanntem Zug straff an den Seiten und hoben den Körper des anderen jeweils mit beiden Händen vom Boden hoch. Und Bakchos berührte den Olymp (345) beim honigsüßen Ringkampf, er hatte eine doppelte Freude in seiner Liebe, weil er emporgehoben wurde und auch selbst emporhob. Und er [Ampelos] wand seine Hand um das Handgelenk des Bromios, mit verschlungenen Händen presste er es in einen ungleich starken Schnürgriff, mit doppelter Fessel umschloss er die verschränkten Finger (350) und fixierte Dionysos' Rechte, der es genauso wollte. Da wand Bakchos die Hände um den Körper des Jünglings, drückte mit den liebestollen Händen dessen Körper und hob Ampelos hoch; dem aber gelang es, mit dem Fuß in seine Kniekehle zu schlagen. Und Euios lachte süß, (355) als er vom zarten Fuß des jugendlichen 
Göttergleichen getreten wurde, und glitt durch eine Drehung um sich selbst rücklings im Sand aus. Und als Bakchos willig am Boden lag, da setzte sich der Knabe von oben auf seinen entblößten Bauch. Aber er freute sich, als er, die Glieder in alle Richtungen gestreckt, auf der Erde lag (360) und mit dem Bauch die süße Last trug. Aufrecht drückte er die den Boden leicht reibende Fußspitze in den Sand und hob den Rücken in einer Drehbewegung in die Höhe. Aber seine Kraft setzte er nur schonend ein, und mit der kämpferischen Faust seiner Hand schüttelte er nur widerstrebend die Last der Eroten ab. (365) Da drehte sich der schlaue Jüngling auf die Seite und stützte den Ellenbogen in den Sand, sprang im Gegengriff auf seinen Rücken schräg an der Seite und fixierte ihn über die Flanken, indem er die Fußspitze in die Kniekehle und die Fußsohle gegen den Knöchel drückte. Er umwand den Bauch in der Mitte mit einer doppelten Fessel, (370) stieß ihn in die Seiten und wand den Fuß um das Knie, indem er diesen geradeaus streckte. Als beide sich im Sand wälzten, floss ihnen als Vorbote der Erschöpfung der Schweiß herab.

Um die Bewegung und Gestik der Figuren wiederzugeben, übernimmt Nonnos bereits aus der Ilias geläufiges Vokabular: ${ }^{25}$ Wiederholt hervorgehoben wird die Tatsache, dass

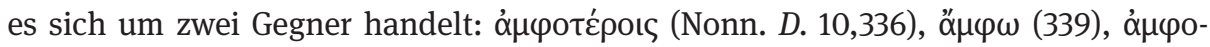

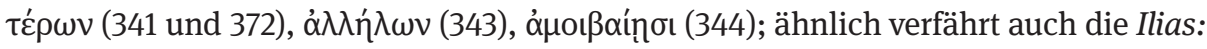

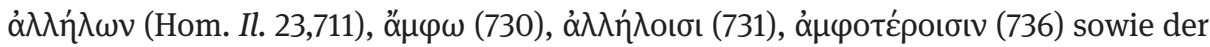

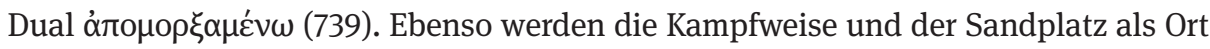
des Geschehens entlehnt. Die Gegenüberstellung der beiden Gegner geht mit der Aufzählung der Körperteile einher, die der Darstellung der verschiedenen Ringergriffe dienen, wobei auch hier wieder Rückgriffe auf Homer erfolgen: v'́tov (Nonn. D. 10,

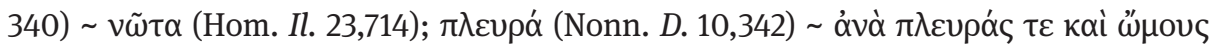
(Hom. Il. 23,716). Die von den beiden Gegnern vollzogenen Bewegungsrichtungen, das

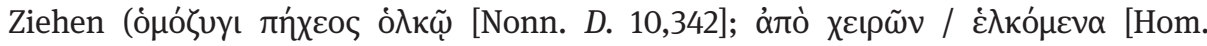

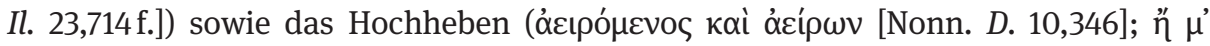

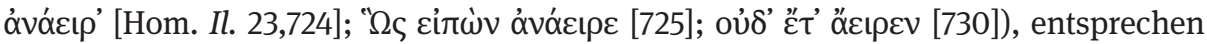
einander. Die Kampftechnik mit dem Schlag in die Kniekehle (Nonn. D. 10,351-356,

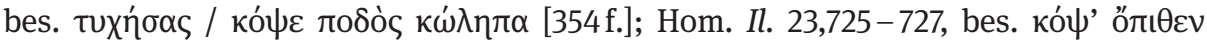

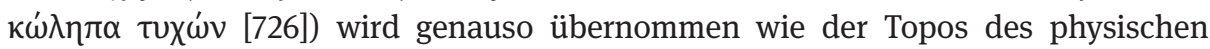

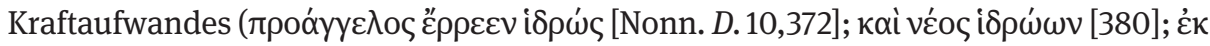

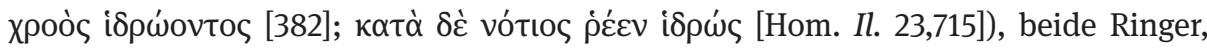
Dionysos bei Nonnos und Odysseus bei Homer, werden schließlich vom Gegner

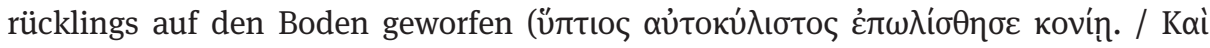

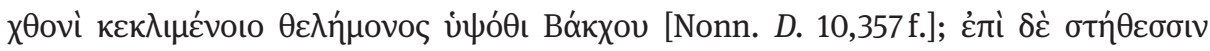

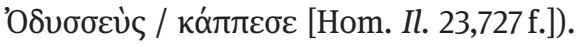

Der Ringkampf zwischen Dionysos und Ampelos orientiert sich sowohl hinsichtlich des Aufbaus als auch in der sprachlichen Ausführung am Wettbewerb im 23. Gesang der Ilias. Zugleich beschreitet Nonnos aber auch eigene Wege und sucht sein

25 Chrétien (1985) 75 Anm. 1 fasst die Parallelen zusammen, die Nonnos zu Homer und auch zu Quintus Smyrnaeus bietet; zu Nonnos und Quintus vgl. auch Haidacher (1949) 67 - 70; Whitby (1994); Hadjittofi (2007); Shorrock (2007). - Nonnos orientiert sich in der Wiedergabe des Kampfstils vielleicht auch am Pankration, vgl. Chrétien (1985) 75f.; Hopkinson (1994a) 41 Anm. 132. 
Vorbild zu übertreffen, ja geradezu zu konterkarieren, indem er, anstatt das agonistische Prinzip und die Ernsthaftigkeit eines sportlichen Zweikampfes in den Mittelpunkt zu stellen, die Kämpfe zwischen beiden Protagonisten der Episode in einem völlig anderen Licht erscheinen lässt, indem er den Satyrn als Wettstreiter einsetzt und dem Geschehen die Ernsthaftigkeit nimmt. Die Szenerie erinnert an vergleichbare Darstellungen in der bildenden Kunst, die Satyrn und Silene bei sportlichen Wettkämpfen zeigen, ${ }^{26}$ oder aber an das literarische Genus des Satyrspiels, für welches ähnliche Themen belegt sind. ${ }^{27}$

Von Beginn an wird das traditionelle homerische Narrativ des Ringkampfes ne-

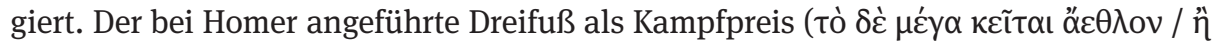

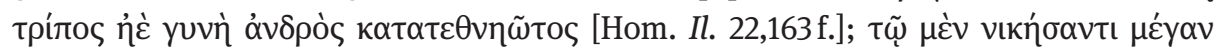

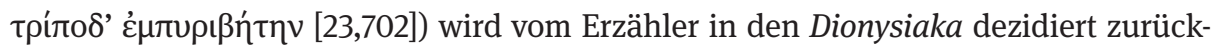
gewiesen (Nonn. D. 10,330-338):

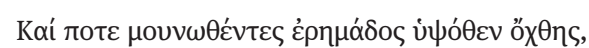

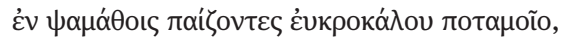

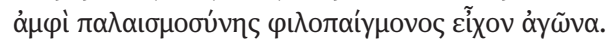

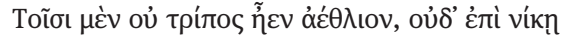

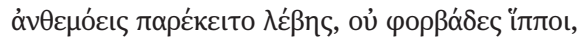

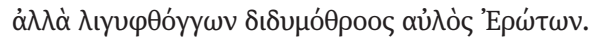

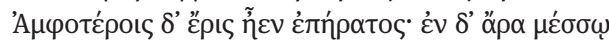

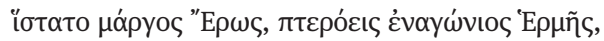

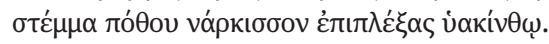

(330) Und einmal sonderten sie sich ab, ganz oben am einsamen Ufer, spielten im Sand des kieseligen Flusses und traten einen sportlichen Wettkampf im Ringen an. Sie hatten keinen Dreifuß als Preis, und für den Sieg lag auch kein blumengeschmückter Kessel bereit, auch keine grasenden Pferde, (335) sondern ein zweistimmiger Aulos der helltönenden Eroten. Unter beiden entbrannte ein lieblicher Streit. Und in der Mitte stand Eros, toll vor Liebe, ein geflügelter und kämpferischer Hermes, der als Kranz des Verlangens eine Narzisse mit einer Hyazinthe verflochten hatte.

Ebenso wenig kommen ein kunstvoll verzierter Kessel und Pferde als Preise in Frage

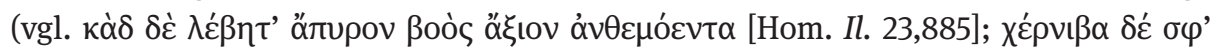

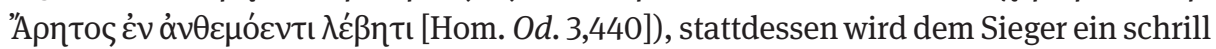
tönender Aulos geboten, der, für das traditionelle Epos untypisch, mit der Bukolik in Verbindung steht. Am deutlichsten wird die Entfernung von Homer in der Charakte-

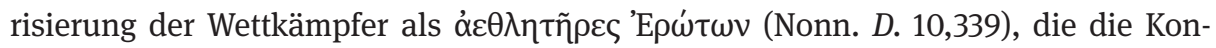
kurrenz unter die Schirmherrschaft des Eros und den folgenden Ringkampf unter ein der homerischen Szene völlig fremdes Licht stellt. ${ }^{28}$ Der seriöse homerische Wettstreit

26 Vgl. etwa einen Münchener Volutenkrater mit der Darstellung von Silenen bei sportlichen Spielen, Brommer (1959) 60 f.; Pritchard (2013) 149f. Abb. 4.3.

27 So ist etwa für das Satyrspiel Amykos des Sophokles ein Boxkampf belegt, vgl. Brommer (1959) 60; zu Amykos siehe $R E \mathrm{I} / 2,2000 \mathrm{f}$.

$28 \mathrm{Zu}$ den Eroten vgl. Nonn. D. 10,335, 339, 364. 
wird von Nonnos aus dem Kontext der heroischen Kriegergesellschaft herausgelöst und in eine erotisch aufgeladene Umgebung transferiert. ${ }^{29}$ Diese Verquickung von homerischem Ringkampf mit erotischem Spiel ist nicht ohne Vorbilder und findet sich etwa im griechischen Eselsroman, der die sexuelle Begegnung des Haupthelden Lukios mit der Magd Palaistra einem Ringkampf gleichsetzt $(8-10) \cdot{ }^{30}$ Eine ähnliche Kombination von Erotik und Sport ist auch in den Aithiopika Heliodors zu finden, wo im Kontext der Pythischen Spiele die Wettkampf-Metaphorik auch auf Theagenes und Charikleia angewendet wird, die in einem erotisch aufgeladenen Agon dem Schiedsrichter Eros erliegen. ${ }^{31}$

Die Szene bei Nonnos ist von Wendungen und Vokabeln aus dem erotischen Bereich geprägt, und der Liebesgott ist Emblem dafür: ${ }^{32}$ In Nonn. D. 10,336 wird der

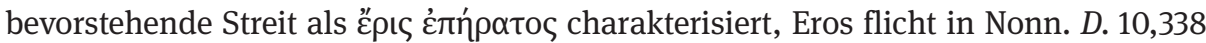

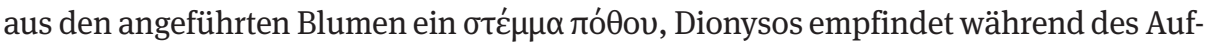
und-Ab im Kampf eine „doppelte Liebesfreude“ (Nonn. D. 10,345f.) und zeigt sich rasend vor Liebe (352); anstatt sich einer echten Auseinandersetzung zu stellen, ist er

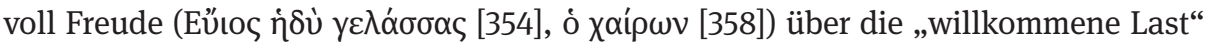

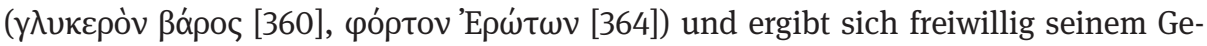
liebten ( $\theta \varepsilon \lambda \eta ́ n$ ovo verkehrt den „Schmerz bereitenden Ringkampf“ bei Homer in sein Gegenteil ( $\delta \varepsilon$ -

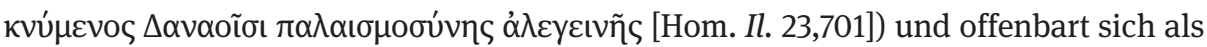

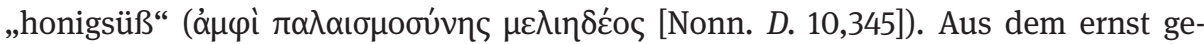
meinten Ringkampf zwischen Aias und Odysseus bei Homer wird in den Dionysiaka ein erotisches Spiel mit Augenzwinkern, der Kampf zwischen Dionysos und Ampelos erweist sich durch die Gegenüberstellung von traditionellen epischen Elementen mit erotischem Vokabular als eine regelrechte literarische Kontrafaktur. Mit der Umarbeitung des homerischen Vorbilds löst sich Nonnos jedoch nicht zur Gänze von den epischen Konventionen, vielmehr deutet er die homerische Szene unter Verwendung homerischer Sprachmittel um. Die Übernahme von Aufbau, Wortmaterial und einzelnen formelhaften Wendungen aus der Ilias sowie auch aus Bukolik und Roman geht einher mit der Verwendung lexikalischer Neologismen und der Kreation einer neuen Geschichte.

29 Vgl. Gigli Piccardi (2003) 631. - Im Gegensatz dazu bleibt Nonnos im Ringkampf anlässlich der Leichenspiele für Staphylos Homer weitgehend treu und liefert einen traditionellen heroischen Wett-

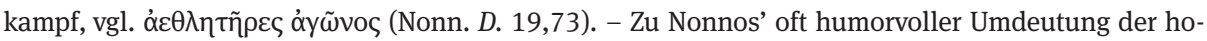
merischen Götter, insbesondere des Dionysos, vgl. Miguélez Cavero (2009).

30 Vgl. van Thiel (1972) 18f.; Gigli Piccardi (2003) 631 Anm. 32.; vgl. auch Ar. Pax 894-898.

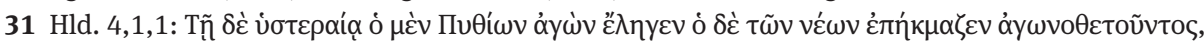

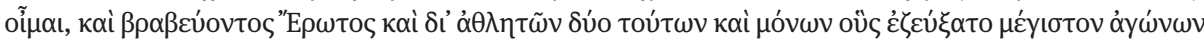

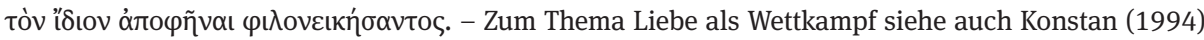
181; Scanlon (2002) 199- 273.

32 Zur Funktion des Eros im antiken Roman und zur möglichen Einflussnahme auf Nonnos vgl. Frangoulis (2014) 43-48. 
Diese Umdeutung im Sinne der nonnianischen Poetik lässt sich auch in der Gestaltung der Figuren beobachten. Statt der Übernahme des Unentschiedens in der IliasSzene lässt Nonnos seinen Protagonisten Dionysos aus freien Stücken gegen seinen Kontrahenten verlieren. Dionysos wäre allein durch seine Göttlichkeit imstande, einen raschen Sieg davonzutragen, tut dies jedoch nicht, sondern unterliegt aus freiem

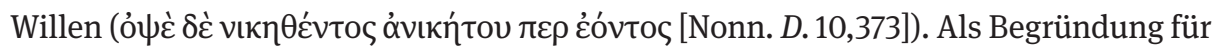
Dionysos' freiwilliges Unterliegen wird in Nonn. D. 10,374-377 ein Mythos herangezogen, wonach seinem Vater Zeus ein ähnliches Schicksal widerfahren sei, als dieser am Fluss Alpheios bei Olympia seinem Sohn Herakles im Ringkampf ebenfalls freiwillig unterlag. ${ }^{33}$ Durch diese Synkrisis nähert Nonnos seinen Helden Dionysos dem Göttervater Zeus an und arbeitet so auf das narrative Ziel seines Epos hin: Dionysos' Anerkennung als vollwertiges Mitglied des olympischen Götterhimmels. ${ }^{34}$

Nicht nur Dionysos, sondern auch Ampelos erhält im Rahmen der Ringkampfszene ein eigenes Profil, welches an die Odysseus-Figur der Ilias-Stelle angelehnt ist, ${ }^{35}$ in der Odysseus' Klugheit von seinem Kontrahenten Aias zur Sprache gebracht wird ( im Kampf anzustreben, stellt Odysseus sein Können unter Beweis und wendet einen Trick an: Als er von Aias in die Höhe gehoben wird und folglich Gefahr läuft, das Ringen zu verlieren, bringt er seinen Gegner durch einen gezielten Tritt in die Knie-

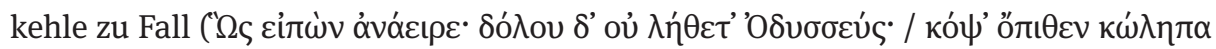

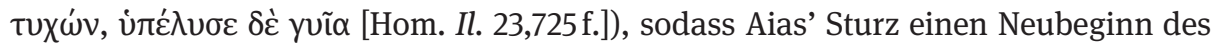
Kampfes und eine neue Chance für Odysseus ermöglicht. Entsprechend tritt Ampelos in den Dionysiaka auf, wenn er, genauso wie Odysseus von Aias, von Dionysos in die Höhe gehoben wird, dann jedoch durch den Schlag in die Kniekehle eine Wende zu seinen Gunsten erreicht (Nonn. D. 10,352-354). Die Übertragung von Eigenschaften des Odysseus auf Ampelos wird zudem in der Charakterisierung des Satyrn als $\grave{\eta} \beta \eta \tau \dot{\eta} \rho$

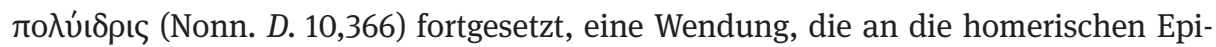

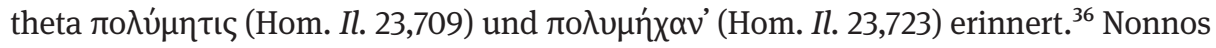
konstruiert seinen Ampelos auf der Grundlage traditioneller mythischer Elemente, präsentiert jedoch durch die Veränderung des Kontexts seine Quellen in einem völlig neuen Licht. Diese poetische Verfahrensweise gibt auch einen Anhaltspunkt für die Frage nach der Herkunft und Tradition der Ampelos-Figur: Nonnos überschreibt den

33 Dieser Mythos wird sonst nur in Lyc. Alex. 40 - 42 angedeutet, eine Stelle, für die Johannes Tzetzes detailliertere Informationen liefert: Demnach habe Herakles gegen Zeus lange unentschieden gekämpft, schließlich aber, als sich Zeus in seiner göttlichen Gestalt offenbarte, gewonnen, vgl. von Holzinger (1895) 94f., 172; Chrétien (1985) 155 Anm. ad 373-377; Gigli Piccardi (2003) 724 Anm. ad $373-377$.

34 Auch auf die Initiierung des dionysischen Kultes wird im Ringkampf verwiesen: Die erotisch aufgeladene Szene verweist auf die enge Verbindung von Wein und Liebe, die sich am Ende der AmpelosEpisode im Spiel der Satyrn und Nymphen manifestiert (Nonn. D. 12,363-379).

$35 \mathrm{Zu}$ Odysseus in der Ilias siehe Kröll (2008).

36 Vgl. Chrétien (1985) 75 Anm. 1. - Das Epitheton für Ampelos steht auch in Kontrast zu Call. Aet.

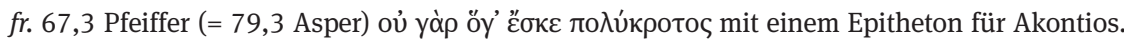


Satyrn niemals nur mit einer Figur der mythischen Tradition, sondern kann diese individuell und mit beliebigen Versatzstücken weiterer Figuren oder aber aus einer alternativen, spätantiken Formensprache versehen.

Nonnos' freie Verarbeitung epischer Traditionen wird aus dem Vergleich der vorliegenden Szene im 10. mit den beiden Ringkämpfen im 37. und 48. Buch besonders deutlich. In der Erzählung der Leichenspiele für Opheltes im 37. Buch arbeitet Nonnos weitgehend homergetreu: ${ }^{37}$ Der knapp 60 Verse umfassende Ringkampf zwischen Aristaios und Aiakos (Nonn. D. 37,546-613) ist deutlich länger als sein Pendant im 10. Buch. Was den Aufbau betrifft, so folgt der Dichter auch hier dem homerischen Schema: Ankündigung, Vorstellung des Schiedsrichters, der Preise (Nonn. D. 37,546552) und der Kämpfer (553-557), Kampf (557-601), Entscheidung (602-609) sowie abschließende Preisverleihung (610 -613). Der Sieg des Aiakos wird ähnlich wie bei Homer durch das Eingreifen von Schiedsrichtern, zwei Herolden, erreicht, und auch in der sprachlichen Ausführung hält sich der Dichter eng an sein Vorbild, doch der in der

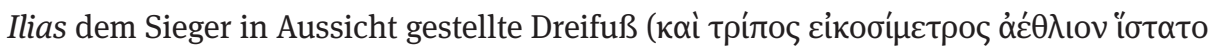

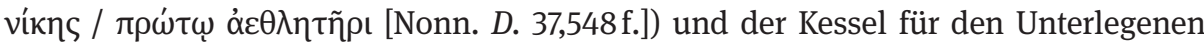
( $\alpha v \theta \varepsilon \mu o ́ \varepsilon v \tau \alpha ~ \lambda \varepsilon ́ \beta \eta \tau \alpha$ [550]) werden in den Dionysiaka ausdrücklich zurückgewiesen.

Die konventionelle Darstellung der typischen Szene Ringkampf wird in der Umdeutung in der Ampelos-Episode gleichsam zur Kontrafaktur, eine narrative Technik, welche Nonnos auch ein weiteres Mal, und zwar im 48. Buch in der Begegnung zwischen Dionysos und Pallene anwendet: Aus dem sportlichen Kräftemessen zwischen zwei ebenbürtigen Gegnern bei Homer wird bei Nonnos ein erotisch aufgeladenes Ringen eines ungleichen Paares. ${ }^{38}$ Es lässt sich eine Reihe von wörtlichen und inhaltlichen Analogien zwischen dem 10. und dem 48. Buch ausmachen, welche eine Umdeutung des heroischen Wettkampfes in eine erotische Auseinandersetzung bewirken: ${ }^{39}$ So wie in der Ampelos-Episode Eros als Schiedsrichter eingesetzt wird und als Symbol für die Erotik des Geschehens einen Kranz aus Narzissen und Hyazinthen flicht (Nonn. D. 10,337 f.), sorgen im 48. Buch Aphrodite und Eros gemeinsam für den

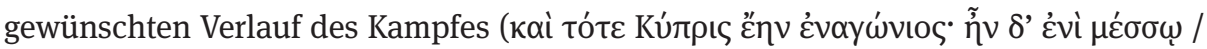

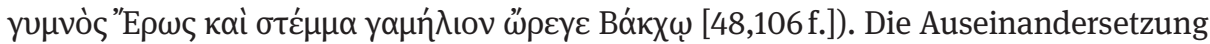

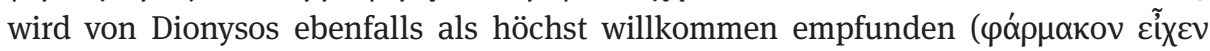

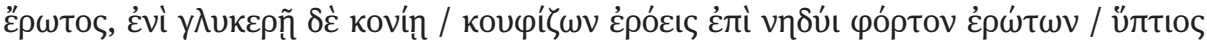

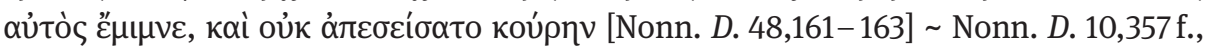

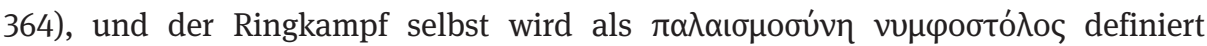

$37 \mathrm{Zu}$ den zahlreichen wörtlichen Parallelen vgl. Chrétien (1985) 75 Anm. 1.

38 Der Mythos liefert nur zwei Beispiele für den ungewöhnlichen Ringwettkampf zwischen Mann und Frau, vgl. Apollod. 3,9,2; 3,13,2; siehe auch Henderson (1975) 169f.; Gigli Piccardi (2003) 632 Anm. 34.

39 Für wörtliche Parallelen zwischen beiden Ringkämpfen siehe Schulze (1965) 102; Chrétien (1985) 76 Anm. 3. - Chrétien (1985) 76f. verweist auf die Möglichkeit, dass eine Variante des Pallene-Mythos existiert haben könnte, die Nonnos bei der Konzeption seiner eigenen Geschichte als Vorbild gedient hat. 
$(48,108)$. Der Zweck des Kampfes im 48. Buch, Pallenes Hochzeit mit Dionysos, be-

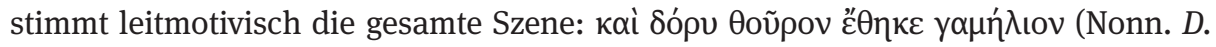

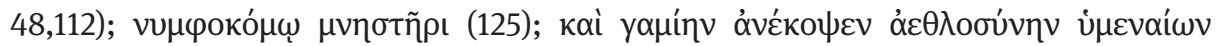

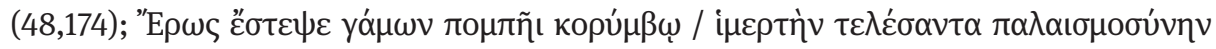
ù $\mu \varepsilon v \alpha i ́ \omega v$ (178f.).

Eros, der jeweils den Kranz vorbereitet und Dionysos am Ende des Ringens mit Pallene zum Sieger krönt, ist Emblem für das Geschehen. Für den Sieg im unter der Schirmherrschaft von Eros stehenden Ringkampf bekommt Ampelos als Siegespreis den Aulos ausgehändigt und nimmt abschließend ein Bad im Fluss (Nonn. D. 10,378382):

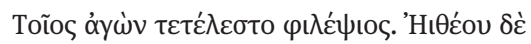

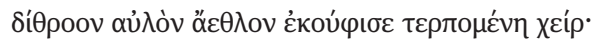

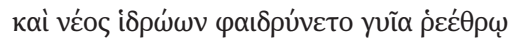

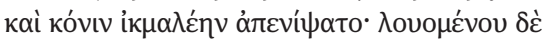

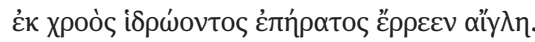

Solch ein sportlicher Wettkampf war zu Ende. Die freudige Hand des Jünglings nahm sich den doppeltönenden Aulos als Kampfpreis. (380) Und der Jüngling reinigte im Strom vom Schweiß seine Glieder und wusch sich den feuchten Staub ab. Und während er badete, strömte lieblicher Glanz von seiner schweißnassen Haut.

In beiden Badeszenen, der des Ampelos sowie der des Dionysos und der Satyrn, ${ }^{40}$ arbeitet Nonnos mit dem Glanzmotiv (" $\rho \rho \varepsilon \varepsilon v$ aly $\lambda \eta$ [Nonn. D. 10,382]) und gibt so einen Vorverweis auf das zukünftige göttliche Schicksal beider Figuren.

Auf das narrative Ziel der Episode, die Genese des Weinstocks, wird auch im Ringkampf selbst verwiesen: Indem Ampelos Dionysos umschlingt, nimmt er damit die sich rankende Weinpflanze vorweg, und der von Eros geflochtene Kranz aus Narzissen und Hyazinthen erinnert an das Schicksal von Tod und Verwandlung in eine Pflanze, der den Leib seines Kontrahenten umschlingende Satyr „bekränzt“ den ei-

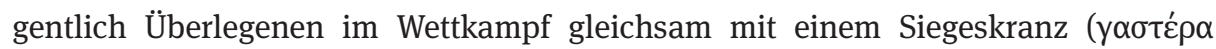

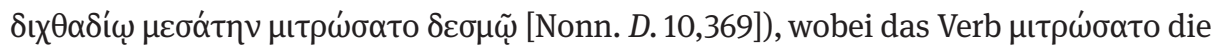
Brücke zwischen Ampelos’ zwei Erscheinungsformen schlägt und die sich windenden Ranken der Rebe vorzeichnet. ${ }^{41}$

40 Zur Badeszene am Beginn der Ampelos-Episode siehe Kap. 2.3.

41 Das Verb findet sich 48-mal in den Dionysiaka, in der Ampelos-Episode an kompositorisch wichtigen Stellen, die das Kommen des Weines vorbereiten: Dionysos wird bereits als Kleinkind von

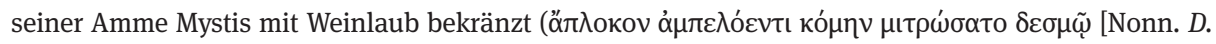

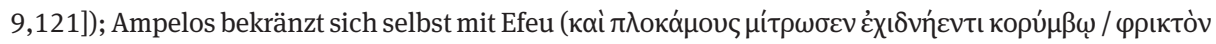

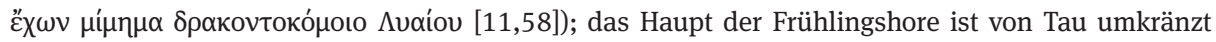

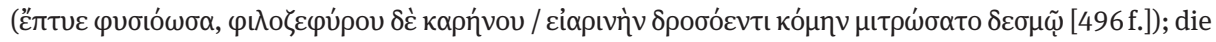

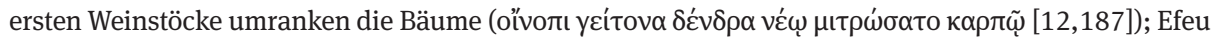

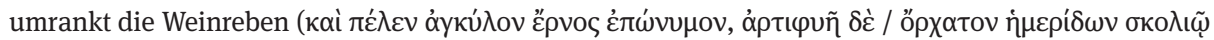

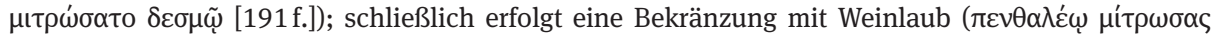

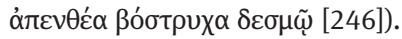


Die Ringkampfszene ist nicht nur kompositorisch bedeutsam, sie ist auch als Chiffre für Nonnos' poetologisches Konzept zu lesen, wenn sich in der Umdeutung der typischen Szene Ringkampf ein regelrechtes Ringen mit den homerischen Erzählstrategien manifestiert. So wie die Figuren in der Erzählung miteinander konkurrieren, misst sich Nonnos auf dichtungstheoretischer Ebene mit seinem Vorbild; er imitiert den epischen Stoff nicht bloß, sondern fügt der homerischen Szenerie Untypisches und Neues hinzu und kreiert so eine neue Art von Epos mit individueller Handschrift. Nonnos ändert die Rahmenbedingungen des Ringkampfes, stellt diesen unter die Schirmherrschaft des Eros und lässt Ampelos den Sieg nicht mit den üblichen Mitteln eines heroischen Wettkampfes erreichen. Er spielt mit der dichterischen Autorität Homer, untergräbt diese jedoch nicht gänzlich, sondern konkretisiert und definiert sein eigenes, dionysisches Epos, indem er seine eigene Poetik mit der Dichtung Homers kontrastiert und ihr so einen festen Platz in der Geschichte des griechischen Epos zuzuweisen versucht.

\section{Der Wettlauf}

Eine ähnlich umfangreiche Auseinandersetzung mit der homerischen Epik unternimmt Nonnos in der Wettlauf-Szene, in der er das Rennen zwischen Ampelos, Leneus und Kissos dem Wettlauf von Aias, Odysseus und Antilochos in der Ilias nachbildet (Hom. Il. 23,740 - 797)..$^{42}$ In der Version in den Dionysiaka findet sich ein ähnlicher Szenenbau wie im iliadischen Vorbild (Nonn. D. 10,383-412):

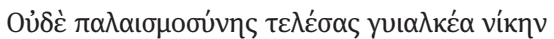

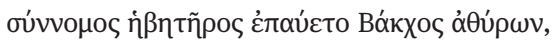
$\dot{\alpha} \lambda \lambda \dot{\alpha} \pi 0 \delta \omega \kappa \varepsilon i ́ n \varsigma$ $\alpha \dot{v} \varepsilon \mu \omega \dot{\delta} \varepsilon \varepsilon \alpha \tilde{\eta} \kappa \varepsilon v \dot{\alpha} y \tilde{\omega} v \alpha$.

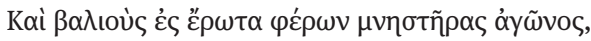

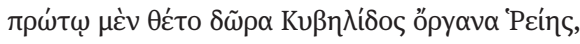

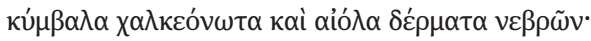

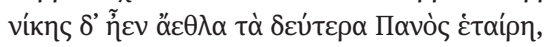

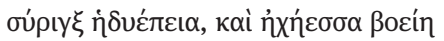

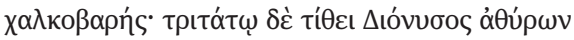

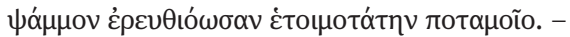

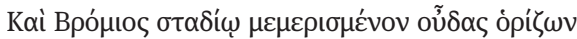

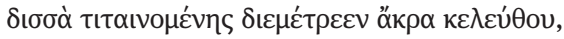

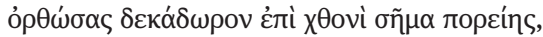

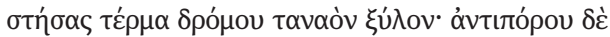

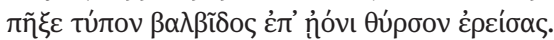

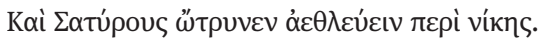

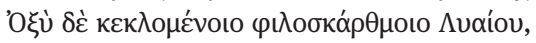

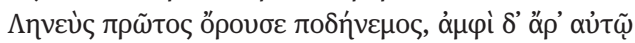




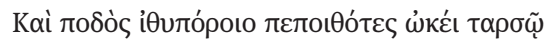

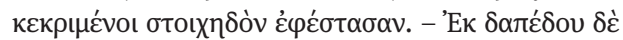

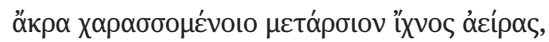

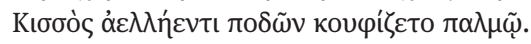

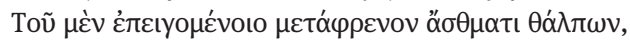

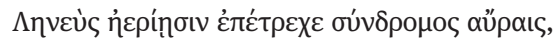

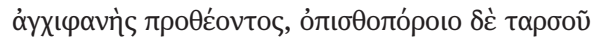

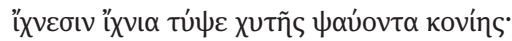

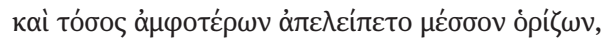

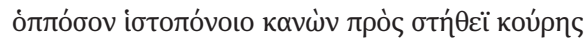

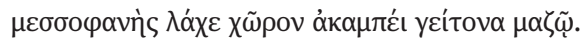

Aber Bakchos, dem Jüngling zugetan, endete nicht mit einem gliederwehrenden Sieg im Ringen und ließ nicht ab vom Spiel, (385) sondern verkündete einen windschnellen Laufwettkampf. Und um die Teilnehmer zu einem schnellen Wettkampf zu bewegen, setzte er für den Ersten die Instrumente der kybelischen Rheia als Geschenke aus: bronzene Zimbeln und glänzende Hirschfelle. Und die zweiten Siegespreise waren die Gefährtin des Pan - (390) die süßtönende Syrinx und eine hell tönende Pauke aus Ochsenfell, schwer und aus Erz. Für den Dritten im Spiel aber setzte Dionysos rötlichen Flusssand aus, der reichlich vorhanden war. Und Bromios vermaß die Strecke, die für den Lauf vorgesehen war und legte die beiden Enden für die ausgelegte Bahn fest, (395) indem er eine zehn Handlängen lange Startmarkierung in die Erde steckte und am Ziel der Laufstrecke ein langes Holz aufstellte. Gegenüber rammte er einen Thyrsos in der Form einer Startschwelle in den Uferboden. Und er ermunterte die Satyrn, um den Sieg zu kämpfen. Auf den lauten Ruf des Lyaios, des Tanzliebenden, (400) stürmte Leneus, der Windschnelle, als Erster nach vorne, und bei ihm stellten sich Kissos mit den schnellen Füßen und der liebliche Ampelos auf. Und im Vertrauen auf die schnelle Sohle des vorwärtseilenden Fußes standen sie der Reihe nach aufgestellt da. Vom Boden, den er nur an der Oberfläche berührte, (405) hob Kissos seine Füße hoch in die Luft und schwebte auf den windschnellen Fußballen. Dieser wurde aber schon bedrängt, und seinen Rücken erwärmte schon Leneus mit seinem Atem und lief den luftigen Winden als Begleiter dicht dahinter; er erschien schon nahe seinem Vordermann, trat mit den Tritten des nachfolgenden Fußes in dessen Tritte und wirbelte den Staub auf. (410) Und in der Mitte zwischen beiden blieb nur so viel Zwischenraum, wie ein Querbalken bei der Brust eines Mädchens am Webstuhl auf halber Strecke Platz braucht nahe ihrem straffen Busen.

An den Vorspann mit der Ankündigung des Wettbewerbs, der Vorstellung des Schiedsrichters und der in Aussicht gestellten Preise (Nonn. D. 10,383-397; Hom. Il. 23,740 - 753) schließt der Laufwettbewerb im engeren Sinn an (Nonn. D. 10,398 - 412; Hom. Il. 23,754-777), dessen Abschluss die Preisverleihung bildet (Nonn. D. 10,427430; Hom. Il. 23,778-783, 785-797). Eine vergleichbare Szenerie bietet Nonnos anlässlich der Leichenspiele für Opheltes im 37. Buch (Nonn. D. 37,614-666): Auch dort folgen auf die Einleitung mit der Präsentation der Preise (614 - 618) Wettlauf (619-659) und Preisverleihung (660-663). Zusätzlich zum kompositorischen Rahmen wird an beiden Stellen der Dionysiaka auch der Rennverlauf der iliadischen Szene entnommen: Zunächst werden die Positionen aller drei Läufer festgelegt, auf Leneus folgen Kissos und als Letzter Ampelos (Nonn. D. 10,402-409; 37,622-630: Okythoos, Erechtheus und Priasos; Hom. Il. 23,754-759: der kleine Aias, Odysseus und Antilochos). Auch das von Homer zur Veranschaulichung von Aias' und Odysseus' Kräftegleichheit eingesetzte Gleichnis mit der am Webstuhl sitzenden Frau (Hom. Il. 23,760-763) übernimmt 
Nonnos sowohl im 10. als auch im 37. Buch (Nonn. D. 10,410-412; 37,630-633), und zwar durch die Wiederholung einschlägiger homerischer Wörter wie etwa kavẃv und

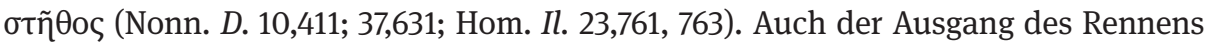
verläuft jeweils nach homerischem Vorbild, wobei Nonnos nicht bloß imitiert, sonden sich bewusst von diesem distanziert: In allen drei Szenen wird der zunächst Zweitgereihte durch ein Missgeschick des Gegners zum Gewinner; sowohl im 37. Buch der Dionysiaka als auch in der Ilias wird ein Gebet an eine Schutzgottheit gerichtet, Erechtheus an den Windgott Boreas (Nonn. D. 37,639-643) ${ }^{43}$ und Odysseus an Athene (Hom. Il. 23,768-771). Das Eingreifen der Gottheiten zugunsten ihres jeweiligen Schützlings führt dazu, dass die Kontrahenten im Rindermist unglücklich ausrutschen und stürzen (Nonn. D. 37,644-656; Hom. Il. 23,771-777). In der Folge wird das Geschehen von beiden Autoren aus dem Blickwinkel des Wettkampfpublikums präsentiert (Nonn. D. 10,425f.; 37,664-666; Hom. Il. 23,766f., 784), welches mit Gelächter

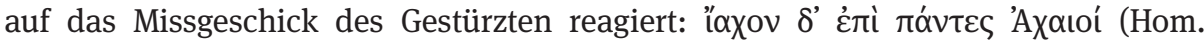

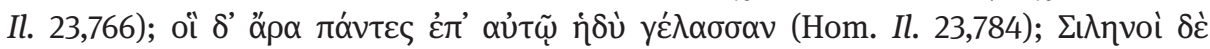

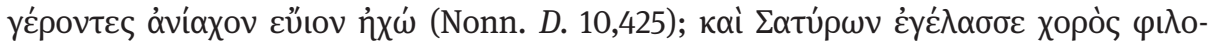

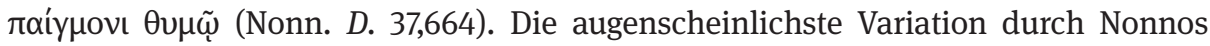
besteht im Aufbau eines dionysischen Umfeldes: Statt der Achaier werden greise Si-

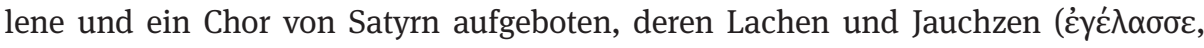

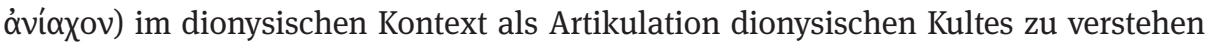
ist.

Trotz der weitgehenden Übereinstimmungen der drei Wettlaufszenen zeigt sich Nonnos' kreativer Umgang mit seinem Vorbild. Der Wettlauf in der Ampelos-Episode weicht stärker vom Ilias-Text ab und verläuft unter völlig anderen Voraussetzungen, wenn nämlich, ähnlich wie im Ringkampf, eine erotische Konnotation vorliegt: Die „flinken Bewerber“ ( $\beta \alpha \lambda$ íous $\mu \nu \eta \sigma \tau \tilde{n} \rho \alpha \varsigma)$ laufen gleichsam als „Freier“ um die Gunst des Dionysos, der sich selbst in einen Liebeswettkampf begibt, der Eros’ Handschrift

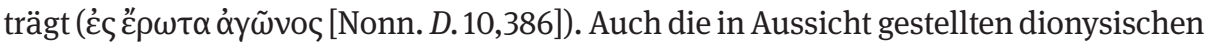
Preise - „die Instrumente der Kybeleischen Rheia“ (Nonn. D. 10,387), „die bronzenen Zimbeln und glänzenden Hirschfelle“ (388), „die süßtönende Syrinx“ (390) und „die erzschwere, helltönende Pauke aus Ochsenfell“ (390f.) - stehen in Kontrast zu den traditionellen homerischen Preisen Krater, Pferd und Schwert im 37. Buch (37,616, 617, 618).

Nonnos' Spiel mit dem Vorbild Homer setzt sich in der Abgrenzung des Wettkampfplatzes und in der Vermessung fort, die von Dionysos in seiner Funktion als Schiedsrichter persönlich durchgeführt werden (Nonn. D. 10,393-397). Ein derartiges Vorgehen ist zwar nicht aus der Wettlaufszene der Ilias, jedoch aus Hom. Od. 8,193f. bekannt, wo Athene anlässlich der sportlichen Wettspiele bei den Phaiaken die Weite

43 Erechtheus spricht ein weiteres Mal zu Boreas und bittet ihn um Hilfe gegen die Inder im Schiffskampf (Nonn. D. 39,174-211). - Zur Figur des Erechtheus und zu ihrer Funktion in den Dionysiaka siehe auch S. 101. 
von Odysseus' Diskuswurf ermittelt. Zweck der Szene in den Dionysiaka ist nicht nur die Eingrenzung der Laufstrecke, sondern auch die Einordnung der Wettkämpfe in die dionysische Sphäre durch das Einrammen des Thyrsos in den Erdboden, einen Akt, der den Ort für den bevorstehenden Wettbewerb vorbereitet und den notwendigen dionysischen Geist in dionysischer Landschaft heraufbeschwört. In diesen kultischen Rahmen fügen sich auch die drei Wettlaufteilnehmer Leneus, Kissos und Ampelos, die als Personifikationen dionysischer Attribute eng mit Dionysos in Verbindung stehen und der Szene einen unmissverständlichen Stempel aufdrücken.

Die Umdeutung der homerischen in dionysische Wettspiele wird ähnlich wie zuvor im Ringkampf durch die Hereinnahme von Elementen der erotischen Literatur erreicht. ${ }^{44}$ Im Gegensatz zum Wettlauf in der Ilias, in dem Odysseus in einer Rede Athene um Unterstützung bittet (Hom. Il. 23,768 - 777), richtet sich Ampelos, der Letztgereihte, gar nicht erst an seinen Schutzgott Dionysos, sondern dieser greift von sich aus zugunsten seines Lieblings ein, ${ }^{45}$ indem er diesem übermäßige Kräfte einhaucht, ihn schnell wie den Wind laufen und schließlich gewinnen lässt (Nonn. D. 10,413-424):

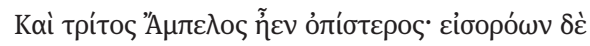

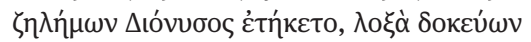

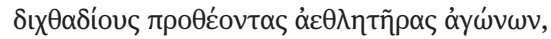

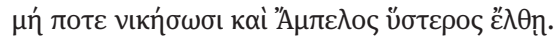

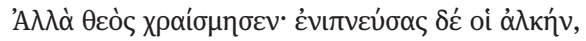

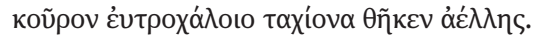

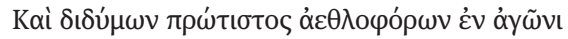

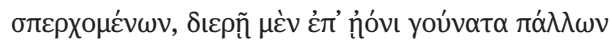

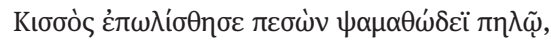

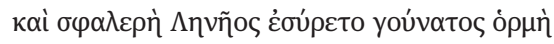

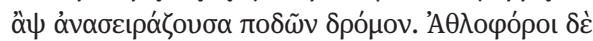

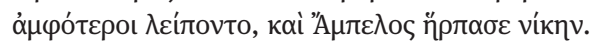

Und dritter und weit hinten war Ampelos. Und dies sah neidisch Dionysos und schmolz dahin, wie er es von der Seite her deutlich sah, (415) und er fürchtete, dass die beiden voranlaufenden Wettkämpfer siegten und Ampelos als Letzter ins Ziel käme. Aber der Gott wehrte es ab, hauchte

\footnotetext{
44 Auch in der antiken Romanliteratur findet sich ein Beispiel für die Mischung der Themen Wettkampf und Erotik: In Heliodors Aithiopika wird Theagenes durch den ausgesetzten Wettkampfpreis, den der Sieger aus den Händen der Priesterin Charikleia erhält, motiviert, den Wettlauf gegen Arkas zu gewinnen (Hld. 4,2,1 -4,4,2). Die erotische Konnotation wird durch die namentliche Nennung des Eros verstärkt; Theagenes fühlt sich im wahrsten Sinne des Wortes „beflügelt“ und läuft wie ein geflügelter

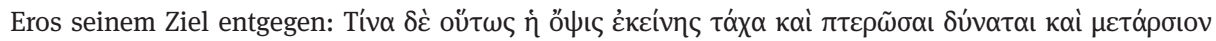

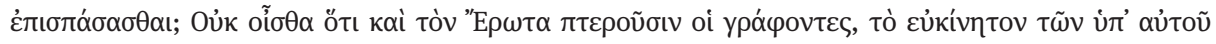

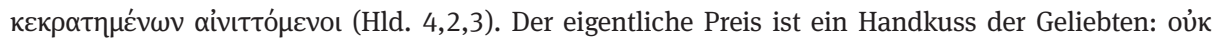

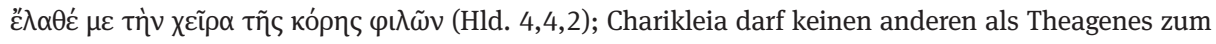
Sieger küren.

45 Im Gegensatz zur Stelle in der Ampelos-Episode hält sich Nonnos im Wettlauf des 37. Buches streng an sein homerisches Vorbild: Genauso wie Athene in der Ilias auf die Bitte ihres Schützlings Odysseus für selbigen eintritt, beeinflusst der Windgott Boreas den Laufwettbewerb zugunsten des Erechtheus in Nonn. D. 37,640-645.
} 
ihm Kraft ein und machte den Knaben schneller als den brausenden Sturmwind. Da kam als Erster von den beiden, die im Wettkampf um die Preise (420) dahineilten, Kissos, da er seine Glieder am feuchten Ufer schwang, ins Rutschen und fiel in den sandigen Schlamm. Und eine schwankende Bewegung der Knie hemmte Leneus und bremste den Lauf seiner Füße wieder. Beide Wettkämpfer blieben zurück, und Ampelos heimste den Sieg ein.

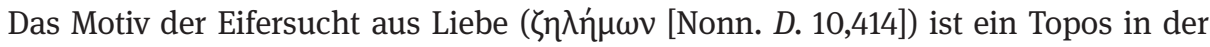
Romanliteratur, der hier mit dem Wettlauf homerischen Typs verwoben wird. Dionysos startet die Aktion aus persönlichem Interesse, das Hingezogensein zum Satyrn Ampelos spiegelt die Verbundenheit des Gottes mit seinem wichtigsten Attribut wider. Die Verliebtheitsthematik wird durch die Eifersucht des Konkurrenten Leneus weitergeführt (Nonn. D. 10,425-430):

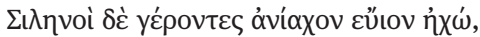

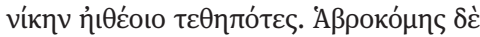

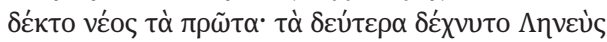

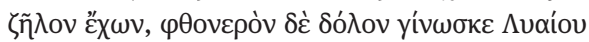

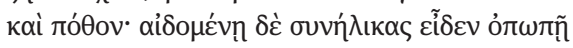

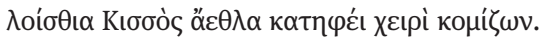

430

(425) Und die greisen Silene jauchzten einen Jubelruf und staunten über den Sieg des Jünglings. Und der schönhaarige Junge erhielt den ersten Preis. Den zweiten Preis erhielt Leneus, der eifersüchtig war und den neidischen Trick des Lyaios und auch sein Verlangen durchschaute. Und mit beschämtem Antlitz sah Kissos seine Altersgenossen (430) und nahm niedergeschlagen mit der Hand die Kampfpreise für den Letzten entgegen.

Das Unterliegen im Wettkampf bedeutet gleichzeitig auch den Verlust der Gunst des Gottes Dionysos, den die Konkurrenten ähnlich den Brautwerbern um Penelope einstecken müssen, wenn das Rennen der drei dionysischen Attribute Keltertrog, Efeu und Wein durch Dionysos' persönliches Einlenken schließlich zugunsten des Weines entschieden wird.

Die Vorrangstellung des Weines gegenüber den übrigen dionysischen Attributen sowie die enge Verbindung des Gottes mit Ampelos münden schließlich in die

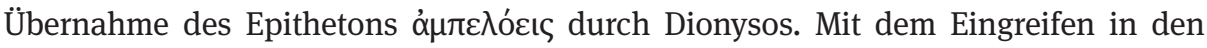
Wettlauf zugunsten des Ampelos wählt Dionysos aus dem vorliegenden Angebot Kelter, Efeu und Wein - selbst sein Hauptattribut, der sportliche Sieg des Satyrn ist daher nur folgerichtig. Nonnos lotet die Möglichkeiten und Grenzen des traditionellen homerischen Epos aus, indem er dieses um narrative Elemente der erotisch-hellenistischen Literatur und des Romans erweitert und diese mit dionysischen Elementen zusammenschließt, um seinen souveränen Umgang mit antiken Traditionen zu demonstrieren. In der Dionysos-Figur, die nach eigenem Gutdünken den Ausgang des Laufwettbewerbs bestimmen kann, wird der Dichter sichtbar und zeigt sich als autonomer Literat, der über die gesamte antike Literatur verfügen, diese umordnen und seinem eigenen poetischen Programm folgend neu interpretieren kann. 


\section{Das Schwimmen}

Der dritte und letzte Wettkampf zwischen Dionysos und Ampelos, das Schwimmen, ist sowohl in der Ilias als auch in der Odyssee nur ein Randthema und im griechischen sowie im römischen Kulturraum insgesamt kaum belegt: ${ }^{46}$ Von einem Wettschwimmen ist außer bei Nonnos nur noch bei Pausanias die Rede, der für die griechische Stadt Hermione auf der Peloponnes einen solchen - mit Dionysos verbundenen - kultischen Wettkampf bezeugt. ${ }^{47}$ Des Weiteren findet sich bei Platon eine Bemerkung, wonach das Schwimmen offenbar einen wesentlichen Teil des Sportunterrichts der Griechen

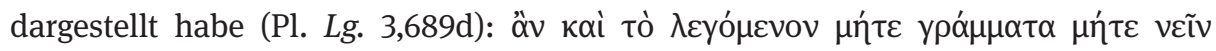

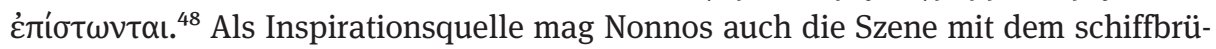
chigen Odysseus im 5. Gesang der Odyssee gedient haben (Hom. Od. 5,313-463). In dieser ausführlichsten Schwimmschilderung, die Homer bietet, muss Odysseus sämtliche Widrigkeiten der Natur überwinden und sich unfreiwillig schwimmend mithilfe eines Balkens seines geborstenen Floßes und des von Ino Leukothea gesandten Schleiers aus den Meereswogen retten. Mehrfach wird auf Odysseus' Schwimmen verwiesen, ${ }^{49}$ nirgends jedoch näher auf die Schwimmtechnik selbst eingegangen, die bei Nonnos eine so detailreiche Ausführung erhält. Wasser stellt bei Homer zumeist ein bedrohliches Element dar und dient niemals als spielerischer Zeitvertreib wie bei Nonnos. Eine Szene der Ilias, die in Zusammenhang mit dem Element Wasser steht, ist die ausführlich geschilderte Schlacht am Skamandros (Hom. Il. 21,7-28), wo sich die in Bedrängnis geratenen Troianer schwimmend vor dem rasenden Achill zu retten suchen. Trotz der unterschiedlichen Rahmenbedingungen nimmt Nonnos punktuell und in einzelnen sprachlichen Details Bezug auf Homer und setzt sich durch intertextuelles Spiel mit seinem Vorbild auseinander. ${ }^{50}$

Der Einzige, der eine den Dionysiaka vergleichbare Szene liefert, ist der lateinische Dichter Ausonius, der in seiner Mosella Satyrn und Nymphen im Fluss baden lässt

46 Zum Schwimmen bei Homer vgl. Mehl (1927) 15 - 21; Mehl (1931); zum Schwimmen in der Antike siehe Mehl (1927) 5f., 12f., 15 - 39; 41 - 89; Mehl (1931) 847 - 864; Schütze (1938); Jüthner u. Brein (1965) 103; Weiler (1981) 74f., 207 f.; Lukas (1982) 101-111; Kröll (2013).

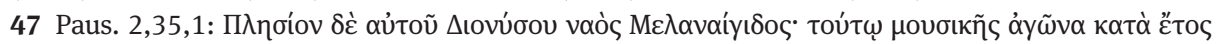

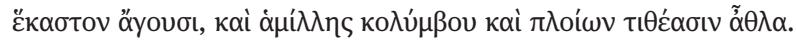

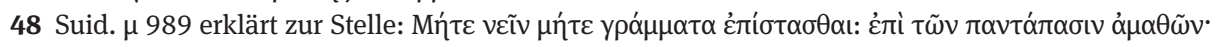

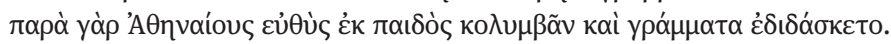

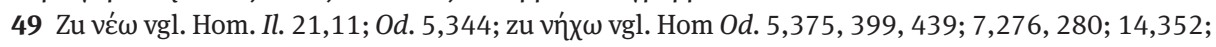
23,233, 237. - Zwei ähnliche Szenen finden sich auch bei Nonnos: In Nonn. D. 23,196- 205 werden zwei im Fluss kämpfende Bakchen gezeigt, in Nonn. D. 34,231-248 eine ertrinkende Bassaride.

50 In ganz anderem Kontext, als Vergleich gebraucht, erscheint Wasser in einer Passage im 16. Gesang der Ilias, in der der für Achill in die Schlacht gezogene Patroklos seinen Gegner Kebriones, den Wagenlenker Hektors, mit einem Stein am Kopf trifft und vom Wagen wirft (Hom. Il. 16,737 - 749); der von Patroklos Verhöhnte wird mit einem ins Meer hinabtauchenden Fischer verglichen (Hom. Il. 16,745749). Ein ähnlicher Vergleich wird auch in Hom. Od. 12,413 gezogen, wo ein von einem Mast getroffener Steuermann wie ein Taucher vom Verdeck in die Tiefe stürzt. 
(Auson. Mos. 169-188). Die Szene bietet keinen Schwimmwettbewerb, sondern ein ungezwungenes Spiel in einer besonderen Flusslandschaft, die an die im Paktolos spielenden Satyrn zu Beginn der Ampelos-Episode erinnert, aber keine direkte Quelle für Nonnos' Wettspiele im 11. Buch darstellt. ${ }^{51}$ Dennoch legt Nonnos' intensive Auseinandersetzung mit dieser Sportart Zeugnis von der Affinität zu derartigen Wettbewerben ab und ist als unmittelbarer Anknüpfungspunkt an Alltagserfahrungen seiner Zeitgenossen $\mathrm{zu}$ werten.

Zweimal im 11. Buch der Dionysiaka lässt Nonnos einen Schwimmwettkampf stattfinden, zunächst im Rahmen der Wettspiele von Dionysos und Ampelos (Nonn. $D$. 11,1-55):

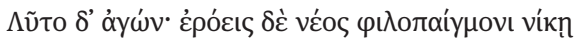

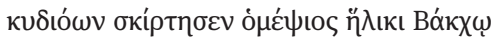

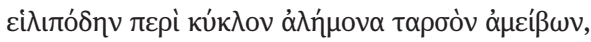

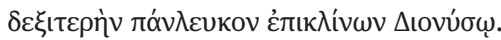

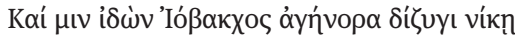

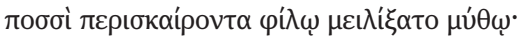

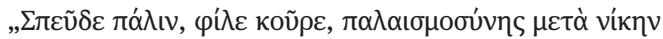

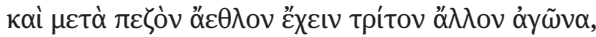

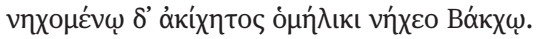

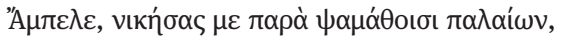

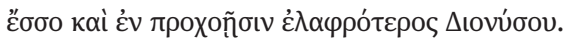

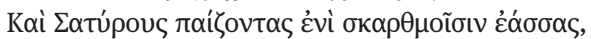

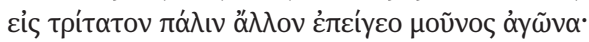

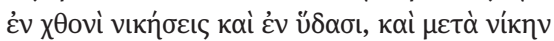

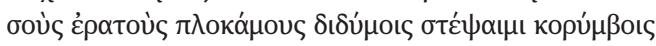

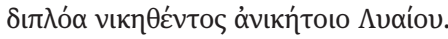

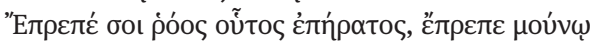

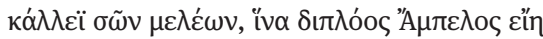

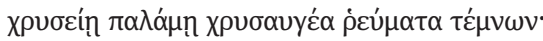

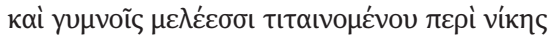

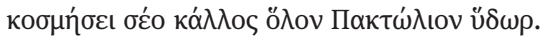

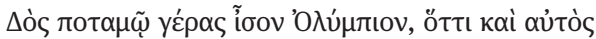

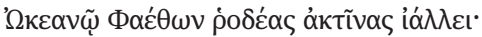

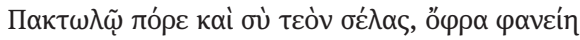

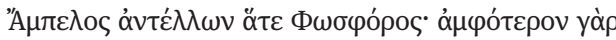

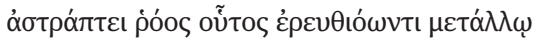

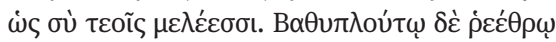

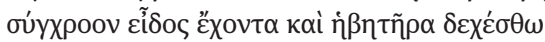

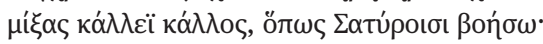

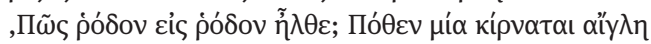

51 Gennaro D'Ippolito zufolge habe sich der Dichter hier von Wasserspielen, idromimi oder mimi acquatici, inspirieren lassen, die sich im spätantiken Theater besonderer Beliebtheit erfreuten, vgl. D’Ippolito (1962) sowie D’Ippolito (1964) 145f. - Diese These erscheint auf der Grundlage entsprechender archäologischer Zeugnisse plausibel, die eine Umrüstung antiker Theaterbauten für die Abhaltung von Wasser- und Seespielen belegen, vgl. Traversari (1960). - Zu möglichen zeitgenössischen Einflüssen auf die Wettspiele in den Dionysiaka vgl. schon Keydell (1955) 487 f. (517f.). 


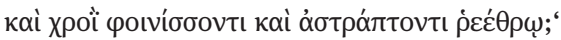

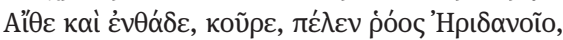

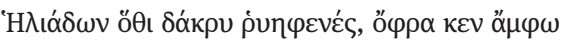

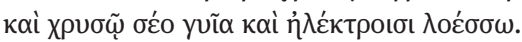

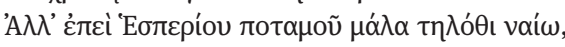

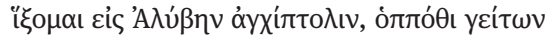

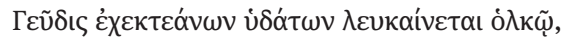

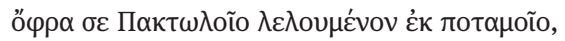

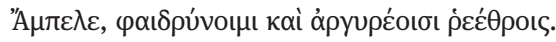

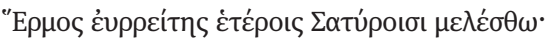
oủ yò

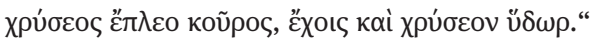

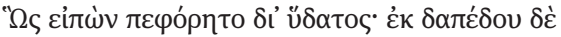

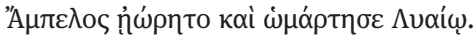

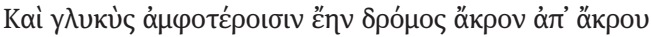

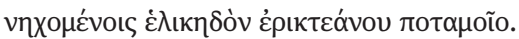

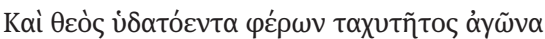

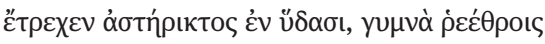

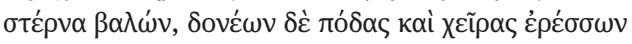

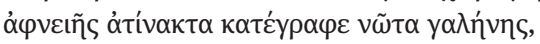

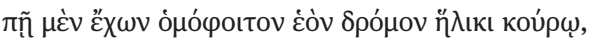

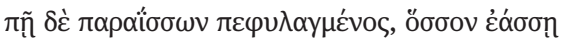

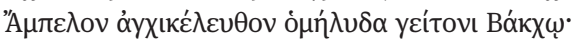

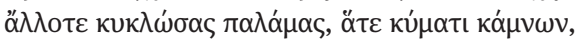

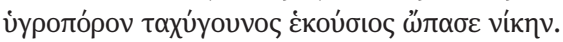

Und beendet war der Wettkampf. Anmutig sprang der Junge umher, stolz auf seinen sportlichen Sieg, dem gleichaltrigen Bakchos ein Spielgefährte, setzte den Fuß schleppend, drehte sich im Kreis und stützte sich mit seiner ganz weißen rechten Hand auf Dionysos. (5) Und als ihn Iobakchos sah, wie er ob des doppelten Sieges selbstbewusst mit den Füßen herumhüpfte, da schmeichelte er ihm mit einer lieben Rede:

„Spute dich gleich noch einmal, lieber Knabe, nach dem Sieg im Ringen und nach dem Wettlauf noch einen dritten, einen anderen Wettkampf in Angriff zu nehmen! Schwimme mit dem gleichaltrigen Bakchos um die Wette! Denn auch beim Schwimmen bist du von ihm nicht zu erwischen. (10) Ampelos, du besiegtest mich beim Ringen im Sand. Sei nun auch in den Fluten schneller als Dionysos! Und lass die Satyrn spielen mit ihren Sprüngen! Mach dich wieder auf, allein, zu einem dritten, einem anderen Wettkampf! Auf der Erde wirst du siegen und auch im Wasser, und nach dem Sieg (15) will ich deine lieblichen Locken mit doppeltem Efeukranz umwinden, weil der unbesiegbare Lyaios zweimal besiegt wurde. Zu dir gehört dieser reizende Fluss, er gebührt dir allein wegen der Schönheit deines Körpers, damit es Ampelos zweimal gibt, wenn er mit goldener Hand den golden strahlenden Fluss durchschneidet! (20) Und wenn du deine bloßen Glieder nach dem Sieg ausstreckst, wird deine ganze Schönheit das Wasser des Paktolos zieren. Gib dem Fluss eine Ehrengabe, gleich einer olympischen, da ja auch Phaethon dem Okeanos rosenrote Strahlen schickt! Dem Paktolos verleihe auch du deinen Glanz, damit (25) Ampelos erscheint und aufgeht wie der Morgenstern! Denn beides strahlt, dieser Strom mit seinem rötlichen Metall wie auch du mit deinem Körper. Und nimm du in deiner reichen Strömung auch den Jüngling auf, dessen Gestalt die gleiche Farbe hat! Vermische Schönes mit Schönem, damit ich den Satyrn zurufen kann: (30) ,Wie kam die Rose zur Rose? Warum entsteht durch Mischung ein einziger Glanz aus purpurner Haut und strahlender Strömung?` Wenn doch auch hier der Eridanos-Strom wäre, mein Knabe, wo die Tränen der Heliaden reichlich fließen, damit ich mit beidem, mit Gold und Bernstein, deinen Körper waschen könnte! (35) Aber da ich sehr weit 
entfernt vom hesperischen Fluss wohne, werde ich mich in die Nähe der Stadt Alybe begeben, wo in der Nachbarschaft der Geudis mit seinen reichen Wassern in der Strömung weiß schimmert, damit ich dich, gebadet im Paktolos-Fluss, Ampelos, auch in silbernen Fluten erglänzen lassen kann. (40) Der schön fließende Hermos soll sich um die anderen Satyrn kümmern! Denn er führt keinen Strom aus Gold. Aber du allein bist der goldene Knabe. Mögest du auch goldenes Wasser haben!“"

So sprach er und glitt durch das Wasser. Und vom Erdboden erhob sich Ampelos und geleitete Lyaios. (45) Und angenehm war beiden der Wettlauf von Ufer zu Ufer: Sie schwammen durch den reichen Fluss und wendeten dabei. Und der Gott trug den Wettkampf aus, wer im Wasser der Schnellste sei; er bewegte sich unablässig im Wasser und warf seine bloße Brust in die Fluten, schlug mit den Füßen und ruderte mit den Händen. (50) Er zerschnitt die unbewegte Fläche der reichen, glänzenden Stille; bald hielt er seine Bahn direkt neben dem gleichaltrigen Knaben, bald hütete er sich davor, ihn zu überholen. Er ließ gerade so viel Zwischenraum, dass Ampelos die Bahn daneben haben und Bakchos ganz nahe begleiten konnte. Dann wieder vollführte er mit den Händen Kreisbewegungen, weil er durch die Strömung müde wurde. (55) Den Sieg auf nasser Bahn vergab der Knieschnelle freiwillig.

Obwohl Nonnos eine neue Art des Wettkampfes bietet, übernimmt er dennoch einzelne sprachliche Details von Homer und setzt diese in den ungewöhnlichen Kontext des Wettschwimmens. Wenig überraschend erscheinen Wörter, die dem Themenfeld

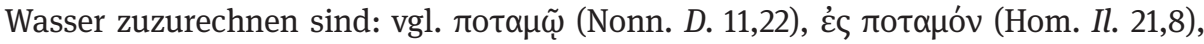

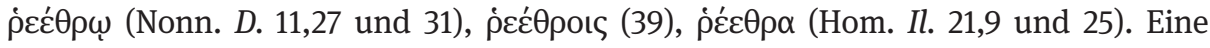
individuelle Note verleiht Nonnos der Szene durch komponierte Adjektive wie $\beta \alpha \theta u$ -

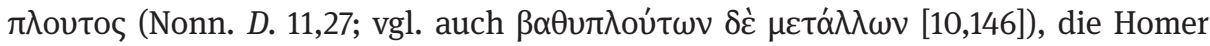
unbekannt sind. Ein hohes Maß an Originalität bei gleichzeitigem Bezug auf literarische Vorbilder ist insbesondere für den Bereich der lexikalischen Neologismen gegeben, die zwar Eigenkreationen des Nonnos darstellen, jedoch häufig an homerisches

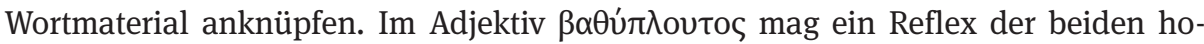

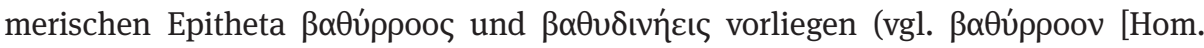

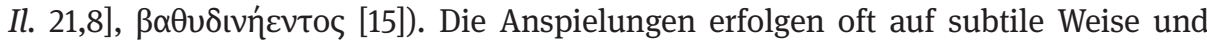
lassen Bekanntes in völlig neuem Licht erscheinen, wobei Nonnos bis hin zur humoristischen Karikatur sämtliche Nuancen abzudecken vermag. So erinnert der im

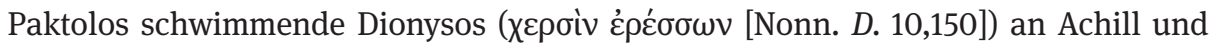

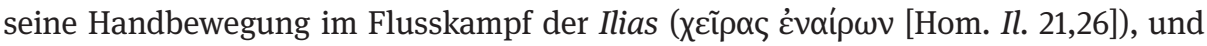

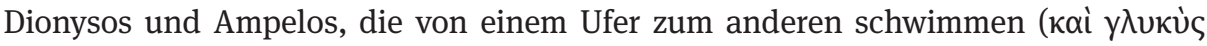

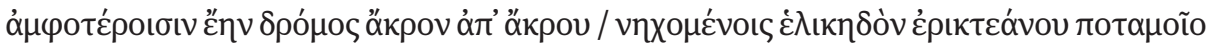

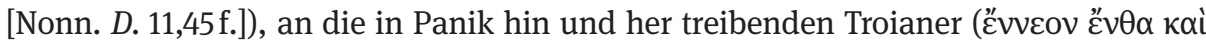

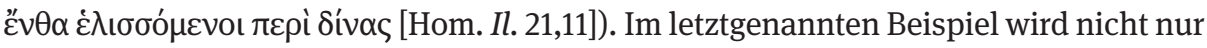
die Hin- und Her-Bewegung von beiden Dichtern angedeutet, sondern auch die

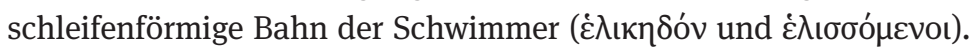

Ein besonderes Spannungsfeld ergibt sich auch aus der Gegenüberstellung des Flusskampfes mit dem Bad des Dionysos im Paktolos zu Beginn der Ampelos-Episode. Beide Dichter lenken die Aufmerksamkeit auf die den Fluss umgebende Landschaft

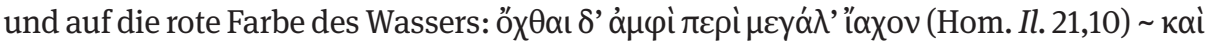

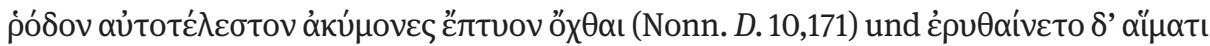




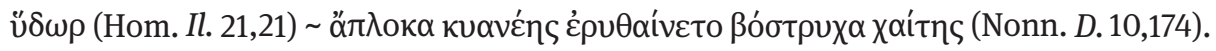
Der schöpferische Umgang mit dem homerischen Vorbild durch den spätantiken Dichter nimmt an dieser Stelle parodistische Züge an, der Ausgangstext wird in sein Gegenteil verkehrt: Während in der Ilias die für die Troianer bedrohliche Lage durch das Brausen der Ufer gleichsam hörbar gemacht wird und als Ergebnis von Achills Morden das Wasser sich mit dem Blut der Gefallenen mischt, weicht die düstere Atmosphäre bei Nonnos einer gelösten, positiven Stimmung. Die mit sprießenden Blumen bedeckten Ufer und das rötliche Schimmern von Dionysos' Locken stehen in scharfem Gegensatz zum dröhnenden Kampfgeschehen im Skamandros. Aus dem leidvollen Kriegsepos Homers wird bei Nonnos ein unbeschwertes Vergnügen, ein Prolog der dionysischen Lebensfreude, die durch die Genese des Weines zu einem ersten Höhepunkt gelangt.

Und dennoch erhält das unhomerische Thema des Schwimmwettkampfes seine Ausgestaltung durch homerische Formensprache. Diese Technik der Abkoppelung bei gleichzeitigem Aufgreifen epischer Traditionen ist ganz besonders im ersten Vers des 11. Buches zu beobachten, in dem Nonnos mit $\lambda \tilde{u} \tau o ~ \delta ’ \alpha$ y $\omega \dot{v}$, einer wohlbekannten homerischen Wendung an markanter Stelle in der Ilias, arbeitet. ${ }^{52}$ Während in der Ilias mit diesen Worten das Ende der Leichenspiele für Patroklos markiert ist (Hom. Il. 24,1), schließt Nonnos seine Spiele zu Beginn des 11. Buches nicht ab, sondern bietet den neuen Wettbewerb des Schwimmens, er beendet seine Spiele also nicht gemäß der epischen Tradition, sondern setzt Homer einen neuen Agon entgegen. Den vorläufigen

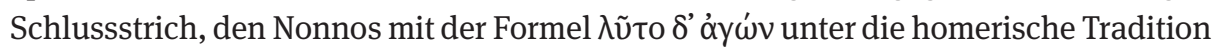
zieht, unterminiert er durch die Herstellung intertextueller Bezugslinien zum prominenten Vorbild. Die bei Homer lediglich einmal gesetzte Junktur verfünffacht Nonnos und bringt sie jeweils am Ende großer narrativer Einheiten: der Typhonomachie (Nonn. D. 3,1), der Leichenspiele für Staphylos $(38,1)$ und Opheltes $(20,1)$ sowie der Kämpfe des Kadmos vor der Gründung Thebens $(5,49) . .^{53}$ Auch hier bleibt Homer Ausgangspunkt, das eigentliche Ziel aber ist es, eine Neudefinition epischer Poetik und ein dionysisches Epos zu erreichen.

Nach welchen Gesetzmäßigkeiten und erzähltechnischen Mitteln diese dionysische Epik funktioniert, ist an der zweiten Schwimmszene in der Ampelos-Episode festzumachen: Analog zu den Wettspielen zwischen Dionysos und Ampelos tragen Kalamos und Karpos Sportwettkämpfe aus (Nonn. D. 11,369-481). ${ }^{54}$ Während Nonnos den Wettlauf am Ende des 10. Buches ähnlich dem homerischen Vorbild gestaltet, verkürzt er den Wettlauf zwischen Kalamos und Karpos auf lediglich sechs Verse (Nonn. D. 11,400-405), zudem hält er sich mit der ausführlichen Schilderung des Schwimmwettbewerbs eng an den Beginn des 11. Buches (406-426). Mit den Spielen von Kalamos und Karpos reduziert Nonnos das Homerische stärker als in der Dionysos-

$52 \mathrm{Zu}$ dieser Formel vgl. auch Orph. A. 594.

53 Vgl. Gigli Piccardi (2003) 274f. Anm. 1.

54 Zur Kalamos-Karpos-Episode und zu ihren Parallelen zur Ampelos-Episode siehe Kap 7.2. 
Ampelos-Szene, die wenigen dem Wettlauf gewidmeten Verse sind ein letztes Aufblitzen traditioneller epischer Formensprache, der die dionysische Poesie gegenübergestellt wird. Im Wettschwimmen zwischen Kalamos und Karpos zitiert er nicht so sehr Homer als vielmehr sein eigenes Epos und schafft durch zahlreiche sprachliche Parallelen zur ersten Schwimmszene ein dichtes Netz an Selbstreferenzen, mittels dessen er seine dionysische Dichtung legitimiert und den homerischen Epen zur Seite stellt.

Nonnos' Auseinandersetzung mit Homer ist zugleich eine Debatte über das epische Dichten an sich. Durch die Orientierung an den iliadischen Leichenspielen zeigt er seinen souveränen Umgang mit dem literarischen Vorbild, der in jenen Abschnitten am deutlichsten wird, in denen er sich bewusst von ihm entfernt, wie etwa in den Schwimmwettkämpfen. Zugleich mit seiner Distanzierung von Homer bleibt Nonnos diesem aber auch verbunden, und zwar im lexikalischen Bereich, wenn er ausgewählte homerische Wörter, Phrasen und Diktionen konserviert und interpretiert, die das geschulte Publikum zu dechiffrieren vermag. In demselben Maß, wie Nonnos eine neue Art des Epos propagiert, ${ }^{55}$ bietet er wie jedes antike Epos eine unentwegte Auseinandersetzung mit Homer, zugleich eine „imitation et amélioration“ 56 und ähnlich wie die hellenistische Dichtung ein gelehrt-philologisches Spiel mit der epischen Tradition. Der Einfluss Homers auf Nonnos, den „segundo Homero“57, ist folglich keineswegs eindimensional im Sinne einer bloßen Imitation zu verstehen, sondern manifestiert sich im Streben nach literarischer Originalität und Anerkennung als ebenbürtiger Autor. Was für sämtliche Epiker nach Nonnos, etwa auch für Quintus Smyrnaeus, gilt, ist einmal mehr für Nonnos kennzeichnend: „To write epic after Homer and then also after Apollonius [...] is to inscribe the past, to declare unavoidable indebtedness within a genre predetermined by interpretation of Homer. “58

\subsection{Ampelos und die hellenistische Dichtung}

Die Aufnahme von Elementen hellenistischer Dichtung in die Dionysiaka wird von Nonnos auf unterschiedlichen Ebenen realisiert; den Entlehnungen im lexikalischen Bereich schließen sich Motive und typische Szenen an, auf deren Grundlage er seine Ampelos-Figur entwirft. Er übernimmt die Schicksale mythischer Figuren wie Hyakinthos und Hylas, wie sie aus Apollonios Rhodios oder Theokrit bekannt sind, überträgt diese auf den jungen Satyrn und generiert so dessen Charakterbild. ${ }^{59}$ Dabei

55 Vgl. Shorrock (2007) 385: „The striking transformation of traditional epic material into the new epic of Dionysus [...].“

56 Frangoulis (1995) 168.

57 Hernández de la Fuente (2008) XI. Vgl. auch Mommsen (1895) 237: „, [...] Nonnos, der Aegyptische Homeros."

58 Maciver (2012) 16.

59 Vgl. D’Ippolito (1964) 87 f. Anm. 4 sowie 131 f.; zu den Vergleichsfiguren für Ampelos siehe Kap. 4. 
geht es dem Dichter nicht nur darum, eine der Tradition unbekannte Figur zu erschaffen, sondern er beansprucht mit der Übernahme zahlreicher bukolischer Motive auch ein für den Hellenismus typisches literarisches Genus für sein Epos: ${ }^{60}$ Ampelos, der im 10. Buch als Tänzer und Musiker gezeigt wird (Nonn. D. 10,230 - 242), ist ebenso als Reminiszenz an die Bukolik zu verstehen wie Hymenaios, der im 29. Buch als zweiter Liebling des Dionysos auftritt. ${ }^{61}$ Die Beschreibung von Ampelos’ Äußerem ist wie die beiden Trauerreden des Dionysos auf den Tod des Satyrn und die Trostrede des Eros der bukolischen Sphäre zuzuordnen. ${ }^{62}$ Die in die Eros-Rede eingebauten Trauerreden des Kalamos auf den toten Karpos (Nonn. D. 11,431-460, 465-474) schöpfen einzelne Topoi aus der bukolischen Liebesdichtung wie auch die beiden Reden des Dionysos auf den toten Ampelos (255-350). Sämtliche Reden ergänzen einander, indem sie unterschiedliche Motive bieten, so etwa die zweite Kalamos-Rede in Nonn. D. 11,474f., welche als Erweiterung und Variation zu den Dionysos-Reden zum Abschluss ein Grabepigramm setzt, oder einige Episoden außerhalb der Ampelos-Episode mit bukolischem Gepräge: der Kampf des Hirten Kadmos gegen den Usurpator Typhon (Nonn. D. 1,409 - 534), die Hymnos-Nikaia-Episode (15,169 - 422;16,1-249), die gastliche Aufnahme des Dionysos durch Brongos und Staphylos (17,32-86;18) und der musische Agon anlässlich der Leichenspiele für Staphylos (19,59-117). Es ist folglich keineswegs verwunderlich, dass der Dichter auch in der Ampelos-Episode auf diese Tradition zurückgreift und in zahlreichen Szenen und Einzelaspekten in den Büchern 10, 11 und 12 einerseits wörtliche Anleihen bei hellenistischen Dichtern nimmt, andererseits Örtlichkeiten, Umgebungen und Stimmungen entwirft, die der allgemeinen poetischen Formensprache bukolischer Dichtung nachempfunden sind. ${ }^{63}$

Bereits in der ersten Szene, dem ausgelassenen Wasserspiel der Satyrn am Paktolos-Fluss, wird eine bukolische Landschaft komponiert, die der Dichter zur idealen Kulisse für die Liebesgeschichte um Dionysos und Ampelos stilisiert. Des

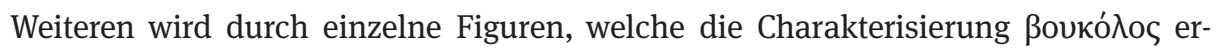

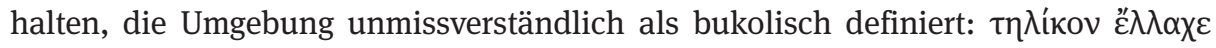

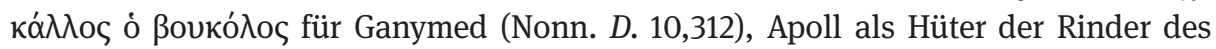

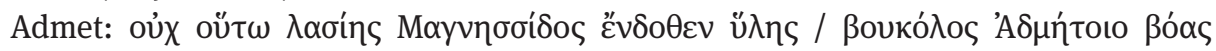

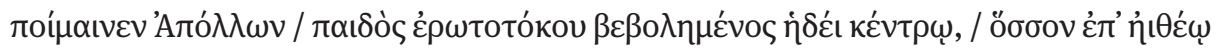

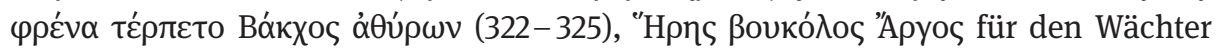
Argos (12,10).

60 Zu hellenistischen Einflüssen vgl. Cazzaniga (1963); D’Ippolito (1964) 41 - 44; Hollis (1976); Hollis (1994); zur Bukolik in den Dionysiaka vgl. Chamberlayne (1916) 48 - 53; Haidacher (1949) 35 - 55; D’Ippolito (1964) 99, 141 - 144; Harries (1994); Shorrock (2001) 141 - 143; Bittrich (2005) 155 - 167; Harries (2006); Lasek (2006); Hernández de la Fuente (2008) 51; Accorinti (2009) 75 f.; Lasek (2009) $107-130$.

$61 \mathrm{Zu}$ Hymenaios vgl. S. 56f. und 234-237.

62 Vgl. Harries (2006) 526-529.

63 Vgl. Mazza (2012) 114-117. - Mit der Epigrammatik verarbeitet Nonnos eine weitere im Hellenismus beliebte Gattung (vgl. auch Nonn. D. 10,278-288), siehe dazu Lasek (2009) 71-106. 
Ebenfalls der bukolischen Sphäre ist eine Reihe von Motiven zum Thema Liebe zuzurechnen, ${ }^{64}$ das sich bereits in der Evokation und Anwesenheit des Gottes Eros, in

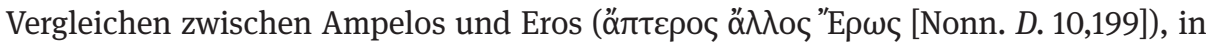
der erotischen Aufladung der Wettspiele sowie im eigentlichen Wettkampfpreis, in

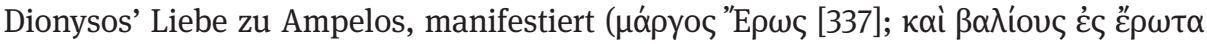

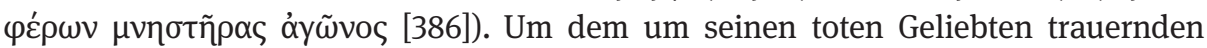
Dionysos Trost zu spenden, tritt Eros persönlich in Erscheinung und gibt in Gestalt eines Silens die Parabel über Kalamos und Karpos zum Besten (Nonn. D. 11,351), in welcher vor allem eine Textpassage besonders ins Auge fällt, die das Nomen ع̋ $\rho \omega \varsigma$ insgesamt fünfmal in unterschiedlichen Flexionsformen innerhalb von fünf Versen

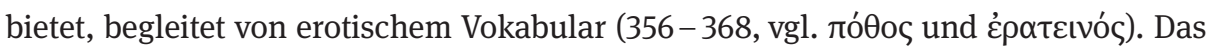
Liebesverhältnis zwischen Dionysos und Ampelos wird schließlich im Verhältnis

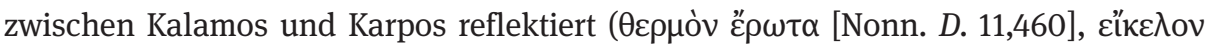

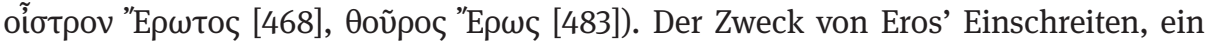

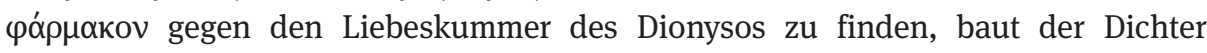
gleichfalls zu einem Thema aus; ${ }^{65}$ die Aussage, wonach Apoll die Hyazinthe als ein Heilmittel gegen seinen Kummer um Hyakinthos erhalten habe ( $\varphi$ ó $\rho \mu \alpha \kappa o v$ [Nonn. $D$. 11,262]), wird in der Rede des Eros direkt auf Dionysos angewandt: Nur durch eine neue

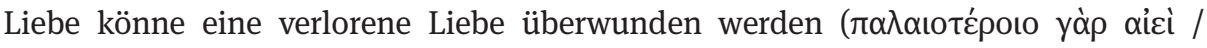

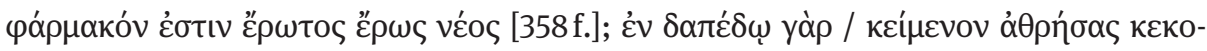

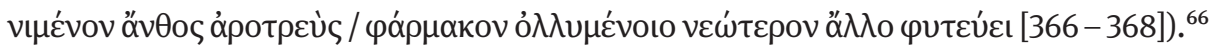
Nach einem letzten Zweifel am Sinn und Nutzen des Schicksalsschlages für Ampelos

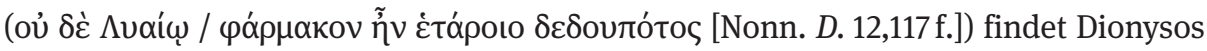
schließlich Genugtuung in der neuen Pflanze, die ihrer berauschenden Wirkung we-

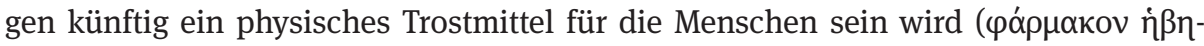

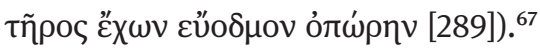

Als weiterer Baustein für eine bukolische Ampelos-Episode dient das Motiv Eifersucht, das im 10. Buch das Verhältnis zwischen Dionysos, Ampelos und den übrigen Satyrn festlegt. Dionysos wird als eifersüchtig gegenüber einem potentiellen Kon-

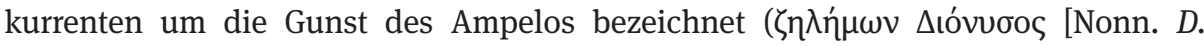
10,245]), und als Gegenspieler des Ampelos tritt ein anonymer Satyr in Erscheinung, der ob dessen Bevorzugung durch Dionysos voller Neid eine Schmährede hält (278-

64 Bei der Ampelos-Episode handelt es sich um eine der großen Liebesgeschichten der Dionysiaka, vgl. auch Dionysos und seine Geliebten Nikaia, Hymenaios, Beroe, Ariadne, Pallene, Aura sowie Kalamos und Karpos, Morrheus und Chalkomede; Agosti (2004) 464; Hernández de la Fuente (2008) 79 - 116; zu Nikaia und Aura vgl. Lightfoot (1998).

65 Zum Motiv der Liebe als Heilmittel vgl. Hollis (1994) 50.

66 Ein charakteristischer Zug der Dionysiaka ist die Auseinandersetzung mit sämtlichen Ausformungen der Liebesdichtung. Eine der vorliegenden Stelle vergleichbare Rede über die Liebe lässt Nonnos Pan in Nonn. D. 42,205 - 273 halten, vgl. Agosti (2004) 464 Anm. 18.

67 Zur Funktion des Weines als Heil- und Trostmittel siehe auch AP 3,10 und 11,298,6f. 


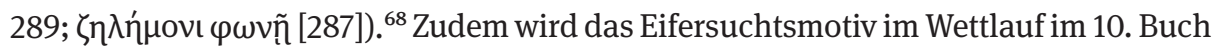

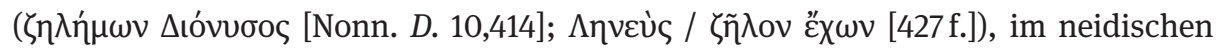

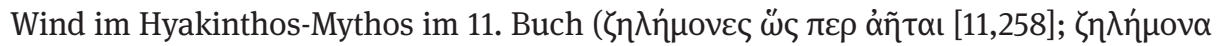

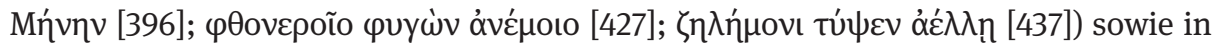
der Prophezeiung von Apolls Neid gegenüber Ampelos in Buch 12 wiederaufgenom-

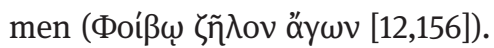

Ein Aufgreifen bukolischer Themen liegt auch in der Trauerszene mit Dionysos und seinem Gefolge sowie in den beiden Trauerreden des Weingottes vor, hellenistischen Topoi der Klage einer Gottheit um den toten Geliebten, die aus Bions Epitaphios auf Adonis geläufig sind.

\section{Klagen auf Ampelos}

In der narrativen Passage und den zwei Reden auf den zu Tode gekommenen Ampelos im 11. Buch gewährt der Dichter einen Überblick über die Gestaltungsmöglichkeiten der hellenistisch-bukolischen Gattung der Klage eines Gottes um einen verunglückten Geliebten und ordnet diese in den dionysischen Kontext ein. ${ }^{69}$ In derselben Funktion wie Polyphem in den Argonautika des Apollonios Rhodios (A. R. 1,1240-1260) unterrichtet ein Satyr als Bote Dionysos vom unglücklichen Schicksalsschlag des Ampelos. ${ }^{70}$ Es folgt eine Trauerszene, in der Nonnos die hellenistische Dichtung mit Homer verschränkt und über alldem dionysisches Flair verbreitet (Nonn. D. 11,224252):

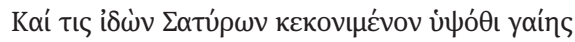

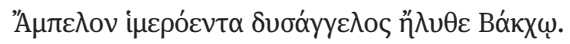
225

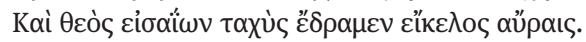

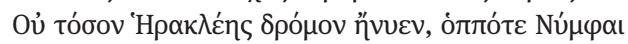

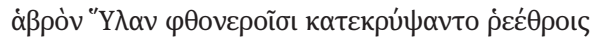

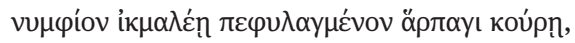

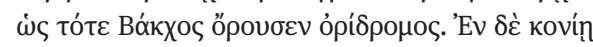

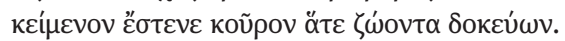

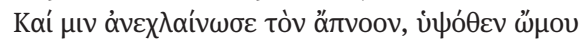

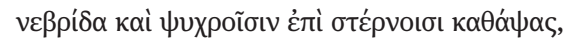

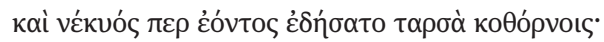

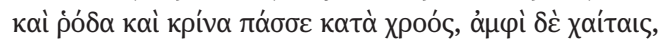

68 Eine direkte Übernahme der Motive Dreiecksverhältnis und Heilmittel gegen die Liebe aus dem griechischen Roman, die Frangoulis (2014) 63-66 und 72-77 vorschlägt, erscheint aufgrund entsprechender Beispiele in der hellenistischen Dichtung wenig wahrscheinlich.

69 Vgl. Mazza (2012) 99-103.

70 Dem Abschluss der Szene in Nonn. D. 11,248f. vergleichbare Trauerbekundungen der Satyrn und

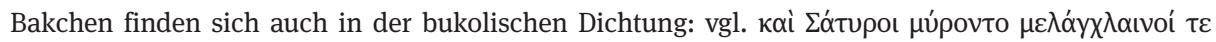

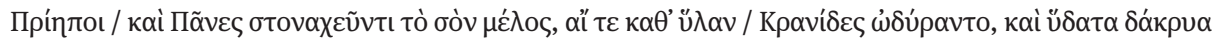
yévтo (Mosch. III,27 - 29 Beckby; siehe auch Bion I,18f. Beckby); vgl. Vian (1995) 170 Anm. ad 249. 


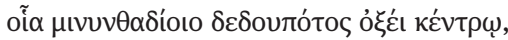

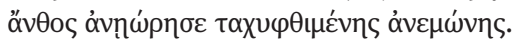

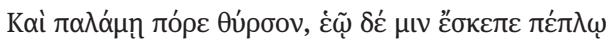

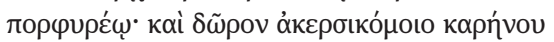

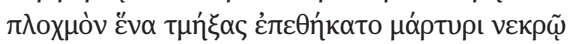

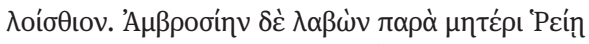

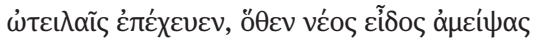

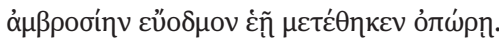

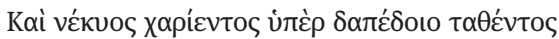

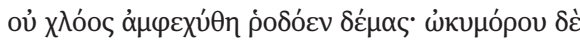

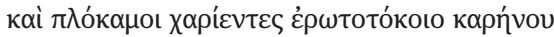

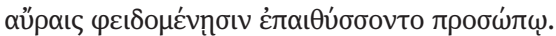

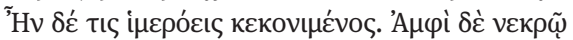

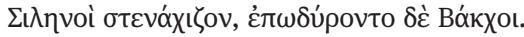

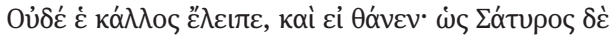

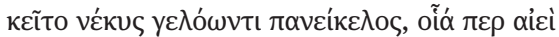

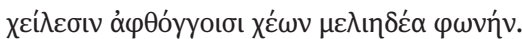

Und einer der Satyrn sah ihn staubbedeckt auf der Erde liegen, (225) den lieblichen Ampelos, und kam als Unglücksbote zu Bakchos. Und der Gott vernahm es und lief schnell wie die Winde. So schnell hatte nicht einmal Herakles seinen Lauf vollendet, als die Nymphen den schönen Hylas in den neidvollen Wogen versteckt hatten, vorgesehen als Bräutigam für ein nasses, räuberisches Mädchen, (230) wie Bakchos da voranstürzte als Bergläufer. Und den im Staub liegenden Knaben beklagte er im Glauben, dass er noch lebte. Und er bekleidete ihn, den Leblosen, mit einem Mantel, über die Schulter zog er das Hirschfell auf die erkaltete Brust, und obwohl er bereits tot war, band er die Schuhe an seine Füße. (235) Rosen und Lilien streute er auf die Haut, und um das Haar, wie es üblich war für einen allzu früh Verstorbenen, der durch einen bitteren Stachel getroffen wurde, legte er eine rasch verwelkende Anemonenblüte. Und in die Hand gab er ihm den Thyrsos und bedeckte ihn mit seinem Peplos, dem purpurnen. Als Gabe von seinem eigenen ungeschorenen Haupt (240) schnitt er sich eine Haarsträhne ab und legte sie als Letztes auf den toten Blutzeugen. Und Ambrosia nahm er von seiner Mutter Rheia und goss sie über die Wunden. Davon sollte der Jüngling, nachdem er seine Gestalt gewechselt haben würde, die süß duftende Ambrosia für seine Früchte erhalten. Über die rosige Gestalt des lieblichen Leichnams, der ausgestreckt auf dem Boden lag, (245) breitete sich keine grünliche Blässe aus. Und die schönen Haarsträhnen am liebreizenden Haupt des allzu früh Verstorbenen flatterten durch einen leichten Lufthauch um sein Antlitz. Es war ein lieblicher Anblick, auch wenn er mit Staub bedeckt war. Und um den Leichnam seufzten die Silene auf, und die Bakchen klagten. (250) Nichts von seiner Schönheit war verschwunden, auch wenn er tot war. Und wie ein Satyr lag er tot da, einem Lachenden ganz ähnlich, wie wenn er immer noch aus seinen stummen Lippen eine honigsüße Stimme hervorbrächte.

Die Homer-Reminiszenzen konzentrieren sich auf den im Sand liegenden Ampelos, der

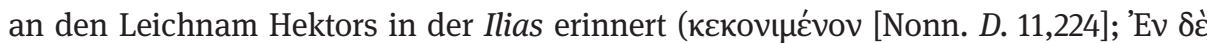

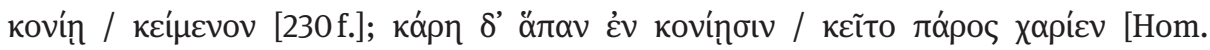

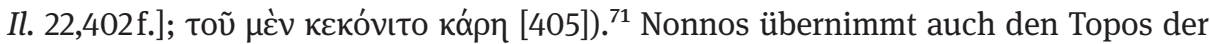

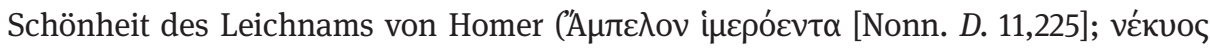

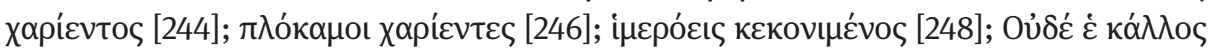

71 Vgl. Vian (1995) 168 Anm. ad 224-231. 


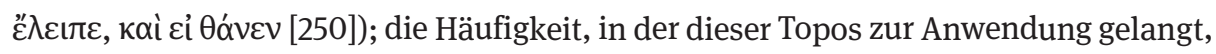
verweist jedoch über Homer hinaus auf die hellenistische Dichtung, so wird auch für den toten Adonis im Epitaphios des Bion die außerordentliche Schönheit des Leich-

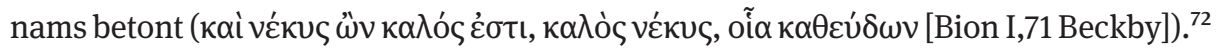
Den Rückgriff auf hellenistische Themen verdeutlichen die Verse Nonn. D. 11,226-230, in denen Nonnos Theokrit und Apollonios Rhodios kombiniert und die Suche des Herakles nach dem vermissten Knaben im Hylas-Mythos aufgreift. ${ }^{73}$

Der Einfluss bukolischer Dichtung wird auch im Leitthema des Textes sichtbar: Vorkehrungen, wie sie Dionysos zur Pflege des Leichnams trifft (Nonn. D. 11,232-241), finden sich in einem weiteren Fragment Bions, in dem Apoll den Tod seines Geliebten Hyakinthos betrauert (Bion III,1 Beckby). Während Apoll vergeblich die Wunden seines Lieblings mit $\varphi \alpha ́ \rho \mu \alpha \kappa \alpha$, namentlich Nektar und Ambrosia, zu heilen sucht, versieht Dionysos Ampelos nicht nur mit verschiedenen Blumen, ${ }^{74}$ sondern kleidet ihn in die dionysischen Insignien Hirschkalbfell und Thyrsos, außerdem in Kothurne und einen purpurnen Peplos und spendet eine eigene Haarlocke. Eine zentrale Rolle in Nonnos' Poetik der subtilen Vorausdeutungen kommt der Unsterblichkeit verleihenden Ambrosia zu (Nonn. D. 11,241-243), wenn Dionysos ähnlich wie Apoll bei Bion den Verstorbenen mit der göttlichen Substanz salbt, welche im Gegensatz zur bukolischen Version von einer doppelten Symbolhaftigkeit getragen wird: ${ }^{75}$ Durch die Einbalsamierung mit Ambrosia erlangt Ampelos nicht nur Unsterblichkeit, sondern wird gleichsam vorab zum Archetyp des zukünftigen Weinstocks. In der Gegenüberstellung

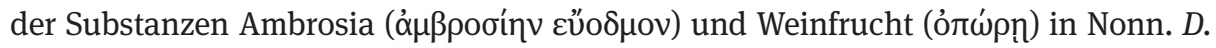
11,243 nimmt Ampelos' Peplos die Purpurfarbe des Weines (11,238f.), das unverändert jugendlich-frische Äußere des Toten das Weiterleben in Gestalt der Pflanze vorweg (244-248). In Kontrast zu Bions Apoll, der mit seinen Versuchen, Hyakinthos wieder

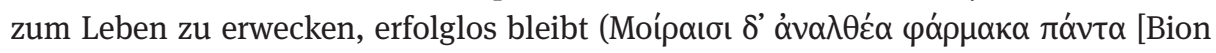
III,1,4 Beckby]), sorgt Dionysos für Ampelos’ Wiederauferstehung. Analog zur Übernahme der bukolischen Erzählformen und zu deren Transferierung in den dionysischen Kontext ist auch die Verarbeitung hellenistischer Erzählungen in den Dionysiaka zu verstehen, wobei der Dichter stets zum Ziel hat, sein Epos innerhalb etablierter

72 Vgl.Vian (1995) 169 f. Anm. ad 247; Gigli Piccardi (2003) 775 Anm. ad 230 - 243 und 777 Anm. ad 244 - 252. - Zur christlichen Konnotation des Topos des schönen Leichnams vgl. Spanoudakis (2014b) 193 Anm. ad 46b.

73 Vgl. Vian (1995) 168 Anm. ad 224-231; Gigli Piccardi (2003) 774f. Anm. ad 224-230. Zu Ampelos und Hylas vgl. Kap. 4.7.

74 Auch der Blumenkatalog ist ein Topos der bukolischen Dichtung, siehe Mosch. III,3 - 8 Beckby, vgl. Vian (1995) 168 Anm. ad 232-239; Gigli Piccardi (2003) 776 Anm. ad 235-237.

75 Nonnos knüpft auch an Homer an: Ähnlich wie Dionysos von seiner Mutter Rheia Ambrosia erhält, werden in der Ilias getötete Helden mit Ambrosia behandelt (Sarpedon [Hom. Il. 16,680], Patroklos [19,38f.], Hektor [23,186f.]), vgl. Vian (1995) 169 Anm. ad 241 - 243. Für die Einkleidung des Ampelos ist ebenfalls Homer Vorbild (Patroklos [Hom. Il. 18,349-353], Hektor [24,587 - 590]), vgl. Gigli Piccardi (2003) 775 Anm. ad 232. 
literarischer Traditionen zu positionieren und in direkte Konkurrenz mit seinen Vorgängern zu treten.

Die an die allgemeine Trauerszene anschließende erste Klagerede des Dionysos entwickelt die Verweise auf das unmittelbar bevorstehende Schicksal des Ampelos weiter, indem mittels unterschiedlicher poetischer Techniken - intertextueller Bezüge auf lexikalischer Ebene und Einflechtungen mythischer Präzedenzfälle - auf das narrative Ziel der Ampelos-Episode, die Initiierung des dionysischen Kultes, hingearbeitet wird (Nonn. D. 11,253-312):

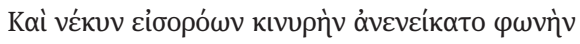

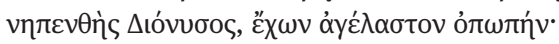

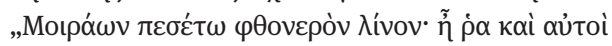

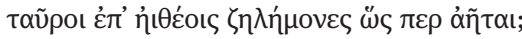

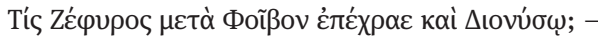

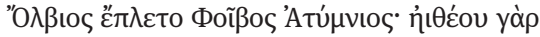

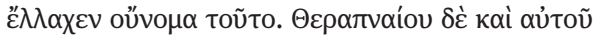

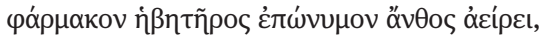

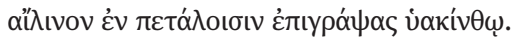

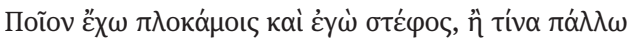

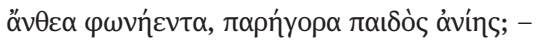

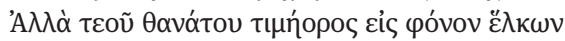

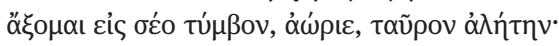

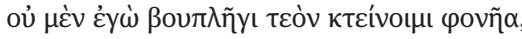

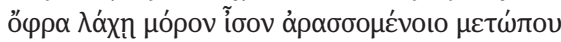

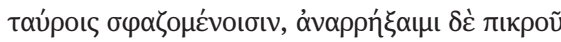

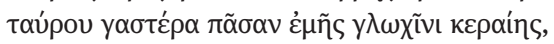

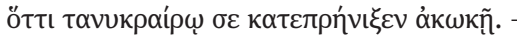

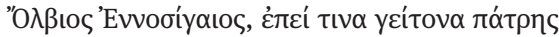

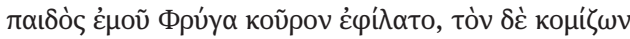

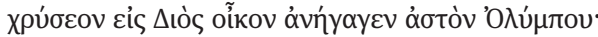

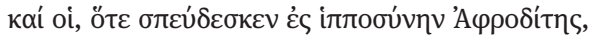

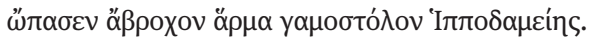

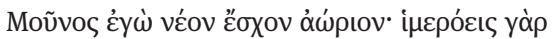

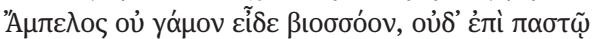

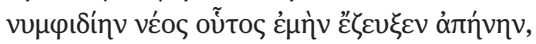

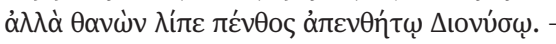

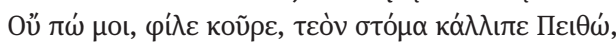

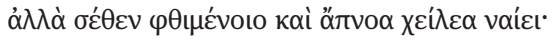

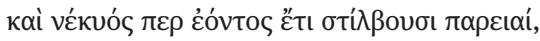

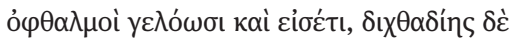

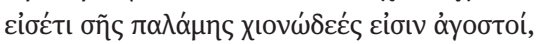

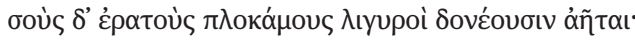

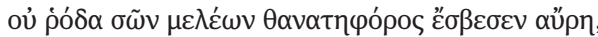

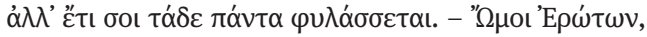

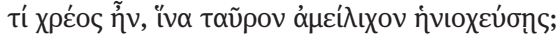

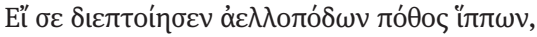

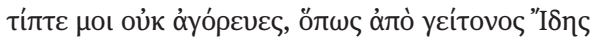

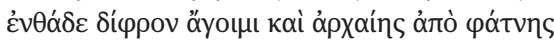

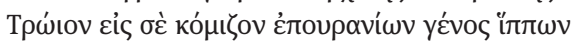




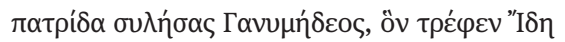

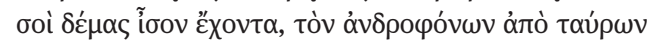

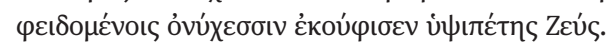

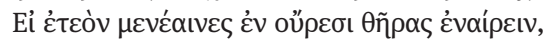

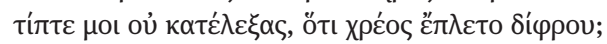

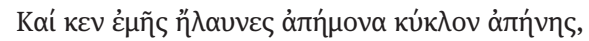

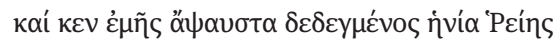

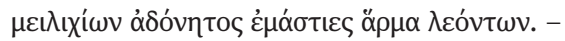

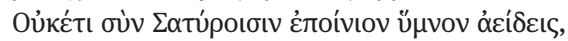

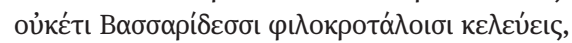

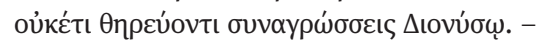

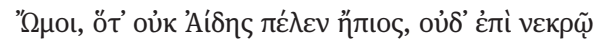

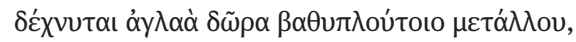

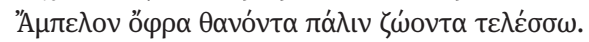

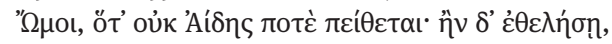

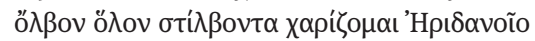

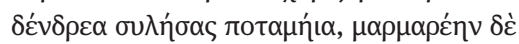

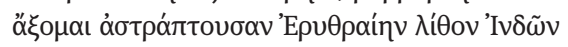

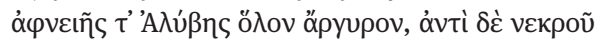

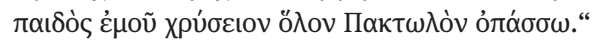

Und als er den Leichnam sah, da klagte mit trauriger Stimme und freudlosem Blick Dionysos, der den Schmerz nicht kennt: (255) „Soll der verderbliche Faden der Moiren nur reißen! Sind jetzt selbst die Stiere schon neidisch wie die Winde auf die Jünglinge? Welcher Zephyros griff nach Phoibos nun auch Dionysos an? Glücklich war Phoibos Atymnios! Denn des Jünglings Namen erhielt er. Und für diesen jungen Freund (260) als Heilmittel bekam er die nach ihm benannte Blume und schrieb seine Klage auf die Blätter der Hyazinthe. Und welchen Kranz habe ich nun in den Haaren? Welche sprechenden Blüten schwenke ich zum Trost über den Verlust des Knaben? Aber als Rächer deines Todes werde ich den umherstreifenden Stier zur Tötung schleppen (265) und auf dein Grab führen, mein Frühverstorbener! Nicht mit dem Ochsenziemer will ich deinen Mörder töten, damit er das gleiche Schicksal erleide und das Antlitz zerschlagen werde wie bei den Stieren, wenn sie geschlachtet werden, sondern aufreißen will ich den ganzen Leib des bitteren Stieres mit der Spitze meines Hornes, (270) da er dich mit dem langgehörnten Stachel niederwarf! Glücklich ist Ennosigaios, weil er einen Nachbarn der Heimat meines Knaben, einen phrygischen Jungen, liebte, und weil er ihn mitnahm und hinaufführte ins goldene Haus des Zeus als Bürger des Olymp. Und als er sich für Aphrodite eifrig in der Kunst des Wagenlenkens bemühte, (275) lieh er ihm seinen unbenetzten Wagen zur Vorbereitung der Hochzeit mit Hippodameia. Allein ich hatte einen Jungen, der vor der Zeit starb! Denn der reizende Ampelos sah keine lebensspendende Hochzeit, und zur Brautkammer schirrte der Junge nie meinen Hochzeitswagen an, sondern er starb und ließ dem leidlosen Dionysos Leid zurück. (280) Noch nicht verließ mir, mein lieber Knabe, Peitho deinen Mund, sondern sie wohnt noch in deinen leblosen Lippen, obwohl du gestorben bist. Und obwohl du tot bist, glänzen deine Wangen noch, deine Augen lachen noch, und immer noch sind deine beiden Hände weiß wie Schnee, (285) und kräftige Winde schütteln dein liebliches Haar. Die Rosen löschte der todbringende Hauch nicht von deinen Gliedern, sondern all dies ist dir noch erhalten. Ach! Ihr Liebesgötter! Welchen Zweck hatte es, dass du den unerbittlichen Stier lenktest? Wenn dich die Sehnsucht nach windfüßigen Pferden erschütterte, (290) warum sagtest du mir nicht, dass ich vom benachbarten Ida hierher den Wagen lenken und von der alten Krippe das Geschlecht der himmlischen Pferde des Tros zu dir bringen sollte? Die Heimat des Ganymed hätte ich beraubt, den der Ida ernährte, der dir an Gestalt ähnlich war, und den der hoch oben fliegende Zeus mit seinen schonenden Krallen (295) von den männermordenden Stieren in die Höhe hob. Wenn du dir wirklich wünschtest, in den Bergen wilde Tiere zu 
erlegen, warum erzähltest du mir dann nicht, dass du einen Wagen benötigst? Auf meinem Wagen hättest du eine gefahrlose Rundfahrt machen können, und das unberührte Zaumzeug meiner Rheia erhalten (300) und unerschüttert den Wagen mit den zahmen Löwen vorangetrieben. Nicht mehr singst du mit den Satyrn zusammen ein Lied zum Wein, nicht mehr führst du die Bassariden an mit ihren geliebten Klappern, nicht mehr gehst du gemeinsam mit dem jagenden Dionysos auf die Pirsch. Ach! Wenn Hades freundlich gesonnen wäre und für den Leichnam (305) glänzende Geschenke aus reichem Metall annähme, dann würde ich es fertig bringen, dass Ampelos aus dem Tod wieder zum Leben erweckt wird! Ach! Wenn sich Hades doch nur einmal überreden ließe! Wenn er will, dann schenke ich ihm den ganzen glänzenden Reichtum des Eridanos. Die Bäume am Fluss werde ich plündern, den glitzernden (310) Stein, den blinkenden, roten der Inder, werde ich nehmen, das ganze Silber des reichen Alybe, und für meinen toten Knaben würde ich den ganzen goldenen Paktolos geben.“

Es findet sich eine erkleckliche Anzahl an motivischen Parallelen und literarischen Topoi zu Aphrodites Klage auf Adonis, dem ersten Fragment des Bukolikers Bion. ${ }^{76}$ Die Ausführung der Rede des Dionysos zeigt Nonnos' autonomen Umgang mit der Tradition, die Übernahmen und Anspielungen sind subtil, die Anordnung einzelner Topoi ist stets auf die unmittelbaren Erfordernisse der Ampelos-Erzählung hin ausgerichtet. Die beständige Schönheit des Jünglings, die auch durch den Tod nicht gemindert wird (Nonn. D. 11,250-252 und 280-287) ist bereits aus Bion I,70f. (Beckby) geläufig

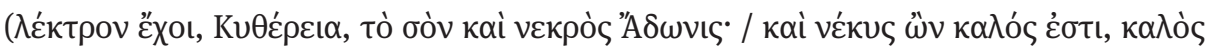

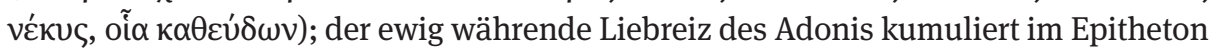

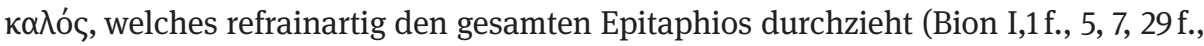
34, 37 f., 61, 63, 67, 71, 92 Beckby), zudem findet sich das Beiwort åßpós auch für den

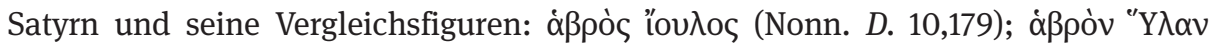

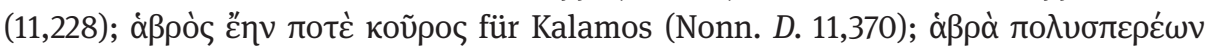

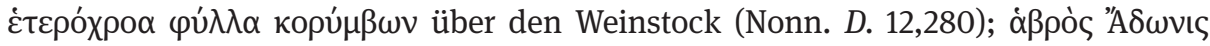
(Bion. I,79 Beckby). Adonis und Ampelos wird Unsterblichkeit zuteil, indem die trauernde Gottheit, Aphrodite bzw. Dionysos, den Leichnam einsalbt: ả $\mu \beta \rho o \sigma i ́ n v ~ \delta \dot{~}$

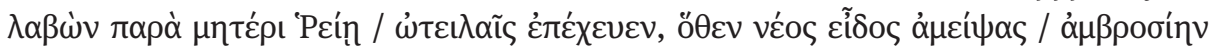

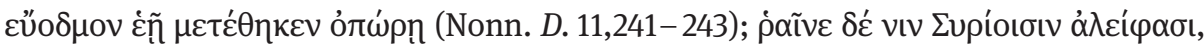

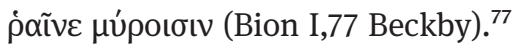

Auch in der Rede des Dionysos findet sich das auf die Genese des Weines vorausweisende Pflanzenmotiv: Die in Nonn. D. 11,286 genannten Rosen sind Teil eines von Nonnos inszenierten Farbkontrastes zwischen dem Weiß von Ampelos' Hautfarbe und dem Rot der Blumen (vgl. Nonn. D. 11,284 und 286), ein Gegensatz, der von Bion in der Gegenüberstellung des schwärzlichen Blutes und der ebenfalls weißen Hautfarbe

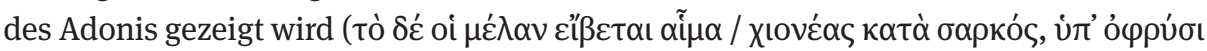

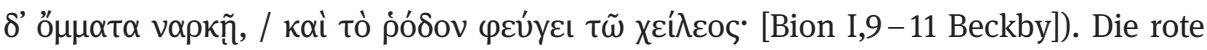
Farbe der Lippen, welche sowohl für Adonis als auch für Ampelos eine ambivalente

76 Zu Text, Übersetzung und Kommentar der Dichtungen Bions siehe Beckby (1975); Reed (1997). 77 Vgl. auch Bion III,1 Beckby, wo der trauernde Apoll den Leichnam des Hyakinthos mit Nektar und Ambrosia salbt. 
Bedeutung trägt, gilt als Zeichen für äußere Schönheit und jugendliche Frische, gleichzeitig aber für den gewaltsamen Tod und das damit verbundene Blutvergießen. ${ }^{78}$ Die Todesthematik und die damit verbundenen Topoi - die Klage über den verfrühten Tod, ohne je verheiratet gewesen zu sein (Nonn. D. 11,276-279; है $\sigma \beta \varepsilon \sigma \varepsilon \lambda \alpha \mu \pi \alpha ́ \delta \alpha \pi \tilde{\alpha} \sigma \alpha v$

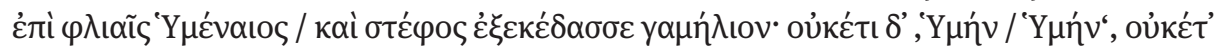

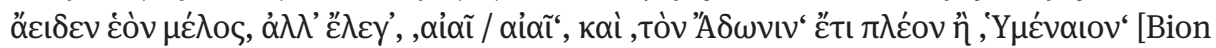
I,87-90 Beckby]) - werden bei beiden Autoren ebenso zu Gegenständen rhetorischer

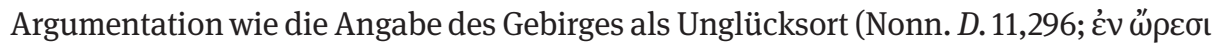
[Bion I,7 und 34 Beckby]), die Beschwörung der Unterwelt (Nonn. D. 11,304, 307; Bion I,51f., $54 \mathrm{f}$. Beckby) sowie die Frage nach dem Zweck des Todes (Nonn. D. 11,288-300;

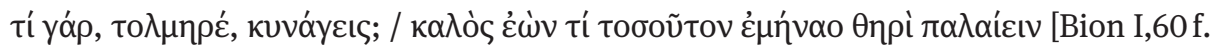
Beckby]). Mit besonderer Ausführlichkeit lässt Nonnos Dionysos Mutmaßungen über den Mörder anstellen und Möglichkeiten für dessen Bestrafung ersinnen (Nonn. $D$. 11,255-263, 264-270), wohingegen für Aphrodite bei Bion die Todesumstände durch den Eberangriff feststehen (Bion I,7-9 Beckby). Die Gestaltung der Rede des Dionysos auf der Grundlage bukolischer Muster erfährt bei Nonnos insofern eine Erweiterung, als der nachdrückliche Hinweis auf die Vergeltung am Mörder der Vorbereitung auf den dionysischen Kult des Stieropfers dient. In diese Richtung weist auch die mythische Parallele von Poseidon und Pelops, die gleichsam spiegelbildlich zu Dionysos und Ampelos (Nonn. D. 11,270 - 275) unter die Götter aufgenommen werden.

An die göttliche Sphäre wird auch in der zweiten Rede des Dionysos appelliert, wenn er nun Zeus mit der Bitte konfrontiert, Ampelos wieder zum Leben zu erwecken (Nonn. D. 11,313-350):

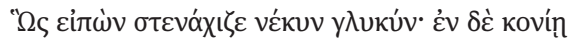

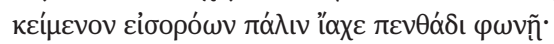

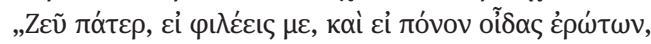

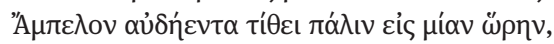

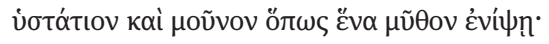

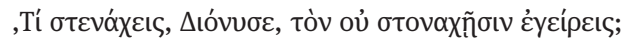

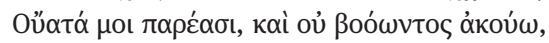

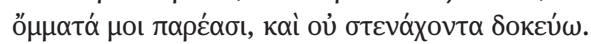

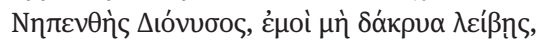

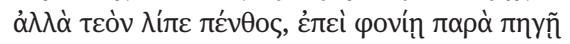

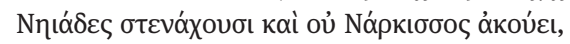

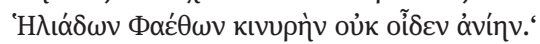

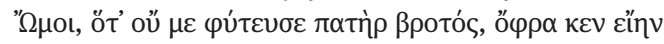

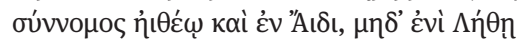

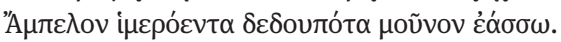

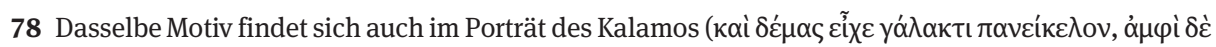

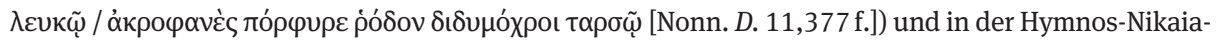
Episode (16,78-81). - Die Kombination von roten Wangen und weißer Hautfarbe ist ein Topos der griechischen Dichtung und Romanliteratur, siehe Ach. Tat. 1,4,3; 1,19,1; 2,1,3; 5,13,1; AP 5,56,1; 5,62,3 f., vgl. Frangoulis (2014) 27-33, 35-37. 


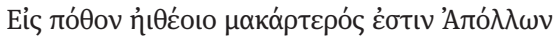

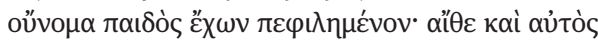

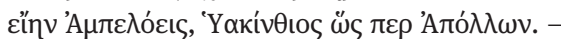

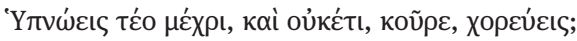

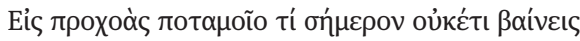

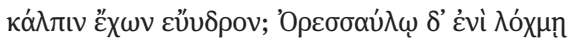

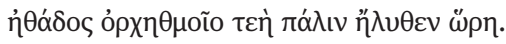

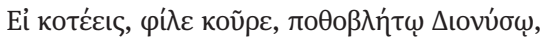

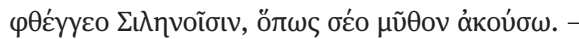

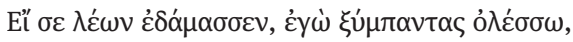

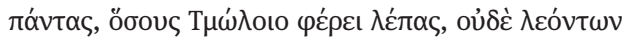

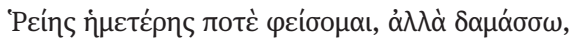

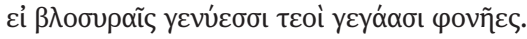

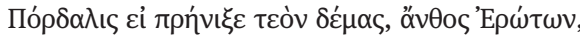

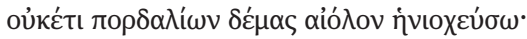

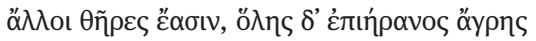

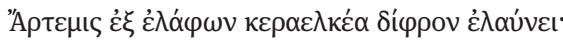

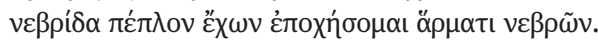

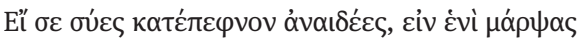

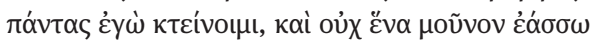

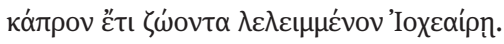

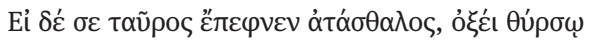

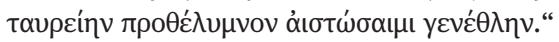

So sprach er und trauerte um den lieblichen Toten. Und als er ihn im Staub liegen sah, jammerte er wieder mit klagender Stimme: (315) „Zeus, Vater, wenn du mich liebst und wenn du Liebesleiden kennst, so lass Ampelos nur für eine Stunde wieder sprechen, dass er mir zum letzten Mal nur eine einzige Rede halte: ,Warum seufzt du über den, den du durch dein Seufzen nicht erweckst, Dionysos? Ich habe Ohren, aber den Rufenden kann ich nicht hören. (320) Ich habe Augen, aber ich kann den Seufzenden nicht sehen. Dionysos, der du den Schmerz nicht kennst! Vergieße mir keine Tränen, sondern lass ab von deinem Leid, da bei der tödlichen Quelle auch die Najaden aufseufzen und Narkissos sie nicht hört und Phaethon nichts von der traurigen Klage der Heliaden weiß!‘ (325) Ach! Wenn mich doch mein Vater als Sterblichen gezeugt hätte, damit ich dem Jüngling auch im Hades ein Gefährte sei und ich der Lethe nicht ganz allein den lieblichen Ampelos überlasse! Im Verlangen nach dem Jüngling ist Apoll glücklicher, weil er den Namen seines geliebten Knaben trägt. Wenn ich doch auch selbst (330), Ampeloeis sein könnte, wie Apollon Hyakinthios! Wie lange schläfst du und tanzt nicht, Knabe? Warum steigst du heute nicht mehr in die Fluten des Flusses, den Krug mit dem guten Wasser tragend? Im gebirgigen Dickicht ist schon wieder die Stunde deines gewohnten Tanzes nahe. (335) Wenn du zürnst, lieber Knabe, dem von Verlangen geschlagenen Dionysos, sag es den Silenen, damit ich deine Rede hören kann! Wenn dich ein Löwe bezwang, will ich alle zusammen vernichten, alle, die der Berg des Tmolos trägt, und auch nicht die Löwen unserer Rheia will ich schonen, sondern bezwingen, (340) wenn sie mit ihren haarigen Schlünden deine Mörder geworden sind. Wenn ein Panther deinen Leib, die Blüte der Eroten, zerriss, dann will ich nicht mehr den gescheckten Leib der Panther lenken. Andere Tiere gibt es noch, denn die Herrin aller Jagdtiere, Artemis, lenkt ihren Wagen, der von Hirschen mit ihren Geweihen gezogen wird. (345) Mit einem Peplos aus Hirschfell werde ich auf einem Hirsch-Wagen fahren. Wenn dich schamlose Wildschweine getötet haben, will ich jedes einzelne packen und alle töten, und nicht einen einzigen Eber will ich am Leben und übrig lassen für Iocheaira. Und wenn dich ein rücksichtsloser Stier getötet hat, dann will ich mit dem spitzen Thyrsos (350) die ganze Gattung der Stiere an der Wurzel ausrotten.“ 
Motive wie der Wunsch der Gottheit nach Sterblichkeit, um dem Geliebten in den Tod nachfolgen zu können, und der Berg als Ort des Unglücks und der Kultbegründung finden sich bei beiden Autoren, Nonnos und Bion (Nonn. D. 11,325-327; Bion I,52f. Beckby; Nonn. D. 11,333; Bion I,7 und 34 Beckby). ${ }^{79}$ Die Mutmaßung über den Mörder, die Vorschläge zur Rachenahme (Nonn. D. 11,335-350) sowie Dionysos' Bitte um Hilfe seitens einer höheren göttlichen Instanz sind bereits aus der ersten Rede des Dionysos bekannt. Die fiktive Rede des Ampelos aus Dionysos' Munde verleiht der Erzählung in Verbindung mit neuerlichen mythischen Parallelen (Nonn. D. 11,327-333: Apoll und Hyakinthos, Hylas) sowie einem von Dionysos selbst geäußerten direkten Verweis auf den kultisch-dionysischen Tanz (333f.) besondere Suggestionskraft. Ähnliche Andeutungen auf die Verbindung des Geschehens zum Kult sind auch in Bion I,68 und 97f. (Beckby) zu finden, wo Aphrodite aufgefordert wird, vom Trauern abzulassen, außerdem in Bion I,64-66 (Beckby), wo die Geburt neuer Pflanzen angekündigt wird:

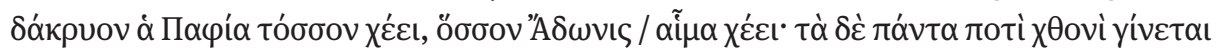

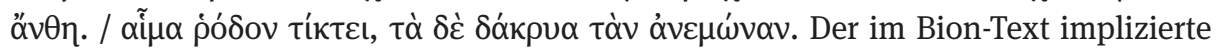
Trost durch die Genese neuer Pflanzen ist einer Tradition zuzurechnen, die sich auch in kaiserzeitlichen Epigrammen findet ${ }^{80}$ und die bei Nonnos zum Leitmotiv einer ganzen Episode wird, welche nach der kultischen Klage und Bestattungszeremonie mit der Auferstehung durch Metamorphose in eine neue Pflanze und die Begründung des dionysischen Kultes schließt.

Bions Klage um den Tod des Adonis dient Nonnos aber nicht nur als kompositorische und thematische Vorlage, sondern ist auch konkrete Bezugsquelle auf lexikalischer Ebene. In einer Passage im 12. Buch greift der Dichter den Topos von der trauernden Natur auf und gewährt einen Einblick in seine profunde Kenntnis der hellenistischen Dichtung (Nonn. D. 12,117-137):

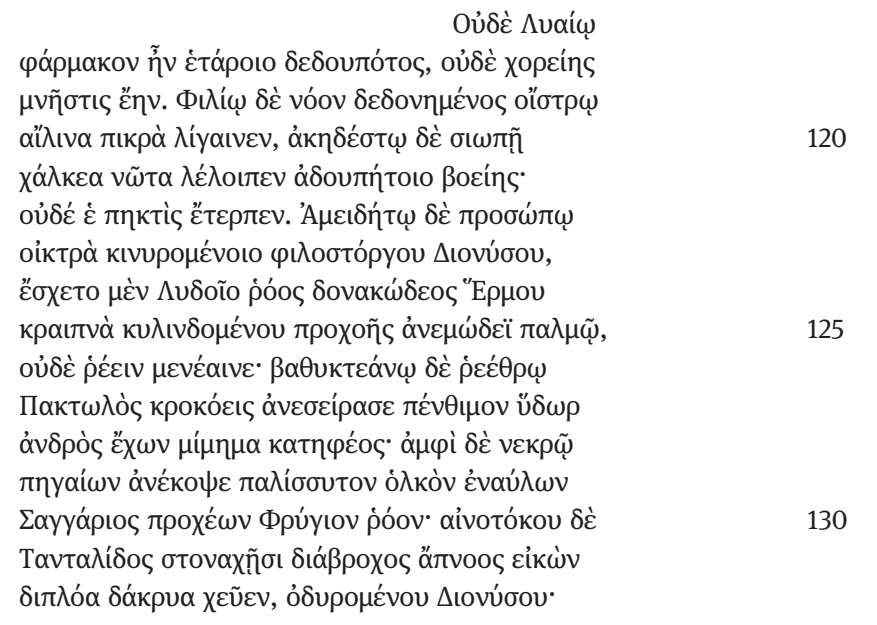

79 Zum Topos des Todeswunsches vgl. auch Mosch. III,115 - 126 Beckby. 80 Vgl. Vian (1995) 170f.; Del Corno u. a. (1997) 317; Gigli Piccardi (2003) 778. 


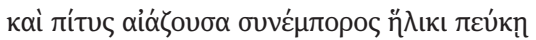

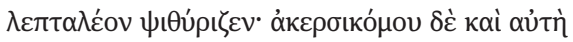

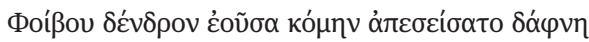

135

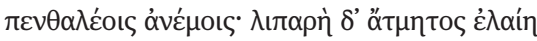

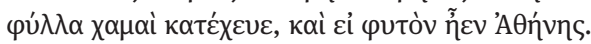

Aber für Dionysos gab es kein Heilmittel für seinen verstorbenen Freund und keine Erinnerung an den Tanz. Und durch den Liebesstachel war sein Sinn erschüttert, (120) herbe Klagerufe stieß er hervor, und dem bisher vernachlässigten Schweigen überließ er die erzenen Becken der klagenden Trommel. Die Harfe erfreute ihn nicht mehr. Ohne Lachen im Gesicht klagte wimmernd der verliebte Dionysos, und die Strömung des schilfigen, lydischen Hermos wurde gehemmt (125) in ihrer schnell dahinrollenden Flut vom zitternden Wind, und er wollte nicht mehr fließen. Und mit seiner schätzebergenden Strömung zog der krokosfarbene Paktolos sein trauerndes Wasser zurück und hatte das Aussehen eines Mannes, der die Augen zu Boden richtet. Und um den Leichnam herum ließ seine Strömung im Flussbett wieder zu seinen Quellen zurücklaufen (130) der Sangarios, der in Phrygien seine Flut ausgießt. Und das leblose Abbild der Unglücksmutter, der Tantalidin, durchtränkt von Seufzern, vergoss doppelte Tränen, da Dionysos trauerte. Und auch die Fichte, die Begleiterin der gleichaltrigen Föhre, wehklagte und wisperte leise. Selbst der Lorbeer des langhaarigen (135) Phoibos schüttelte noch als Baum sein Haar in den klagenden Winden. Und der fette, noch ungeschnittene Ölbaum ließ seine Blätter auf den Boden hinabfallen, auch wenn er die Pflanze der Athene war.

Die Szene bildet die Scharnierstelle zwischen der Kalamos-Karpos-Erzählung und der Atropos-Rede, indem sie die letzte Trauerbekundung vor der irreversiblen Metamorphose darstellt. Der zweigliedrige Aufbau zeigt Dionysos ein letztes Mal in vollem Trauergestus (Nonn. D. 12,117-123) sowie die schmerzliche Anteilnahme der Natur der drei kleinasiatischen Flüsse, Hermos, Sangarios und Paktolos, der Pinie, des Lorbeers und des Ölbaumes - am Schicksal des Ampelos (Nonn. D. 12,123-137). ${ }^{81}$ Das Mitleid, das die Natur einem unglücklich zu Tode gekommenen Jungen zuteil werden lässt, wird in der hellenistischen Literatur vielfach greifbar: Landschaft, Gewässer, Flora und Fauna trauern um Adonis (Bion I,31-35 Beckby), Daphnis (Theoc. 1,66 - 142) und Bion (Mosch. III,1-25 Beckby). ${ }^{82}$ In der Passage bringt Nonnos wörtliche Zitate aus der hellenistischen Dichtung und bietet für das Genus der Bukolik typisches Vokabular

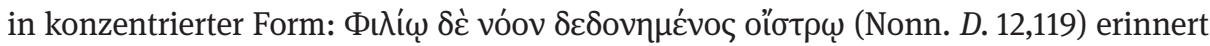

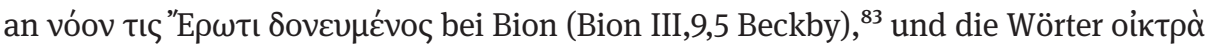

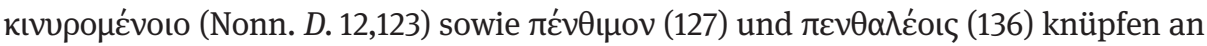

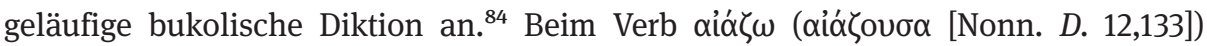
handelt es sich um ein nonnianisches hapax legomenon, mit dem auf den Beginn von

81 Vgl. Gigli Piccardi (2003) 828 Anm. ad 117 -137; Mazza (2012) 103-105.

82 Ähnlich schildert Ov. met. 11,44-49 die Trauer der Natur beim Tod des Orpheus.

83 Vgl. Vian (1995) 192 Anm. ad 119 und 123-137.

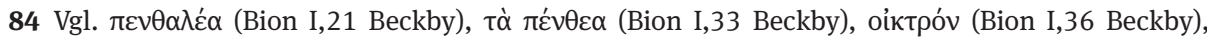

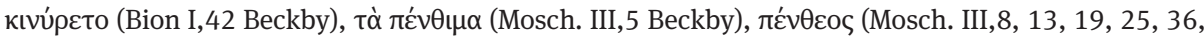

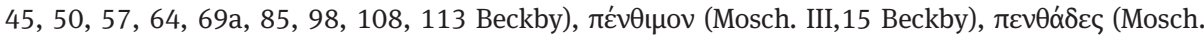

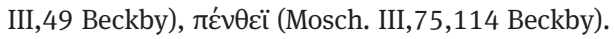


Bions Epitaphios auf Adonis verwiesen wird (Bion I,1 Beckby). ${ }^{85}$ Das Adjektiv $\lambda \varepsilon \pi \tau \alpha \lambda \varepsilon$ ćov (Nonn. D. 12,134), ein weiteres hapax, erinnert an das poetische Konzept des $\lambda \varepsilon \pi \tau o ́ v$ und rührt somit an die dichtungstheoretischen Prinzipien hellenistischer Dichtung. ${ }^{86}$

Neben dem Rückgriff auf die hellenistische Dichtung nimmt Nonnos in der Szene mit der Trauer der Natur auch auf Homer Bezug, indem er auf eine Odyssee-Stelle verweist, die zwar keine inhaltliche Verbindung hat - Odysseus schildert Athene nach seiner Ankunft auf Ithaka die Wirrnisse seiner Seereisen -, jedoch eindeutige lexi-

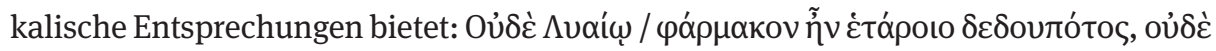

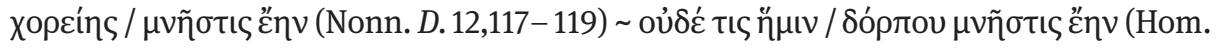
Od.13,279f.). ${ }^{87}$ Die Verquickung unterschiedlicher literarischer Traditionen und deren Brechung durch das allseits präsente Thema des Dionysischen bilden den Kern nonnianischer Poetik. Begriffe wie Zitat oder Imitation vermögen die facettenreiche und polymorphe Anlage der Dionysiaka und der spätantiken griechischen Dichtung insgesamt nur höchst unzulänglich zu erfassen. ${ }^{88}$ Nonnos unternimmt vielmehr eine umfassende Reflexion und schöpferische Auseinandersetzung mit lexikalischem Material, stilistischen und kompositorischen Verfahrensweisen sowie traditionellen

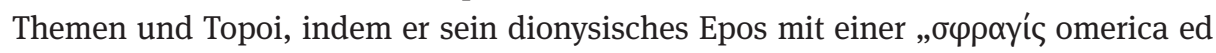
ellenistica“89 versieht. Vergleichbar mit der hellenistischen Dichtung konstruiert Nonnos eine „Para-Formelhaftigkeit, nämlich die Ausdrücke, die an Formeln erinnern, aber keine Formeln mehr konstituieren““ ${ }^{90}$ Der Zweck der Ampelos-Episode wird durch die vielfachen Bezugslinien zwischen dem jungen Satyrn und Adonis deutlich, ${ }^{91}$ wobei es Nonnos um die Einordnung seines Mythos in die literarisch-mythische Tradition, um die Umgestaltung bekannter Motive und um deren Kontextualisierung im dionysischen Epos geht. Während die Trauerszene des Dionysos zum letzten Mal das Genus der Bukolik in Reinform bietet, bricht der Hymnos-Mythos im 15. und 16. Buch mit der literarischen Tradition, rückt mit der unerbittlichen Nikaia endgültig dionysische Kräfte ins Zentrum ${ }^{92}$ und lässt so das Resultat der Ampelos-Episode, die Genese des Weines, als Vorbedingung zur vollen Ausprägung dionysischen Wirkens erscheinen.

85 Vgl. Vian (1995) 193 Anm. ad 133f. - Das Motiv der Wehklage wiederholt Nonnos in Nonn. D.

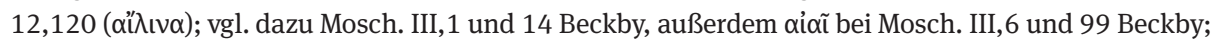
Bion I,28, 31, 37, 39, 63, 86, 89, 90 und 93 Beckby; Theoc. 2,55; 4,40; 7,121.

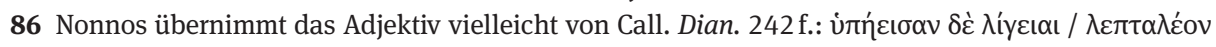
oúptyyes, vgl. Vian (1995) 193 Anm. ad $133 \mathrm{f}$.

87 Vgl. Vian (1995) 192 Anm. ad 119.

88 Vgl. Agosti (2011-2012) 236.

89 Franchi (2013) 8.

90 Skempis (2010) 4.

91 Im Unterschied zur Ampelos-Geschichte weist der Adonis-Mythos eine lange Tradition in der griechischen Literatur und bildenden Kunst auf, vgl. dazu Koortbojian (1995) 23-62.

92 Vgl. Miguélez Cavero (2009a) 268f. 


\subsection{Nonnos und der Roman}

Sowohl das griechische Epos als auch die fiktive Prosaerzählung der Kaiserzeit sind Produkte der hellenischen $\pi \alpha \_\delta \varepsilon i ́ \alpha$, deren Träger das gebildete Publikum des hellenischen Ostens ist, welches sein Selbstverständnis aus den kulturellen und literarischen Traditionen schöpft. Hierin besteht auch die Schwierigkeit einer genauen Analyse des Verhältnisses zwischen Nonnos und dem antiken Roman, da die teils gemeinsame Formensprache nicht immer zwingend auf eine direkte Einflussnahme eines bestimmten Romans auf Nonnos zurückgeführt werden darf, sondern vielmehr im Kontext genusübergreifender Traditionen gesehen werden muss. Die den Dionysiaka und dem Roman gemeinsamen Inhalte und Motive sind oft auch in anderen Genera, etwa der hellenistischen Dichtung, anzutreffen und somit der für die Spätantike charakteristischen Freude an der Einverleibung sämtlicher Literaturgattungen zuzurechnen. ${ }^{93}$

Die Problematik wird in der jüngsten von Hélène Frangoulis verfassten und bislang einzigen umfangreicheren Studie zum Verhältnis der Dionysiaka zum Roman insofern deutlich, als die direkten Bezugslinien zwischen Nonnos und den griechischen Romanautoren, allen voran Achilleus Tatios und Longos, nicht immer zweifelsfrei nachzuvollziehen sind. ${ }^{94}$ Die Parallelen, die zumeist in Motiv und Thema liegen und kaum wörtliche Anleihen nehmen, könnten oft überzeugender mit Beispielen der hellenistischen Dichtung gezogen werden. Diese Unsicherheit begründet auch das Zögern der Nonnos-Forschung, sich auf eindeutig fassbare Abhängigkeiten festzulegen, und auch der Blick auf die Literatur zeigt, dass die Entsprechungen zumeist in lediglich vagen Anklängen bestehen: Für Quintino Cataudella gilt die Technik der Einlage von Episoden in der Romanliteratur als Inspirationsquelle für die KalamosKarpos-Episode, ${ }^{95}$ während Helmut Haidacher in der Anwendung rhetorischer Gestaltungsprinzipien durch Nonnos eine Beeinflussung durch das Genus Roman vorliegen sieht, ${ }^{96}$ wofür er als konkretes Beispiel den Europa-Mythos am Beginn der Dionysiaka heranzieht und diesen dem Anfang von Achilleus Tatios' Roman gegenüberstellt; bei beiden Autoren, so Haidacher, werde insbesondere in den Klagereden und Ethopoiien die gemeinsame rhetorische Tradition fassbar. ${ }^{97}$ Neben einer gesteigerten Rhetorisierung hebt Barbara Abel-Wilmanns die ähnlichen Verfahrensweisen

93 Die gemeinsamen Kulturtraditionen von Roman und spätantikem Epos werden auch an der Thematisierung dionysischer Wirkkräfte im Roman ersichtlich: Dionysischer Wahnsinn umfängt Leukippe (Ach. Tat. 4,9), von dem sie schließlich wieder erlöst wird (Ach. Tat. 4,17), die Ägypter trinken ungemischtes Nilwasser und kennen keinen Wein (Ach. Tat. 4,18), und anlässlich eines Dionysos-Festes in Tyros wird eine tyrische Sagenversion der Entstehung des Weines wiedergegeben, in der explizit auf die athenische Version mit Ikarios Bezug genommen wird (Ach. Tat. 2,2,2 - 6); vgl. dazu Fayant (2000) $36 \mathrm{f}$. 94 Vgl. Frangoulis (2014).

95 Vgl. Cataudella (1936) 181. Zum Einfluss des Romans auf Nonnos vgl. auch Rohde (1914) 140f., 169; Frangoulis (2009).

96 Vgl. Haidacher (1949) 5.

97 Vgl. Haidacher (1949) 94f., 98-101. 
von Roman und nonnianischem Epos hervor, die sich im Vorrang einer abwechslungsreichen Vielfalt an Themen und Motiven vor einer logisch stringenten Komposition manifestieren..$^{98}$ Insbesondere auf motivische und strukturelle Entsprechungen verweisen auch Rưžena Dostálová-Jeništová und Marie-Christine Fayant. ${ }^{99}$

Obwohl es sich bei der Ekphrasis um ein wesentliches Charakteristikum des Romans und der Dionysiaka handelt, ist dies weniger der direkten Einflussnahme des Genus Roman auf Nonnos als vielmehr gemeinsamen rhetorischen Traditionen zuzuschreiben. Die narrative Funktion der Ekphrasis äußerst sich beispielsweise in der Darstellung eines Bildes bei Achilleus Tatios, welches das Schicksal der Hauptheldin Leukippe proleptisch vorwegnimmt (Ach. Tat. 5,3f.), ähnlich wie auch in der dritten Tafel der Harmonia, die Ampelos' Schicksal in den Dionysiaka spiegelt (Nonn. D. 12,64-102). ${ }^{100}$ Auf der Grundlage literarischer Konventionen operiert Nonnos auch in seiner Ekphrasis der Jahreszeiten (Nonn. D. 11,485-521), indem er eine literarische Schreibweise zur Anwendung bringt, welche nicht nur in der Romanliteratur, ${ }^{101}$ sondern auch in der spätantiken Dichtung ihren Platz findet. ${ }^{102}$ Naturwissenschaftliche und kulturkundliche Digressionen, die sich sowohl im Roman als auch in den Dionysiaka an Beliebtheit erfreuen, ${ }^{103}$ sind ebenfalls dem gemeinsamen literarischen Formenschatz zuzurechnen wie die Einblicke in die Geographie des östlichen Mittelmeerraums: Die Lokalisierung der Herkunft des Weines in Lydien/Maionien bei Nonnos erhebt ebenfalls das östliche Mittelmeergebiet zum griechischen Kulturland wie bei Achilleus Tatios, der den Ursprung des Weines in Tyros ansiedelt (Nonn. $D$. 10,139 und 144; Ach. Tat. 2,11,4) ${ }^{104}$ und ähnlich wie auch Nonnos eine Ekphrasis auf Tyros liefert (Nonn. D. 40,298-365; Ach. Tat. 2,14). ${ }^{105}$

98 Vgl. Abel-Wilmanns (1977) 98-101.

99 Vgl. Dostálová-Jeništová (1962); Fayant (2003a); siehe auch Shorrock (2001) 192 - 194; Frangoulis (2006a) und Miguélez Cavero (2008) 172-174.

100 Vgl. Ach. Tat. 2,3 (Becher mit dionysischen Szenen); X. Eph. 1,8; siehe Haidacher (1949) 114; Graf (1995) 152. - Zur Ekphrasis siehe Kap. 6.5.

101 Vgl. Longus 1,9 und 3,12 (Frühling); 1,23 und 3,24 (Sommer); 2,1 (Herbst); 3,3 (Winter).

102 Vgl. Vian (1995) 26 Anm. 3.

103 Vgl. die Ekphrasis eines Elefanten (Nonn. D. 26,295 - 330; Ach. Tat. 4,4), einer Halskette (Nonn. D. 5,135-189; Ach. Tat. 2,11) und die Entdeckung des Purpurs (Nonn. D. 40,306-310; Ach. Tat. 2,11,4-8); vgl. Haidacher (1949) 101.

104 Zur kleinasiatischen Geographie bei Nonnos und Achilleus Tatios vgl. Vian (1995) 191 Anm. ad $98-102$.

105 Vgl. Chuvin (1991) 13, 224 - 228. - Im Roman Leukippe und Kleitophon werden auch dionysische Mythen reflektiert, die sich bei Nonnos zu vollständigen Szenen ausgebaut finden, etwa Dionysos' Besuch bei Ikarios (Nonn. D. 47,34-264; Ach. Tat. 2,2). Einer gemeinsamen Formensprache entspringen ferner einige narrative Details wie das Fischen nach Gold in Libyen in Ach. Tat. 2,14,9, das an die im goldenen Paktolos fischenden Satyrn in Nonn. D. 10,139-174 erinnert, sowie Angaben über die Symbiose verschiedener Pflanzen; für Bäume, die sich in Liebe miteinander verbinden, siehe Nonn. $D$. 12,272 - 284; Ach. Tat. 1,15,2; Longus 4,2,5; vgl. Vian (1995) 200f. Anm. ad 272-284; an anderen Pflanzen emporwachsende Weinstöcke finden sich in Nonn. D. 12,314-318 und Ach. Tat. 1,15,3 f., vgl. 
Besondere Vorsicht ist bei dem Versuch der Formulierung eines direkten Abhängigkeitsverhältnisses in der Motivik Liebe und Erotik geboten, welche die Dionysiaka und der Roman bieten. ${ }^{106}$ Details des Ampelos-Porträts - die besondere Beto-

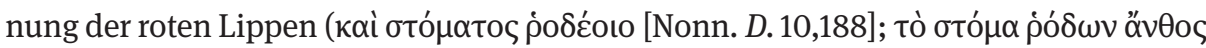

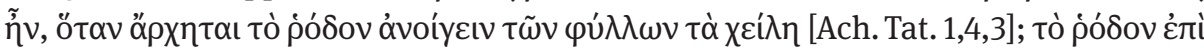

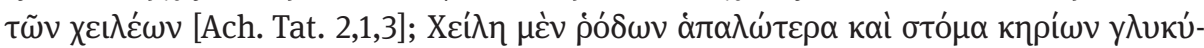

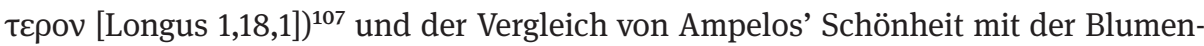

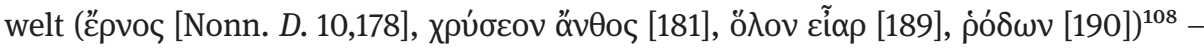
erinnern an vergleichbare Personenbeschreibungen im Roman, etwa an das Porträt Leukippes bei Achilleus Tatios (Nonn. D. 10,175-192; Ach. Tat. 1,4,2-5). Auch die insbesondere in den Büchern 10 und 11 verwendeten erotischen Topoi - der Traum des Verliebten, der vorübergehende Linderung des Liebesleids verspricht, ${ }^{109}$ der Ringkampf als Metapher für den Liebesakt, ${ }^{110}$ die Beständigkeit des Liebeshungers, der trotz Anschauens und Küssens keine Sättigung erfährt, ${ }^{111}$ die Kompensation einer verlorenen Liebe durch eine neue, ${ }^{112}$ die Metapher des Liebesfeuers ${ }^{113}$ und die enge Verbindung von Dionysos und Eros $^{114}$ - können ebenso wenig vollständig von einem direkten Abhängigkeitsverhältnis zum Roman überzeugen wie der locus amoenus des Paktolos-Ufers, der zum poetischen Symbol für die Liebesbeziehung zwischen Dionysos und Ampelos wird und als Gegenbild zur Störung der Liebesidylle durch die Verwüstung des Gartens durch Lamon in Longus 4,7f. gesehen werden kann. ${ }^{115}$

Vian (1995) 205 Anm. ad 314-318, und ein in die Pflanzen fahrender Wind findet sich in Nonn. D. 12,317 und Ach. Tat. 1,15,4, vgl. Vian (1995) 205 Anm. ad 317.

106 Vgl. Chamberlayne (1916) 55; Bezdechi (1940); Haidacher (1949) 101f.; Martínez (2007). - Zu dieser Motivik siehe besonders die Szene der Entführung Europas durch Zeus sowie die Frauenfiguren Nikaia, Ariadne, Aura, Beroe und Chalkomede mit ihren Liebhabern Dionysos, Poseidon und Morrheus; zu Europa vgl. Kuhlmann (1999) 397, zu Morrheus und Chalkomede Agosti (2004) 460 - 471 und Gerlaud (2005) 3-74, zu Aura Schmiel (1993) und Schulze (1966).

107 Vgl. Chrétien (1985) 144 Anm. ad 188; Gigli Piccardi (2003) 702. Zum Porträt des Ampelos siehe Kap. 3.3.

108 Siehe außerdem die Porträts des Kadmos, der Nikaia und der Chalkomede (Nonn. D. 4,126f.; 15,224-226; 16,72-81; 34,106-113), vgl. Gigli Piccardi (2003) 703. Zur Motivverknüpfung von Blumen mit menschlicher Schönheit bei Nonnos siehe auch Gigli Piccardi (1985) 63 - 69. Zum Topos vgl. auch AP 5,144, wo die Schönheit einer Geliebten namens Zenophila mit der Pracht von Blüten verglichen wird, vgl. Kost (1971) 242f. mit weiteren Beispielen aus Musaios und anderen griechischen Autoren.

109 Vgl. Nonn. D. 10,266; 34,89-99; 42,333-335; 47,328-349; Ach. Tat. 1,6,5; Longus 2,10,1; vgl. Chrétien (1985) 148f. Anm. ad 266.

110 Vgl. Nonn. D. 10,330-382; Ach. Tat. 2,38,3 f.; zum Ringkampf in der Ampelos-Episode siehe S. $102-110$.

111 Vgl. Nonn. D. 11,102; Ach. Tat. 2,38,5; vgl. Vian (1995) 160 Anm. ad 102.

112 Vgl. Nonn. D. 11,351, 368; Ach. Tat. 6,17,4; vgl. Vian (1995) 17 Anm. 4.

113 Vgl. Nonn. D. 11,463; Ach. Tat. 4,7,4; vgl. Vian (1995) 179 Anm. ad 463.

114 Vgl. Nonn. D. 11,351-368; Ach. Tat. 2,3,3.

115 Vgl. Vian (1995) 175 Anm. ad 366-368. - Gelegentlich finden sich bei Nonnos auch einzelne

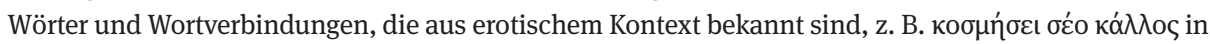


Nur selten fühlt sich der Leser an eine konkrete Textstelle erinnert, am ehesten in zwei Szenen, die Inhalt und Ausführung möglicherweise aus zwei ganz bestimmten griechischen Romanen schöpfen: Ampelos' Sturz vom Stier und der Tod von Kalamos und Karpos während ihres Wettschwimmens im Maiandros. Die auffallenden Entsprechungen zwischen dem Schicksal des Ampelos in den Dionysiaka und dem des Charikles bei Achilleus Tatios werden schon früh in der Forschung konstatiert; ${ }^{116}$ Ampelos' Sturz vom Stier (Nonn. D. 11,113-223) und die daran anschließende Trauerszene mit Dionysos (224-350) scheinen den Sturz des Charikles vom Pferd und die Trauerreden seines Vaters und seines Geliebten Kleinias $\mathrm{zu}$ rekapitulieren (Ach. Tat. 1,12; 1,13 und 14). Der mehrfache explizite Vergleich des für Ampelos tödlichen Stieres mit einem Pferd, den Ate mit den beiden mythischen exempla des Glaukos und des Bellerophon vornimmt, spricht eventuell für einen direkten Verweis auf Leukippe und Kleitophon (Nonn. D. 11,139-146): ${ }^{117}$

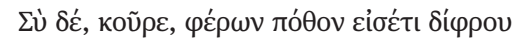

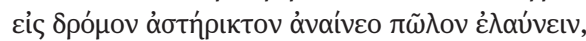

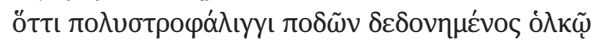
140

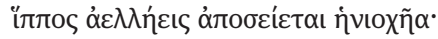

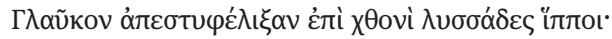

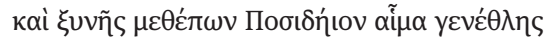

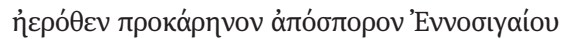

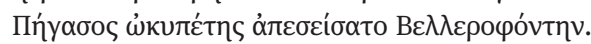

Aber du, Knabe, der du nach einer Wagenfahrt verlangst! (140) Lass ab davon, auf unsicherem Pfad ein Fohlen zu treiben, weil, vom vielen Herumwirbeln der Füße durchgeschüttelt, das windschnelle Pferd seinen Lenker abwirft! Rasende Pferde warfen Glaukos mit Gewalt auf die Erde. Und als Pegasos dem poseidonischen Blut der gemeinsamen Abstammung folgte, (145) da warf er aus der Luft mit dem Kopf voran den Sprössling des Ennosigaios, Bellerophon, in schnellem Flug ab.

Ein direkter Vergleich des Stieres mit Pferden erfolgt auch in Dionysos' erster Trauerrede, in welcher durch die Referenz auf Ganymed und dessen Aufstieg in den Olymp zugleich auf Ampelos' Unsterblickeit verwiesen wird (Nonn. D. 11,287-295), ${ }^{118}$ wie auch in der Szene um Ampelos' Sturz (188-223), die das Unglück in direkten Zusammenhang mit dem Reittier bringt: ${ }^{119}$

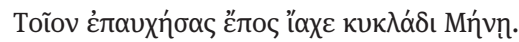

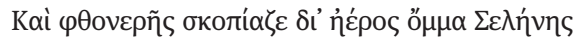

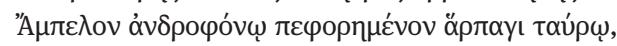

190

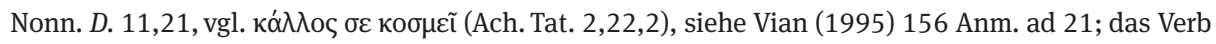

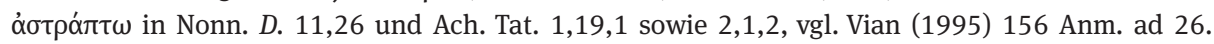
116 Vgl. Keydell (1936) 907; Böhm (1948) 57; Haidacher (1949) 96f., 120; D’Ippolito (1964) 139; Vian (1995) 9 Anm. 3; Fayant (2003a) 35; Webb (2009) 179f.; Frangoulis (2014) 80 f.

$117 \mathrm{Zu}$ den Mythen um Glaukos und Bellerophon in der Ampelos-Episode siehe Kap. 4.8.

$118 \mathrm{Zu}$ Text und Übersetzung der Stelle siehe S. 126-128; zu Ganymed und Ampelos siehe Kap. 4.6. 119 Vgl. Haidacher (1949) $96 \mathrm{f}$. 


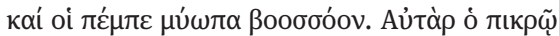

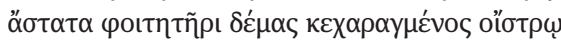

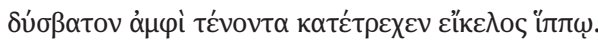

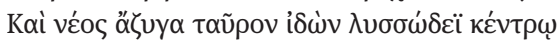

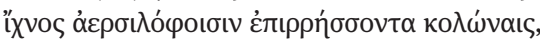

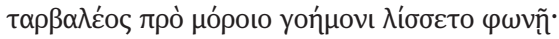

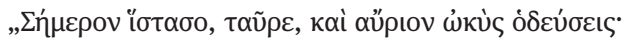

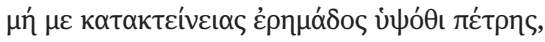

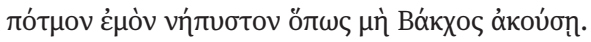

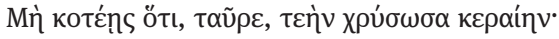

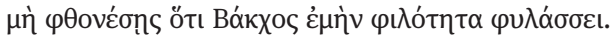

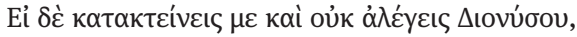

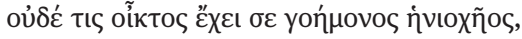

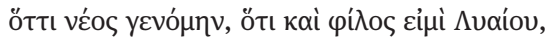

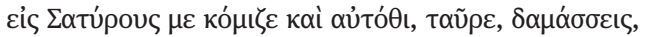

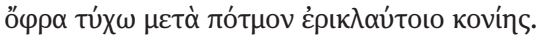

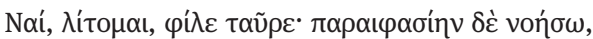

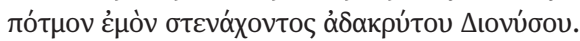

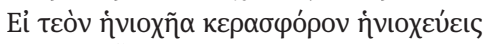

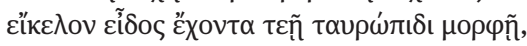

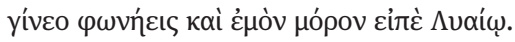

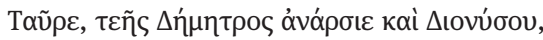

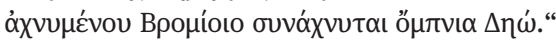

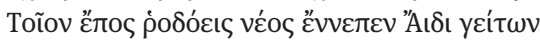

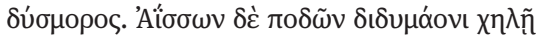

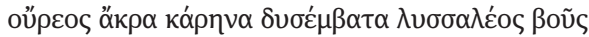

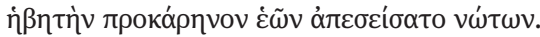

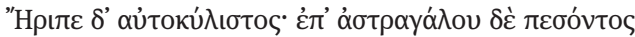

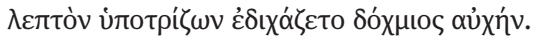

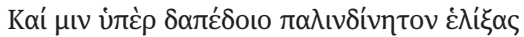

$\theta \eta \gamma \alpha \lambda \varepsilon_{n} \eta$ y

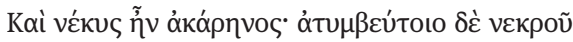

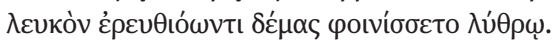

Eine derartige prahlerische Rede gab er von sich und jauchzte zur kreisrunden Mene. Und mit neidischem Auge beobachtete Selene durch die Luft hindurch (190) Ampelos, wie er vom männermordenden, räuberischen Stier getragen wurde, und schickte ihm eine rinderaufreizende Stechmücke. Aber der Stier, von der lästigen und rastlos herumschwirrenden Bremse am Leib gestochen, lief durch das unwegsame Dickicht einem Pferd gleich. Und als der Jüngling sah, wie der Stier ohne Joch durch den rasenden Stachel (195) in seinem Lauf auf die luftigen Hügel zusteuerte, flehte er mit klagender Stimme gegen sein schreckliches Schicksal: „Heute bleib stehen, mein Stier, und du wirst morgen schnell laufen! Töte mich nicht oben am öden Felsen, dass Bakchos unwissend bleibe und nichts von meinem Schicksal höre! (200) Zürne nicht, mein Stier, weil ich deine Hörner vergoldet habe! Sei nicht neidisch darauf, dass Bakchos Liebe zu mir hegt! Denn wenn du mich tötest und dich nicht um Dionysos kümmerst, dann hat kein klagender Wagenlenker Mitleid mit dir. Da ich jung und auch der Freund des Lyaios bin, (205) bringe mich zu den Satyrn und bezwinge mich dort, mein Stier, damit ich nach dem Todesschicksal den Staub voll von Tränen vorfinde! Ja, ich flehe dich an, lieber Stier! Ich werde Trost finden, wenn über mein Todesschicksal der tränenlose Dionysos seufzt. Wenn jetzt du deinen gehörnten Lenker lenkst, (210) der eine Stiergestalt hat ähnlich wie du, sollst du eine Stimme bekommen und mein 
Schicksal dem Lyaios berichten! Mein Stier, Feind deiner Demeter und des Dionysos! Wenn Bromios trauert, trauert zusammen mit ihm auch die nährende Deo.“120

Ein solches Wort sprach der rosige Jüngling, dem Hades schon nahe, (215) der Unglückliche. Und mit seinen doppelten Klauen an den Füßen stürmte es voran auf die schwer zugänglichen Berggipfel, das rasende Rindvieh, und warf den Jüngling mit dem Kopf voran von seinem Rücken. Und er überschlug sich und stürzte hinunter. Er fiel auf den Wirbelknochen, und mit einem zarten Knacken brach der Nacken hinten entzwei. (220) Und er wirbelte ihn wieder und wieder über den Boden und warf ihn mit der scharfen Spitze seines Horns kopfüber hinab. Und er war ein Leichnam ohne Kopf, und die weiße Gestalt des unbestatteten Toten wurde purpurn vom rötlichen Blut.

Ähnlichkeiten lassen sich bis in motivische Details feststellen: Das Hauptmotiv in der Rede des Ampelos, der letzte Beschwichtigungsversuch des Stieres, findet sich auch bei Achilleus Tatios wieder, wenn es Kleinias reut, seinem geliebten Charikles mit dem Pferd ein solch verhängnisvolles Geschenk bereitet $\mathrm{zu}$ haben und wenn er letzte be-

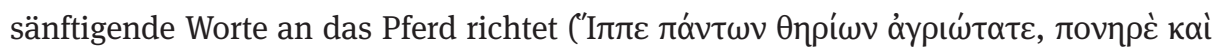

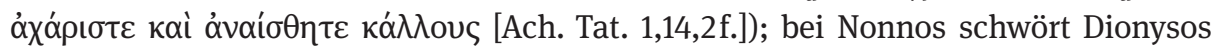
überdies, Rache am Stier, dem Mörder des Ampelos, nehmen zu wollen (Nonn. $D$. 11,264-270). Der minutiös geschilderte Todessturz vom Stier findet im Botenbericht des Dieners des Charikles ein fernes Echo (Nonn. D. 11,224-226; Ach. Tat. 1,12), der, ähnlich wie der anonyme Satyr dem Dionysos, dem Liebhaber des Knaben die unglücklichen Todesumstände - das Verlassen der menschlichen Zivilisation und das Abgleiten in unwegsames Gelände - schildert (Ach. Tat. 1,12,5). In beiden Szenen bilden je zwei Trauerreden den narrativen Rahmen, die des Liebhabers Kleinias und des Vaters des Charikles in Ach. Tat. 1,13 sowie die beiden Reden des Dionysos in Nonn. D. 11,255-312 und 315-350, ${ }^{121}$ und eröffnen die Motive des plötzlichen, unerwarteten Todes sowie der versäumten Hochzeit (Ach. Tat.1,13,4-6; Nonn. D. 11,276-279). Einen möglicherweise bewussten Gegensatz zu Achilleus Tatios setzt Nonnos mit der äußeren Erscheinung von Ampelos' Leichnam, welcher - im Gegensatz zu Charikles nicht von Wunden entstellt, sondern höchst ansehnlich gezeigt wird, nachdem er von Dionysos mit unsterblich machender Ambrosia gesalbt worden ist (ő

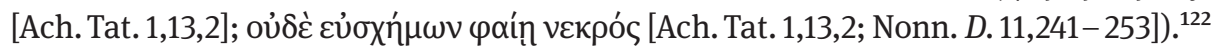

Eine weitere potentielle Reminiszenz an den Roman liegt in der Szene um Kalamos und Karpos vor, welche den Tod des Liebespaares im Fluss Maiandros anlässlich eines sportlichen Wettkampfes schildert und ein Pendant in der Episode um Hippothoos und Hyperanthes in den Ephesiaka des Xenophon von Ephesos findet: ${ }^{123}$ Als Erzählung in der Erzählung berichtet der Räuber Hippothoos dem Protagonisten des Romans, Habrokomes, von seiner Jugendliebe Hyperanthes, den er dereinst durch tragische

120 Hopkinson (1984) 138 weist darauf hin, dass Nonn. D. 11,212 f. Call. Cer. 70 f. wiederaufnimmt:

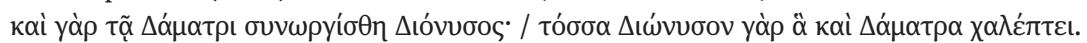

121 In Ach. Tat. 3,10 findet sich mit der Rede des Kleitophon um die tot geglaubte Leukippe eine vergleichbare Trauerrede; zum Motiv des Todes, der eine Hochzeit vereitelt, vgl. Ach. Tat. 5,11,2.

122 Vgl. den Schutz des Patroklos durch Thetis in Hom. Il. 19,23-33.

123 Zur Episode bei Xenophon vgl. Schmeling (1980) 53-55. 
Umstände verloren habe (X. Eph. 3,2). Die anfänglich positive Liebesgeschichte findet mit dem Auftauchen eines Konkurrenten um die Gunst des Hyperanthes ein abruptes Ende und gipfelt im bewaffneten Rachefeldzug und Befreiungsversuch des Geliebten durch Hippothoos; nachdem beiden die Flucht auf ein Schiff gelungen ist, erleiden sie jedoch nahe Lesbos Schiffbruch, gehen über Bord und versuchen sich schwimmend zu retten, da der Tod des jungen Hyperanthes in den Wellen jedoch nicht verhindert werden kann, führt Hippothoos eine rituelle Bestattung durch und lässt einen Grabstein mit Epitaph errichten. Die eigentliche Schwimm- und Todesszene findet sich in X. Eph. 3,2,11f.: ${ }^{124}$

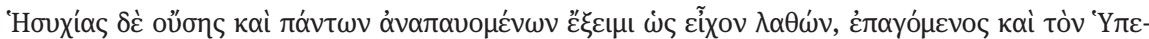

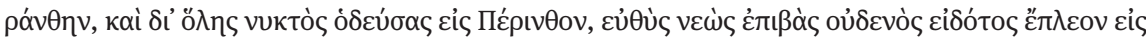

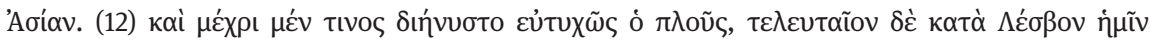

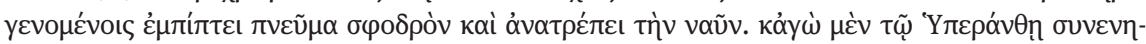

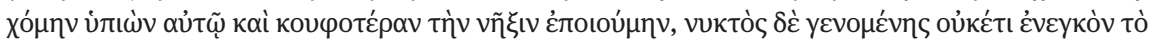

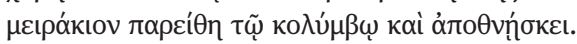

Es blieb still, alles schlief. Ich verließ das Haus ungesehen und hatte Hyperanthes bei mir. Die ganze Nacht wanderten wir nach Perinth. Dort gingen wir sofort an Bord eines Schiffes und segelten, ohne daß irgendjemand etwas erfuhr, nach Kleinasien hinüber. (12) Eine Weile ging die Fahrt gut; schließlich aber gerieten wir auf der Höhe von Lesbos in einen heftigen Sturm, der unser Schiff zum Kentern brachte. Ich kam schwimmend davon, zusammen mit Hyperanthes. Ich nahm ihn auf meinen Rücken, um ihm das Schwimmen zu erleichtern. Als aber die Nacht hereinbrach, brachte ihn das Schwimmen ans Ende seiner Kräfte; er starb.

Trotz des unterschiedlichen Kontexts bei Nonnos findet sich eine Reihe von Motiven aus dem Roman wieder: der junge Geliebte und dessen vorzeitiger Tod im Wasser sowie das abschließende Grabepigramm (Nonn. D. 11,470 - 474). Den Haupterzähllinien um Habrokomes und Anthia sowie um Dionysos und Ampelos soll zusätzliche Wirkung verliehen werden, indem durch das jeweils eingeschobene Erzählelement das narrative Tempo gedrosselt wird, gleichzeitig aber wesentliche, bereits aus der AmpelosErzählung geläufige Aspekte innerhalb des Exkurses reflektiert und Parallelen zu den Schicksalen der jeweiligen Protagonisten gezeichnet werden. ${ }^{125}$

Da es sich bei den fraglichen Motiven um auch in anderen literarischen Genera und mythischen Erzählungen geläufige narrative Muster handelt, lassen sich die genannten Parallelen nur bedingt als direkte Quellen heranziehen und eine direkte Abhängigkeit von den Romanautoren lässt sich nicht zweifelsfrei festmachen: So fordert etwa im Mythos um Antiope die rachsüchtige Dirke die Zwillinge Amphion und

124 Text: O’Sullivan (2005) 40; Übersetzung: Kytzler (2001) 129. - Im Unterschied zum unglücklichen Schicksal des Hyperanthes überleben Habrokomes und Anthia, als der Piratenkapitän Korymbos sich dazu entschließt, ein Schiff mit Sklaven in Brand zu stecken, auf dem sich auch das Protagonistenpaar befindet (X. Eph. 1,14,4-6), vgl. Schmeling (1980) $35 \mathrm{f} . ;$ Konstan (1994) $26 \mathrm{f}$.

125 Zur kompositorischen Funktion der Erzählung des Hippothoos in den Ephesiaka vgl. Schmeling (1980) $54 \mathrm{f}$. 
Zethos auf, deren Mutter Antiope an einen Stier zu binden, was schließlich von Zeus verhindert wird, der Dirke selbst an den Stier fesselt; ${ }^{126}$ berücksichtigt werden müssen außerdem Szenen aus der Tragödie wie etwa der Tod des Orest im Wagenrennen in S. El. 680-763 oder der Tod des Hippolytos in E. Hipp. 1213-1248. Dennoch ist die Ampelos-Episode, die bestenfalls an wenigen konkreten Einzelstellen einen Nachhall der Romanliteratur zu bieten vermag, in den einzelnen strukturellen und motivischen Anlehnungen, insbesondere in der Verarbeitung der Liebesthematik, Ergebnis des Bestrebens der nonnianischen Poetik, die Grenzen zwischen den einzelnen traditionellen Genera zu verwischen.

\subsection{Einflüsse weiterer Genera}

Das Wesen nonnianischer Poetik liegt oft weniger in der Verwendung konkreter Texte und Autoren als vielmehr in der Reflexion sämtlicher antiker dichterischer Ausdrucksformen, welche in den dionysischen Kontext eingebettet und, gebrochen durch die Kunstauffassung der Spätantike, einem zeitgenössischen Publikum dargeboten werden. Nonnos ist bestrebt, möglichst viele literarische Genera in die Dionysiaka aufzunehmen, neben der Vermessung des homerischen Epos, der hellenistischen Dichtung und des Romans erfolgt auch eine Auseinandersetzung mit der Lehr- und Hymnendichtung sowie mit einzelnen narrativen Elementen der Tragödie.

\section{Didaktische Dichtung}

Dem Alternativmythos zur Entstehung des Weines am Ende der Ampelos-Episode (Nonn. D. 12,292-397) wurde lange dichterische Unzulänglichkeit angelastet. Er wurde vielfach als bloße sekundäre Addition eingestuft, die der geschlossenen narrativen Einheit der Ampelos-Episode zuwider laufe. Tatsächlich jedoch spricht Einiges für die bewusste Komposition dieses Parallelmythos und die Positionierung gerade an diese Stelle im Epos. Der erzählerische Schwerpunkt dieses Mythos liegt auf einer Reihe von Elementen, die für die Lehrdichtung charakteristisch sind. ${ }^{127}$ Im Vergleich zur Erzählfreudigkeit, die er in der ausführlichen Schilderung von Aufstieg, Fall und Metamorphose des Satyrn an den Tag legt, bietet Nonnos in der Alternativversion eine gleichsam realistische, sachlich beschreibende Abhandlung über die Genese des Weines. Gemäß der hellenistischen Tradition, mehrere Versionen einer Sage aufzu-

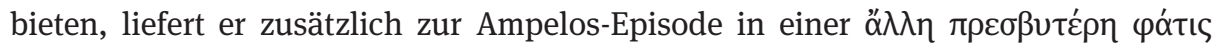
(Nonn. D. 12,294) ein weiteres Aition für den Wein und schildert, wie der wilde

126 Vgl. Detienne (1992) 62; zu Antiope siehe RE I/2, 2495 - 2497 und Roscher Bd. I/1, 380 - 383 mit Quellenangaben.

127 Zur Definition von antiker Lehrdichtung siehe Effe (1977), bes. 22 - 26; zum Lehrgedicht in der Spätantike vgl. Charlet (1997) 514-522. 
Weinstock zufällig und ohne menschliches Zutun aus dem Götterblut hervorgeht, und schließt sogleich eine ekphrastische Beschreibung der Pflanze an (Nonn. D. 12,292318): ${ }^{128}$

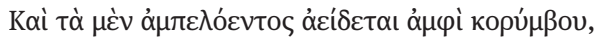

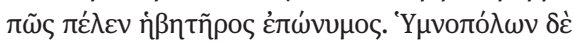

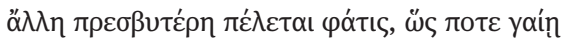

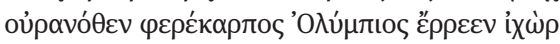

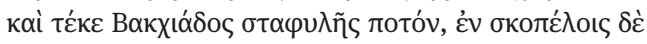

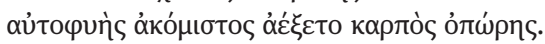

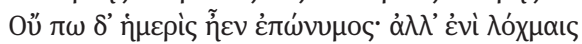

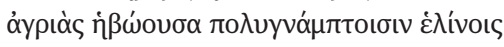

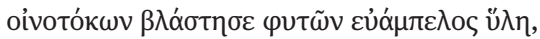

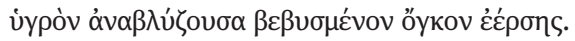

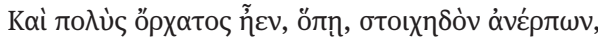

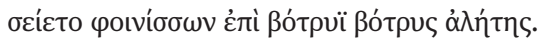

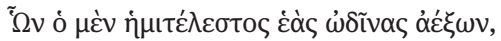

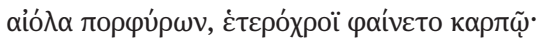

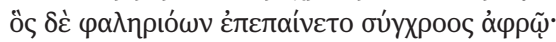

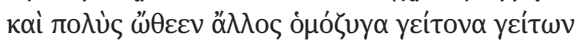

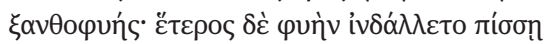

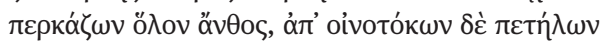

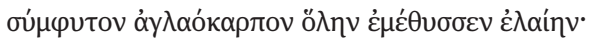

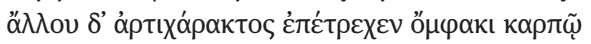

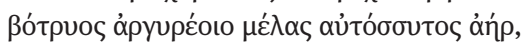

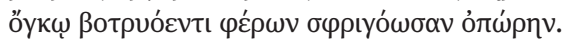

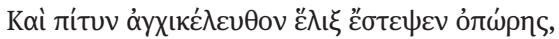

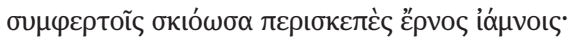

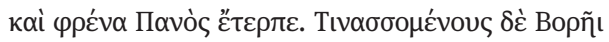

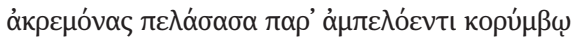

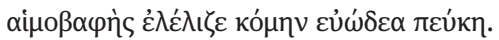

Und dies singt man von der Traube der Weinrebe, wie sie ihren Namen vom Jungen erhalten hat. Aber von den Hymnendichtern stammte noch eine andere, ältere Sage: Dass einmal vom Himmel (295) der fruchtspendende olympische Ichor auf die Erde herabtroff, den Trank der bakchischen Weintraube hervorbrachte und auf den Hügeln von selbst und unkultiviert die Frucht des Weinstocks zu wachsen begann. Noch nicht hatte nämlich der kultivierte Wein seinen Namen, sondern im Dickicht wuchs mit seinen vielgewundenen Ranken wilder Wein heran. (300) Der Wald mit seinen schönen Weinstöcken erblühte von Weinpflanzen und ließ den saftigen Tropfen aus der Traube hervorquellen, die zum Bersten gefüllt war. Und es gab einen großen Garten, wo sich reihenweise Rebe an Rebe, rötlich schimmernd, hinaufwand, und sich wiegend hin und her bewegte. Eine von diesen, eine fast reife, ließ ihre Früchte wachsen (305) und zeigte sich rötlich funkelnd, mit mehrfarbiger Frucht. Eine andere reifte, weißlich gefärbt, und war obenauf schaumfarben. Wieder manch andere, direkt daran anstoßend, eine neben der anderen, war von gelber Farbe, und eine weitere schien ihrem Aussehen nach wie Pech, da die ganze Pflanze dunkel

128 In der Ausführung des Alternativmythos folgt Nonnos hellenistischer Praxis; auch im homerischen Epos gibt es die Möglichkeit alternativer Mythenversionen, die jedoch vom Dichter nicht als solche deklariert werden, vgl. dazu Danek (1998) 7-23. 
war und sie von den Wein tragenden Blättern (310) den Gefährten, den Ölbaum, mit seiner glänzenden Frucht ganz trunken machte. Und auf die unreife Frucht einer anderen lief, soeben frisch zerteilt, wie von selbst der schwarze Hauch einer silbrig schimmernden Beere und ließ auf die pralle Traube dickflüssigen Saft fließen. Die gewundene Rebe umkränzte auch eine Pinie daneben, (315) warf ihren Schatten auf den Spross, der rund herum von dichtem Unterholz abgedunkelt war, und erfreute das Herz des Pan. Und wenn die Föhre ihre vom Nordwind gerüttelten Äste an die Weintraube drängte, erzitterte mit blutrotem Saft getränkt ihr wohlduftendes Nadelkleid.

Im noch unkultivierten Weingarten wachsen unterschiedlich gefärbte Weintrauben, deren Aussehen mit beinahe naturwissenschaftlicher Exaktheit beschrieben wird. Der

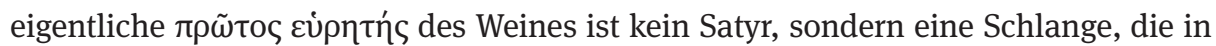
der Folge für Dionysos zur Lehrmeisterin in der Technik des Kelterns wird (Nonn. $D$. 12,319-336):

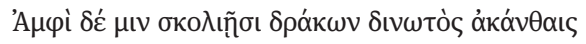

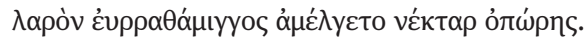

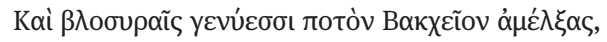

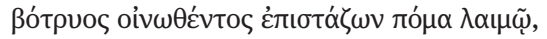

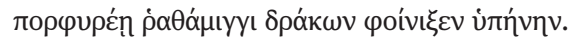

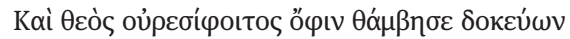
oiv $\omega \pi \tilde{n} \dot{\rho} \alpha \theta \alpha \dot{\alpha} \mu$ เy

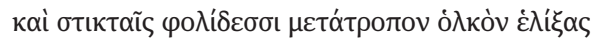

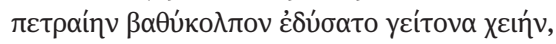

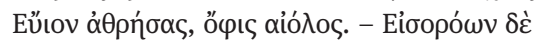

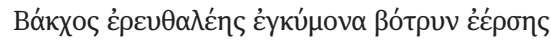

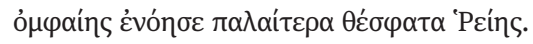

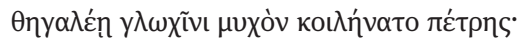

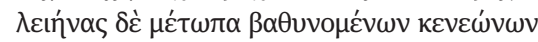

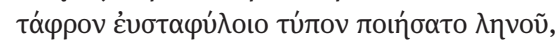

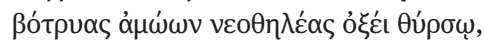

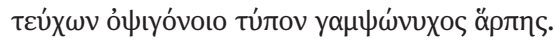

Und um sie geringelt melkte eine Schlange mit gewundenem Rücken (320) den süßen Nektar der triefenden Weinrebe. Mit schuppigem Maul molk die Schlange den bakchischen Trunk, träufelte den Saft der gepressten Traube in ihren Schlund und rötete ihre Oberlippe mit den purpurnen Tropfen. Und als der Gott die Berge durchstreifte, staunte er beim Anblick der Schlange (325) und ihres von Weintropfen benetzten Kinns. Und in schneller Bewegung schlängelte sie sich mit ihren gesprenkelten Flecken in die entgegengesetzte Richtung und tauchte gleich daneben in einem tiefen Felsloch unter, als sie Euios erblickte, die scheckige Natter. Aber als Bakchos die von rötlichem Saft schwere Traube sah, (330) erkannte er die alten Prophezeiungen der Seherin Rheia. Er scharrte eine Vertiefung aus, indem er die Erde mit einem Eisen umgrub und mit der scharfen Spitze den innersten Teil eines Felsens aushöhlte. Er glättete die Oberfläche der eingetieften leeren Fläche und schuf den Prototyp einer Keltergrube für die Weinpressung. (335) Er schnitt die neu entstandenen Weinbeeren mit dem scharfen Thyrsos ab und fertigte den Prototyp der erst später erfundenen, krummkralligen Sichel. 
Der knappen Schilderung der ersten Weinpressung in Nonn. D. 12,193-206 ${ }^{129}$ wird im Alternativmythos eine ausführlichere Version gegenübergestellt. An das eingehend und wortreich beschriebene عü $\eta \mu \alpha$ des Weines durch die Schlange und Dionysos schließt eine technische Beschreibung des Keltervorgangs an (Nonn. D. 12,337-344):

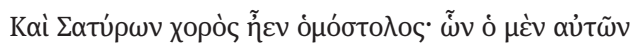

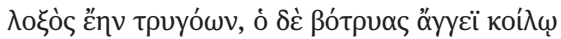

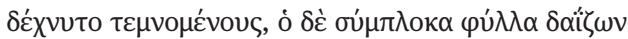

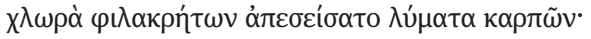

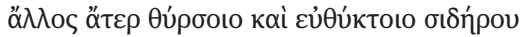

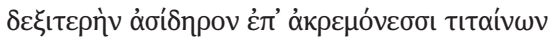

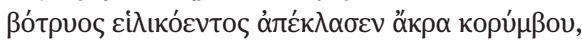

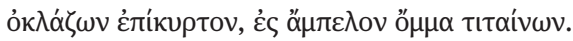

\begin{abstract}
Und es begleitete ihn ein geschlossener Reigen von Satyrn. Einer von ihnen las gekrümmt Trauben, ein anderer füllte die abgeschnittenen Weintrauben in einen bauchigen Krug, wieder ein anderer nahm die verflochtenen Blätter auseinander (340) und schüttelte das grüne Wasser von den Früchten, die zum Keltern bereit waren. Und wieder ein anderer streckte ohne Thyrsos oder gut gespitztes Eisen, völlig ohne Werkzeug, die rechte Hand nach den Zweigen aus und brach die rankenden Beeren von den Stielen ab, indem er hockend den Rücken krümmte und den Blick auf einen Weinstock richtete.
\end{abstract}

Die Textstellen illustrieren die Genese des Weinstocks und des Weines in minutiös ausgeführter Bildhaftigkeit, Nonnos bietet hier gleichsam eine Schritt-für-Schritt-Anleitung zur Weinpressung und legt den erzählerischen Fokus - im Unterschied zum Finale des Ampelos-Mythos - auf die kulturgeschichtliche Bedeutung des Weines. ${ }^{130}$ Der Endpunkt des Aitions, die Darstellung des dionysischen Kultes, wird im zweiten Mythos stärker akzentuiert, das Hauptaugenmerk liegt auf dem Kult-Aition selbst: „,...] l'un est plus ,théologique', l'autre près de realia par son charactère étiologique. "131 Mit der Ekphrasis des Weinkonsums und mit seinen Folgen, der Trunkenheit der Satyrn, dem bakchischen Tanz und der Verfolgung der Nymphen, setzt Nonnos einen adäquaten Schlusspunkt (Nonn. D. 12,363-393). ${ }^{132}$ Er schlüpft hier in die Rolle eines Alexandriners, der sein vielseitiges poetisches Können am Beispiel der didaktischen Dichtung zur Schau stellt. Seine schillernde und nuancenreiche sprachliche Ausdruckskraft wird insbesondere durch die Wahl bedeutungsschwerer Adjektive erreicht

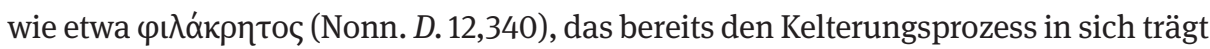
und vorwegnimmt, sowie durch die Verwendung von Wörtern, die typisch für die didaktische Poesie des Hellenismus sind, etwa iá $\mu v o s$ in Nonn. D. 12,315, das aus den Lehrdichtungen Nikanders von Kolophon bekannt ist (Nic. Ther. 30,200, 538 und 901).

Da wesentliche Eigenschaften und phänotypische Details der neuen Pflanze ausschließlich in dieser Passage zu finden sind, handelt es sich beim zweiten Mythos

129 Für Text und Übersetzung der Stelle siehe S. 144.

130 Vgl. Gigli Piccardi (2003) 744.

131 Vian (1995) 88.

132 Vgl. S. $232 \mathrm{f}$. 
keinesfalls um einen funktionslosen, beliebigen oder gar sekundären Anhang zur Ampelos-Episode. Die technische Verarbeitung der Pflanze und ihrer Frucht schließt unmittelbar an Dionysos' Enkomion-Rede in Nonn. D. 12,207-291 an und vervollständigt diese. ${ }^{133}$ Nonnos demonstriert an dieser Stelle einmal mehr seine Fähigkeit, jedes beliebige literarische Genus in die Dionysiaka aufzunehmen und der dionysischen Thematik einzuverleiben. Mit dem Alternativmythos zur Genese des Weines reiht sich Nonnos zudem in die Tradition der mythischen Mehrfacherklärungen ein, die seit dem Hellenismus ein gängiges dichterisches Ausdrucksmittel darstellen. ${ }^{134}$ Mythendoppelungen zeugen nicht nur von enzyklopädischem Interesse und antiquarischer Sammeltätigkeit, sondern erfüllen stets eine erzähltechnische Funktion im jeweiligen dichterischen Werk. Das von Nonnos erzeugte kaleidoskopartige Bild von unterschiedlichen Mythenvarianten steht für den Anspruch des Dichters, ein höchst vielgestaltiges und komplexes Epos zu schaffen, das dem hellenischen Erbe Genüge leistet. Die Anknüpfung an eine seit dem Hellenismus gängige Formensprache reiht den Panopolitaner einmal mehr unter die griechischen Dichter seit Kallimachos ein und reflektiert das Selbstverständnis einer hellenischen Gesellschaft im spätantiken Ägypten.

\section{Hymnendichtung}

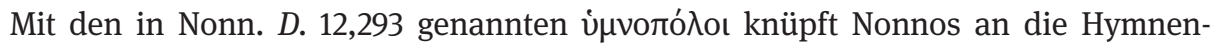
dichtung an. ${ }^{135}$ Seit den homerischen Hymnen sind Lobpreisungen auf Götter fester Bestandteil epischen Erzählens. Die typisch hymnischen Elemente, das Gedenken an die mythischen Taten und den Zuständigkeitsbereich der Gottheit, die Anrede- und Grußformeln, die rühmenden Epitheta, die Epiphanieszene, das rituelle Bittgesuch sowie das abschließende Kult-Aition, finden sich auch in den Dionysiaka wieder, ${ }^{136}$ was schon Franz Braun zu einem Überblick über die hymnischen Gebete im Epos des Nonnos veranlasste. ${ }^{137}$ Kennzeichnend für die poetische Verfahrensweise des Nonnos

133 Siehe dazu S. $169-172$.

134 Vgl. Loehr (1996).

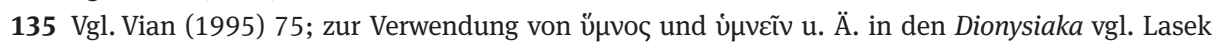
(2009) 16f., 136-143.

136 Zur Definition und zu den Charakteristika der Hymnendichtung siehe Braun (1915) 27; Lattke (1991) 3, 14-16, 44; Evans S. (2001) 62 -66; Lasek (2009) 33, 53.

137 Vgl. Braun (1915) 9-29: Hymnus des Dionysos an Herakles-Astrochiton (Nonn. D. 40,369-410); vgl. auch Chuvin (2009) 193f., 203-205, $208 \mathrm{f}$., der die Verwandtschaft mit den neuplatonischen Hymnen des Proklos betont; Braun (1915) 29-38: Dionysos an Selene mit der Bitte um Hilfe gegen Pentheus (Nonn. D. 44,191-216), 39-47: Hymnos auf Beroe/Berytos (Nonn. D. 41,143-154), 47: Stoßgebet des Erechtheus an Athene beim Wagenrennen (Nonn. D. 37,320 - 323), 51 f.: Orontes' Gebet an Helios (Nonn. D. 17,271-286), 52: Gaia bemitleidet Dionysos im harten Kampf gegen die Inder (Nonn. D. 22,276-283), 52-54: Maron an Staphylos (Nonn. D. 19,169-197), 54: Morrheus an Chalkomede (Nonn. D. 34,103-121), 55 f.: Dionysos' Hymnos auf die Stadt Tyros (Nonn. D. 40,338- 
ist einmal mehr die Tatsache, dass er keinen überlieferten Hymnos imitiert, sondern die homerischen, kallimacheischen und prokleischen Hymnen zum Ausgangspunkt nimmt, um unter Anwendung von neuem lexikalischen Material eine eigene dionysische Hymnensprache zu formulieren. ${ }^{138}$

In der Ampelos-Episode sind es insbesondere zwei Szenen, in denen Nonnos hymnische Elemente verarbeitet: die Rede des Dionysos an Zeus in Nonn. D. 10,292320 und der Bittgang der Herbsthore zu Helios in Nonn. D. 12,23-28. ${ }^{139}$ Die Rede des Dionysos wird durch eine hymnische Formel eröffnet, in welcher Zeus namentlich

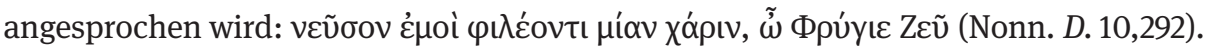
Die rituelle Bitte setzt sich in weiteren für die Hymnendichtung typischen Phrasen fort:

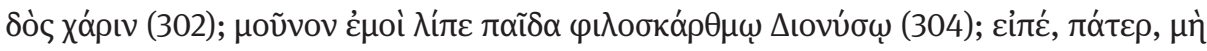

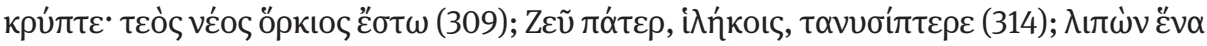

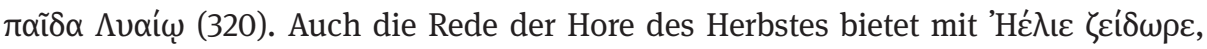

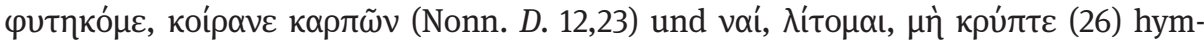
nische Elemente. ${ }^{140}$ Zweck der beiden Bittreden ist die Einführung dionysischer Wirkkräfte in der Welt, die sich in der Verbindung von Dionysos mit seinem Hauptattribut, dem Wein, manifestiert. Dionysos fordert von Zeus den Satyrn Ampelos und somit seine persönliche göttliche Macht, mit der Aufählung der olympischen Götter ordnet er sich selbst in die Riege der Unsterblichen ein.

Dem Bereich der Performanz von Hymnen ist ferner die Praxis des Tanzes zuzurechnen, die der Dichter in die Komposition der Ampelos-Episode einbezieht. ${ }^{141}$ Mehrmals werden Ampelos (Nonn. D. 10,238-242; 11,331-334), Dionysos (Nonn. D. 10,304, 399; 12,350) und die Satyrn (Nonn. D. 12,382f.) dargestellt, wie sie einen Tanz oder tanzähnliche Bewegungen vollführen. ${ }^{142}$ Hymnos und Tanz, zwei unverzichtbare kultische Ausdrucksformen des antiken Menschen, einer Gottheit in ehrfurchts- und respektvoller Weise zu begegnen, fügt Nonnos in seinen Ampelos-Mythos ein, um den Protagonisten, den jungen Dionysos, auf seinem Weg zur bedingungslosen Anerkennung als vollwertigen Gott einen Schritt weiter zu führen. Die Kultbegründung am Ende des 12. Buches kündigt nachdrücklich und einprägsam die Apotheose des Weingottes am Ende des Epos an.

352), 56: Selene verspricht Dionysos Hilfe gegen Pentheus (Nonn. D. 44,218-252), 56 f.: Anrufung des Okeanos und seiner Frau Tethys (Nonn. D. 23,284-319). - Lasek (2009) 49-58 führt außerdem folgende Stellen an: Zeus an Kadmos (Nonn. D. 1,378 - 397), einen Hymnos auf Eros (Nonn. D. 1,398 407). - Zur Verschränkung von Hymnos und Gebet vgl. die Einleitung zum Sammelband Goeken (2010).

138 Vgl. Braun (1915) 28.

139 Vgl. Braun (1915) 50 f; zur Dionysos-Rede siehe auch Lasek (2009) 101 - 103; Kröll (2014) 254 257.

140 Vgl. Stegemann (1930) 141.

141 Zur Verbindung von Hymnos und Tanz vgl. Evans S. (2001) 76-106.

142 Auch die Sommerhore tanzt, vgl. Nonn. D. 11,505 f. 


\section{Ein Ampelos-Drama}

Die Sujets Tanz und Musik sind fester Bestandteil des dionysischen Kultes. Mit diesem Ausklang der Ampelos-Episode bekennt sich Nonnos zu seinem poetischen Programm: der Etablierung dionysischer Rituale und der Vergöttlichung des jugendlichen Zeus-Sohnes. Tanz, Musik und Kultstiftung bilden auch elementare Komponenten der griechischen Tragödie, einer Gattung, die Nonnos als Bezugsquelle für mehrere Passagen seines Epos heranzieht. ${ }^{143}$ Am deutlichsten wird der Einfluss in der Pentheis der Bücher 44-46, in denen sich Nonnos die euripideischen Bakchen zum Modell nimmt, ${ }^{144}$ oder auch in der Episode um Ambrosia und Lykurg in Buch 21. Die Wirkung des dramatischen Genus darf keinesfalls unterschätzt werden, da die Umsetzung tragischer Themen und Techniken zur gängigen poetischen Praxis im spätantiken Epos wird. ${ }^{145}$

Auch in der Ampelos-Episode bietet Nonnos tragische Grundthemen: Die erste Weinpressung und Berauschung sowie der erste kultische Komos für Dionysos münden in einer Kultstiftung, wie sie typisch für die Tragödie ist. Dabei machen weniger die Dialogpartien die Bücher 10, 11 und 12 zu einem dramatischen Stück ${ }^{146}$ als vielmehr die Struktur der Episode. Die Gliederung in drei Teile - (1.) Aufbau des Spannungsbogens mit den Wettspielen und Ampelos' dreifachem Sieg, (2.) Hybris und Peripetie sowie (3.) Sturz und Metamorphose - ruft den narrativen Duktus einer griechischen Tragödie in Erinnerung. ${ }^{147}$ Nonnos transferiert, wie für seine Art des Dichtens bezeichnend, auch hier kein konkretes Drama in sein Epos, sondern nimmt das Tragische lediglich als Ausgangspunkt zur Konzipierung einer völlig neuen Formensprache, einer Mélange aus Epos und Tragödie, in der er eigene poetische Akzente setzt; den Umschwung des Geschehens zum Negativen macht er nicht nur durch Ampelos' hybrides Verhalten nach seinem dritten sportlichen Sieg sichtbar, sondern er hält an diesem Wendepunkt der Erzählung inne und liefert eine detaillierte poetische Auseinandersetzung mit dem Hybris-Motiv selbst: ${ }^{148}$ Die Überheblichkeit des Satyrn erfährt in Nonn. D. 11,113-154 in der als sprechende Figur auftretenden Ate ihre Personifizierung; somit geht Nonnos, wenn er die Verblendung als selbstständige Figur auftreten lässt, einen Schritt weiter als die Tragödie. Zudem nimmt er Anleihe bei Homer, der das Prinzip der Ate in der Ilias mehrfach thematisiert - dort können Figuren wie Hektor, Achill oder Zeus von ätn

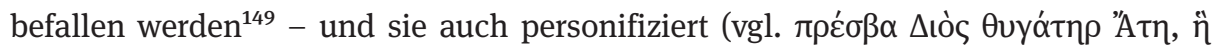

143 Vgl. Haidacher (1949) 25 - 34; Hernández de la Fuente (2008) 50 f.

144 Vgl. Tissoni (1998); Shorrock (2001) 194-197; Aringer (2002).

145 Vgl. Wasyl (2011) $94 \mathrm{f}$.

146 Zur dramatischen Frage-Antwort-Technik vgl. Petropoulos (2003) 25-27.

147 Zur Dreiteilung vgl. D’Ippolito (1964) 133.

148 Hybris als kompositorisches Element findet sich auch in der Aktaion- und Phaethon-Episode (Nonn. D. 5,287-551; 38,105-434), vgl. D’Ippolito (1964) 177-190; Hopkinson (1994) 33-42, 125 -136; Cuartero i Iborra (2003) 186-188; Hernández de la Fuente (2008) 167 - 182.

149 Vgl. Hershkowitz (1998) 125-155. 


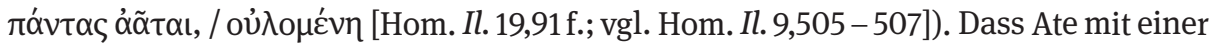
eigenen Rede bedacht wird, spiegelt die besondere Vorliebe der Spätantike für Personifikationen von abstrakten Begriffen wider. Ampelos' tragisches Los erfährt durch den Auftritt Ates eine ungeahnte Steigerung, welche durch das parallele Schicksal von Kalamos und Karpos sowie durch weitere tragische Figuren, die auf der dritten Tafel Harmonias abgebildet sind (Nonn. D. 12,64-102), zusätzlich hervorgehoben wird. ${ }^{150}$ Die mythischen Sünder und Ehebrecher auf den Tafeln exemplifizieren zudem die

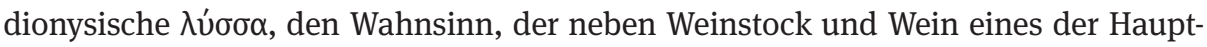
charakteristika dionysischen Wirkens darstellt.

Mit dem Botengang eines anonymen Satyrn setzt Nonnos ein gleichfalls für die Tragödie typisches Strukturelement ein (Nonn. D. 11,224f.). ${ }^{151}$ Anstatt jedoch einen ausführlichen Botenbericht zu liefern, lässt der Dichter Dionysos geradewegs zum verunglückten Ampelos eilen und das Geschehene aus nächster Nähe beobachten. Der Todessturz selbst wird ebenfalls nicht, wie in der Tragödie üblich, durch einen Botenbericht im Nachhinein erzählt, sondern ist dem kurz angedeuteten Botengang des Satyrn bereits vorausgegangen (Nonn. D. 11,214-223). ${ }^{152}$ Nonnos hält sich insofern nicht an die Konventionen der Tragödie, als er die Unglücksszene nicht durch einen sekundären Bericht eines Augenzeugen schildert, sondern in epischer Manier das Publikum im unmittelbaren Erzähllauf damit konfrontiert.

Um eine Reminiszenz des Genus Tragödie könnte es sich auch bei Ampelos' Sturz vom Stier handeln, welcher motivische Verbindungen zum Todessturz des Charikles im Roman des Achilleus Tatios erkennen lässt: Dieser wurde von Françoise Létoublon mit dem (falschen) Bericht über den Tod des Orest im Wagenrennen in der sophokleischen Elektra verknüpft (S. El. 680 -763). ${ }^{153}$ Ins Treffen geführt wird außerdem der Tod des Hippolytos in E. Hipp. 1213-1248, der mehrere Gemeinsamkeiten mit der Szene um Charikles aufweist. ${ }^{154}$

Nonnos verleiht der Ampelos-Episode nicht nur durch entsprechende Sujets eine tragische Färbung, sondern bringt gelegentlich auch eine für die musischen und darstellenden Künste charakteristische Lexik zur Anwendung. Die Sprache der Tragiker wird an einer Stelle besonders augenscheinlich: In der prophetischen Rede der Schicksalsgöttin Atropos wird neben dem Einsatz von einschlägigem Theater-Vokabular auch auf die attische Tragödie selbst Bezug genommen (Nonn. D. 12,147-153). ${ }^{155}$

150 Zur dritten Tafel siehe S. 190 - 194; vgl. Gigli Piccardi (2003) 741.

151 In Nonn. D. 33,21 - 59 wird das für die Tragödie typische Element des Botenganges gleichsam parodiert: Die Botin Pasithea schweigt, der eigentliche Botenbericht an Aphrodite wird lediglich in indirekter Rede wiedergegeben, vgl. Gerlaud (2005) 35.

152 Zur Sturzszene und zum möglichen Einfluss des Achilleus Tatios vgl. S. 134-139.

153 Vgl. Létoublon (1993) 100.

154 Beide Male handelt es sich um Pferde, der Schauplatz ist die Wildnis, und die Metapher des sich wie eine Meereswoge sträubenden Pferdes korrespondiert mit Hippolytos' Tod am Strand, zudem entspräche Charikles’ homoerotische Neigung Hippolytos’ Ablehnung der Frauen, vgl. Webb (2009) $179 \mathrm{f}$.

155 Zur Rede der Atropos sowie zu Text und Übersetzung der Stelle siehe S. 167 - 169. 


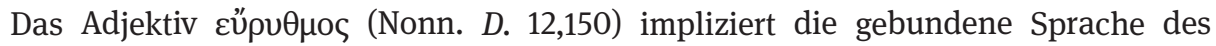
Theaters sowie die Praxis der musikalischen Begleitung, ${ }^{156}$ und mit $\Delta \omega \rho$ í $\delta \alpha \mu о \lambda \pi \eta ́ v$

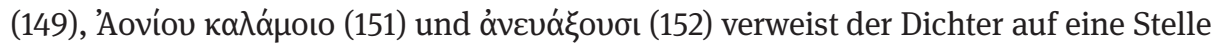

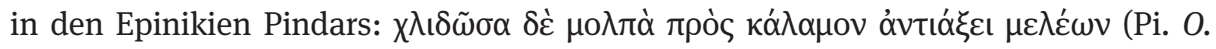
10,84). Wiederum wird das Vorbild nicht unverändert, sondern moduliert übernom-

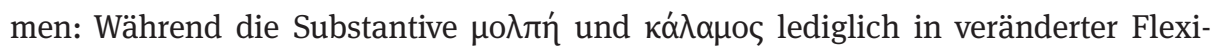

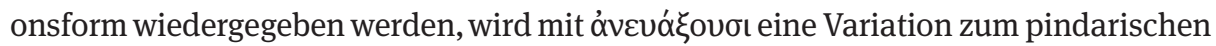

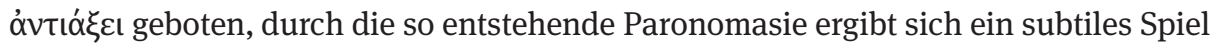
mit einem prominenten Vertreter griechischer Dichtung. Mit dem „dorischen Lied“, der „aonischen“/ böotischen „Rohrflöte“ und dem „ismenischen“ / thebanischen „Klang“ entwirft Nonnos gleichsam einen akustischen Klangteppich, der Pindars Dichtungen sowie seine Wirkungsstätte auf inhaltlicher und phonetischer Ebene wiedererkennen lässt. ${ }^{157}$

Die Rede der Atropos auf Ampelos' Zukunft darf nicht nur als ein Hymnus auf alles Dionysische gesehen werden, ${ }^{158}$ sondern ebenso als ein Lobgesang auf Pindars Dithyrambendichtung und auf die attische Tragödie, zwei Genera, die Nonnos hiermit in sein Epos aufnimmt. ${ }^{159}$ Ein Hinweis darauf, dass Nonnos den Fokus auf die Vorankündigung der attischen Tragödie und des damit verbundenen Dionysos-Kultes legt,

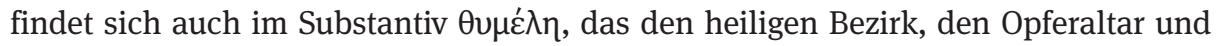
auch die Orchestra im Theater meinen kann. ${ }^{160}$ Erst Ampelos' Metamorphose in einen Weinstock bildet die unabdingbare Voraussetzung für die Einführung des dionysischen Kultes in Athen, dessen Medium die attische Tragödie sein wird. Was den Mythos um den Ursprung der Tragödie betrifft, so könnte Nonnos wiederum von der hellenistischen Dichtung beeinflusst sein: In der Bocksepisode in Eratosthenes' Erigone (Eratosth. Erig. fr. 3 und 4) tötet Ikarios einen Bock, der sich über die frisch gepflanzten

156 Vgl. auch Nonn. D. 13,499; 18,57; 19,111, 220; 21,245; 28,289, 327; 45,278; E. Cycl. 563. 157 Nonnos nimmt an der zitierten Stelle auf lexikalischer Ebene mehrfach Bezug auf die Profession

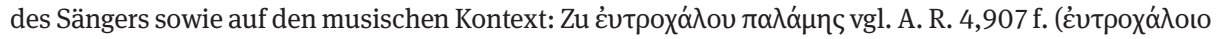

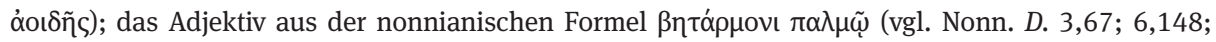
18,$140 ; 22,317 ; 28,128 ; 33,87 ; 41,78 ; 43,310 ; 45,275$, 344; 46,187; 47,226; vgl. außerdem

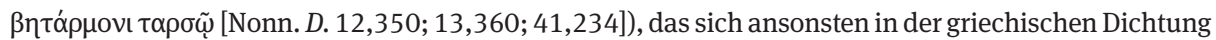
lediglich in Hom. Od. 8,250 und 383 (für Odysseus tanzende Phaiaken) sowie in A. R. 1,1135 (zur

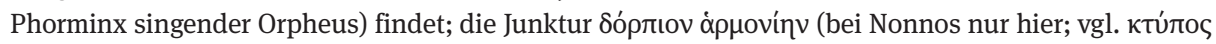

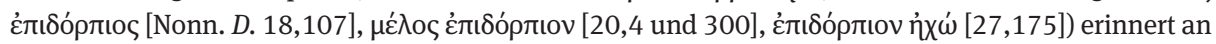
Pi. Fr. 124a,1 f., ein Enkomion auf Thrasybulos von Akragas, wo eine „Wagenladung voller Lieder“ als

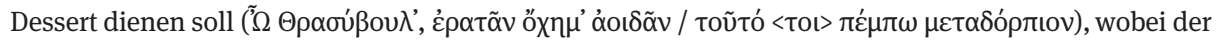

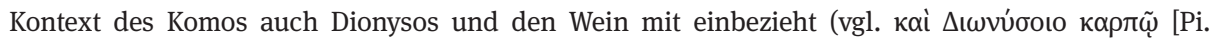

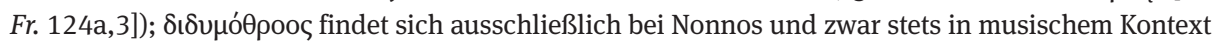
(vgl. Nonn. D. 10,234, 335; 17,70; 43,345; Nonn. P. 9,84).

158 Vgl.Vian (1995) 193f. Anm. ad 147 -153; Fayant (2001) 78; Gigli Piccardi (2003) 832f. Anm. ad $147-153$.

159 Für weitere Anklänge an Pindars Oden in der Ampelos-Episode siehe S. 70-73 und $83 \mathrm{f}$.

160 Vgl. E. Suppl. 64; E. El. 713; E. Ion 46, 114, 161, 228; E. IA 152. 
Weinreben hermacht, setzt den mit Wein gefüllten Schlauch als Tanzpreis aus und erfindet so die attische Tragödie. ${ }^{161}$

Von besonderem Interesse an dieser Stelle ist das Verhältnis zwischen dem chronologisch nicht näher bestimmbaren Mythos, dem Goldenen Zeitalter der griechischen Tragödie im 5. Jh. v. Chr. sowie Nonnos' eigener Zeit. Durch die Einbeziehung des gebildeten Publikums wird eine direkte Verbindungslinie vom Ampelos-Mythos zu einer religiös-kulturellen Institution im historischen Griechenland gezogen. Nonnos umspannt mit der Atropos-Rede eine maximale zeitliche Ausdehnung, die von einer vagen mythischen Urzeit über die klassische Periode der griechischen Kultur und Literatur bis in die ausgehende Antike reicht. Dionysos wird so als Archeget der griechischen Kultur stilisiert, ohne den weder Pindars Dichtungen noch das griechische Drama möglich gewesen wären. Umgekehrt dürfen Nonnos und seine Leser als Repräsentanten eines kulturellen Selbstverständnisses betrachtet werden, das sich auf Attika und Böotien als Kult(ur)- und Literaturlandschaften gründet. ${ }^{162}$ Mit der Anspielung auf das böotische Theben und Athen bringt der Dichter zwei literarische Geburtsorte des Dionysos ins Spiel, die in einer Biographie über den Gott nicht fehlen dürfen, wobei die Vervielfachung des Geburtsortes - in den Dionysiaka gilt die Landschaft Maionien/Lydien als Heimat des Dionysos - nicht als kompositorische Unzulänglichkeit zu verstehen ist, sondern als umfassende Zusammenschau sämtlicher überlieferter mythischer Varianten - und somit nur als eine weitere Spielart

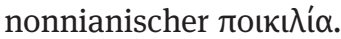

